\title{
Studies of dense molecular cores in regions of massive star formation.
}

\section{Multitransition CS-study towards southern $\mathrm{H}_{2} \mathrm{O}$ masers in the longitude range $l=308^{\circ}-360^{\circ \star, \star \star}$}

\author{
M. Juvela \\ Helsinki University Observatory, Tähtitorninmäki, P.O. Box 14, SF-00014 University of Helsinki, Finland \\ Received September 25; accepted December 19, 1995
}

\begin{abstract}
We have observed $\mathrm{CS}$ and $\mathrm{C}^{34} \mathrm{~S}$ emission towards $33 \mathrm{H}_{2} \mathrm{O}$ maser positions in the southern sky $\left(\delta<-28^{\circ}\right)$ using the SEST telescope. Most of the sources were selected also for their association with strong IRAS sources. $\mathrm{CS}(2-1)$ was detected in all sources, with the possible exception of two. Most sources were also mapped in the transitions $\mathrm{CS}(5-4)$ and $\mathrm{C}^{34} \mathrm{~S}(2-1)$ and half of the sample also in $\mathrm{CS}(2-1)$. CS and $\mathrm{C}^{34} \mathrm{~S}$ transitions $J=2-1, J=3-2 J=5-4$ were measured towards the centres of the clouds as determined from the mapping. CS and $\mathrm{C}^{34} \mathrm{~S}$ transitions $J=7-6$ were measured in about a half dozen clouds. $\mathrm{CO}(1-0)$ was measured in most clouds in order to determine the kinetic temperatures. The CS column densities were calculated using the LTE approximation. All measurements were also analyzed using a spherical LVG model. We present the observational data and the results of this analysis.
\end{abstract}

Key words: masers — stars: formation — ISM: clouds — ISM: molecules — radio lines: ISM

\section{Introduction}

Several massive star forming regions have already been subject to detailed investigations (see e.g. reviews by Genzel 1991; Churchwell 1991) but until recently there have not been any systematic studies based on a larger number of such cloud cores. Since the previous studies have concentrated on a few of the most prominent sites, generalization of the results obtained by these investigations to the whole class of massive star forming cores is still uncertain.

Zinchenko et al. (1995) have recently published observations of $\mathrm{CS}(2-1)$ and $\mathrm{C}^{34} \mathrm{~S}(2-1)$ in 30 southern cores associated with $\mathrm{H}_{2} \mathrm{O}$ and $\mathrm{OH}$ maser emission. The present paper represents a continuation of this study.

Like Zinchenko et al. we have selected the sources mainly from the list of nonstellar maser sources published by Braz \& Epchtein (1983). $\mathrm{H}_{2} \mathrm{O}$ maser emission has been detected towards almost all of them; in one case only $\mathrm{OH}$ maser emission has been detected. $\mathrm{H}_{2} \mathrm{O}$ masers are known to be good indicators of the location of massive star

\footnotetext{
${ }^{\star}$ Based on the observations collected at the European Southern Observatory, La Silla, Chile

${ }^{\star \star}$ Tables 2, 3 and 5-7 are also available in electronic form at the CDS via anonymous ftp 130.79.128.5
}

formation and the list of Braz and Epchtein presents a rather comprehensive and unbiased selection of such sources. Our objective is to present a sample large enough to facilitate general conclusions about regions of massive star formation.

In this paper we present the results of observations towards 33 new southern cloud cores. CS molecule was chosen because it is an excellent density probe and also the isotope $\mathrm{C}^{34} \mathrm{~S}$ can be easily detected. Furthermore, CS has several suitable millimeter and submillimeter transitions that enable multitransition modelling of the clouds. We have observed several $\mathrm{CS}$ and $\mathrm{C}^{34} \mathrm{~S}$ transitions in all cores and the measurements enable us to derive the basic physical parameters of the cores, both in LTE approximation and through LVG modeling.

Some of the objects are already well known and have been observed in the past using different molecules e.g. $\mathrm{CO}$ and $\mathrm{NH}_{3}$. The presence of such measurements also gives the opportunity to make some comparisons between the results obtained using different molecular probes. 


\section{Observations and data analysis}

\subsection{Observational procedure}

The observations were made using the 15-meter SEST telescope on La Silla, Chile. Our sample consists of 33 dense cloud cores. Practically all clouds were mapped at least in $\mathrm{C}^{34} \mathrm{~S}(2-1)$ and $\mathrm{CS}(5-4)$ and many additional smaller maps were made using the transitions $\mathrm{CS}(2-1)$ and $\mathrm{CS}(3-2)$. The maps were used to determine the centre positions of the cloud i.e. the position of the maximum emission. The transitions $J=2-1,3-2$ and 5-4 of both $\mathrm{CS}$ and $\mathrm{C}^{34} \mathrm{~S}$ were then observed at these centre positions in almost all of the clouds. Additional onepoint measurements of the transition $\mathrm{CS}(7-6)$ were made in 14 clouds and of the transition $\mathrm{C}^{34} \mathrm{~S}(7-6)$ in seven clouds.

Observations were made during three different periods. The CS(2-1) maps and some of the CS(5-4) maps were made in April 1994. In February 1995 we mapped the clouds in $\mathrm{C}^{34} \mathrm{~S}(2-1)$ and $\mathrm{CS}(5-4)$ and observed the $J=$ $2-1$ and $J=5-4$ transitions towards the centre positions. $\mathrm{CO}(1-0)$ was also observed towards most of the centre positions. The $\mathrm{CS}$ and $\mathrm{C}^{34} \mathrm{~S}$ transitions $J=3-2$ and $J=7-6$ were observed in June 1995 with some additional $\mathrm{C}^{34} \mathrm{~S}(2-1)$ observations.

The telescope and the $1.3 \mathrm{~mm}$ and the $3 \mathrm{~mm}$ receivers are described by Booth et al. (1989). Table 1 lists the observed transitions and the beam sizes at these frequencies.

Table 1. The observed transitions. The third column gives the critical density at which the collisional and the spontaneous radiative transition rates are equal and the last column the beam size of the SEST radiotelescope at these frequencies

\begin{tabular}{llll}
\hline Transition & frequency $(\mathrm{GHz})$ & $n_{\mathrm{c}}\left(\mathrm{cm}^{-3}\right)$ & beam size $\left(^{\prime \prime}\right)$ \\
\hline $\mathrm{C}^{34} \mathrm{~S}(2-1)$ & 96.4130 & $5.410^{5}$ & 52 \\
$\mathrm{CS}(2-1)$ & 97.9810 & $5.710^{5}$ & 52 \\
$\mathrm{C}^{34} \mathrm{~S}(3-2)$ & 144.6171 & $1.410^{6}$ & 36 \\
$\mathrm{CS}(3-2)$ & 146.9690 & $1.510^{6}$ & 35 \\
$\mathrm{C}^{34} \mathrm{~S}(5-4)$ & 241.0161 & $6.910^{6}$ & 22 \\
$\mathrm{CS}(5-4)$ & 244.9357 & $7.210^{6}$ & 22 \\
$\mathrm{C}^{34} \mathrm{~S}(7-6)$ & 337.397 & $2.110^{7}$ & 16 \\
$\mathrm{CS}(7-6)$ & 342.8829 & $2.210^{7}$ & 15 \\
\hline
\end{tabular}

For the $J=2-1$ observations the front end was a $3 \mathrm{~mm}$ Schottky mixer receiver. The single sideband system temperatures outside the atmosphere were typically $350-450 \mathrm{~K}$ for both $\mathrm{CS}$ and $\mathrm{C}^{34} \mathrm{~S}$. For the $J=3-2$ observations the system temperatures of the SIS receiver were around $200 \mathrm{~K}$. A $1.3 \mathrm{~mm}$ SIS receiver was used for $J=5-4$ observations. The system temperatures varied between 600 and $1000 \mathrm{~K}$ during both observation periods in 1994 and in 1995. The $J=7-6$ observations were made using a $0.8 \mathrm{~mm}$ SIS receiver (Whyborn et al. 1992). Because of the unfavorable weather conditions in June 1995 the system temperatures were around $1000 \mathrm{~K}$ during the
CS(7-6) observations and between 1000 and $1500 \mathrm{~K}$ during the $\mathrm{C}^{34} \mathrm{~S}(7-6)$ observations.

The backend was a 2000 channel acousto-optical spectrometer with a $100 \mathrm{MHz}$ bandwidth, a channel separation of $43 \mathrm{kHz}$ and a resolution of $80 \mathrm{kHz}$.

The maps were made mainly in the frequency switching mode. The maps consist typically of around 30 points and cover at least the area where the intensity of the $\mathrm{C}^{34} \mathrm{~S}(2-1)$ line is more than half of the peak value. All centre point measurements and some maps were made using beam switching with a beam throw of $11^{\prime} 37^{\prime \prime}$ or with position switching.

Pointing was checked every three or four hours by observing nearby $\mathrm{SiO}$ masers. The pointing accuracy is expected to be approximately $5^{\prime \prime}$. On some occasions the observations were hampered by strong winds. Therefore, in some cases, the pointing may not have been this accurate.

The calibration was made using the chopper-wheel technique. We present the observational results in the main beam brightness temperature scale. These temperatures were obtained by dividing the observed antenna temperatures $T_{\mathrm{A}}^{*}$ with the main beam efficiency $\eta_{\mathrm{mb}}$ as given in the SEST Handbook (1993). This procedure gives in Orion $\mathrm{SiO}\left(\alpha=5^{\mathrm{h}} 32^{\mathrm{m}} 47.0^{\mathrm{s}}, \delta=-5^{\circ} 24^{\prime} 23^{\prime \prime}\right)$ a peak main beam temperature of $15.1 \mathrm{~K}$ at $\mathrm{CS}(2-1)$ and for M17SW temperatures $1.9 \mathrm{~K}, 18.0 \mathrm{~K}$ and $8.20 \mathrm{~K}$ for $\mathrm{C}^{34} \mathrm{~S}(2-1)$, $\mathrm{CS}(3-2)$ and $\mathrm{CS}(5-4)$, respectively. An additional elevation dependent correction had to be made to those $J=7-6$ observations where the elevation was below $60^{\circ}$ (Nyman 1995, private communication). This correction is somewhat uncertain but since practically all observations were made above this limit this correction should have little effect on the results we present here. The main beam temperature for M17SW CS(7-6) was, after corrections, $14.1 \mathrm{~K}$.

\subsection{Source list}

The source list in Table 2 is mainly a subset of the catalogue of Braz \& Epchtein (1983) of non-stellar molecular maser sources. One additional source (G021-0.01) was taken from the article by Güsten \& Downes (1983), two sources (G 318.05+0.09 and G 323.74-0.25) are from an article by Scalise et al. (1989) and two sources (G 308.00-0.25 and G 316.37-0.37) from Braz et al. (1989). The clouds are situated southwards of $\delta=-28^{\circ}$ and extend over the galactic longitude range from $308^{\circ}$ to about $360^{\circ}$. Table 2 gives details of the sources. The name in the first column refers to the position of the $\mathrm{H}_{2} \mathrm{O}$ maser and the following coordinates are for the zero offset positions in the cloud maps (mostly the positions of maximum $\mathrm{C}^{34} \mathrm{~S}(2-1)$ emission). The following column contains the radial velocity of the $\mathrm{H}_{2} \mathrm{O}$ maser. The next three columns list the galacto-centric distance, distance from the Sun as determined from the observed CS velocity, and the height 
Table 2. The source list. The radial velocity of the $\mathrm{H}_{2} \mathrm{O}$ maser is given in Col. (8) and the galacto-centric distance is in Col. (9). Columns (10) and (11) contain the kinematic distance and the height above the galactic plane. Some distance estimates from the literature are given in Col. (12)

\begin{tabular}{|c|c|c|c|c|c|c|c|c|c|c|c|c|}
\hline$\overline{\text { Name }}$ & RA & $950)$ & & Dec & 1950 & & $V_{\mathrm{H}_{2} \mathrm{O}}$ & $R_{\mathrm{G}}$ & & & $d_{\text {ref }}$ & Maser \\
\hline & (h) & $(\mathrm{m})$ & $(\mathrm{s})$ & $\left({ }^{\circ}\right)$ & $\left({ }^{\prime}\right)$ & $\left({ }^{\prime \prime}\right)$ & $\mathrm{km} / \mathrm{s}$ & $(\mathrm{kpc})$ & $(\mathrm{kpc})$ & $(\mathrm{pc})$ & $(\mathrm{kpc})$ & references \\
\hline$(1)$ & $(2)$ & $(3)$ & (4) & $(5)$ & (6) & $(7)$ & $(8)$ & $(9)$ & $(10)$ & (11) & (12) & (13) \\
\hline G 308.00-0.25 & 13 & 29 & 27.0 & -60 & 11 & 22 & -22 & 7.41 & $2.06 /(8.41)$ & $72 / 296$ & & $\mathrm{c}$ \\
\hline $\begin{array}{l}\text { G } 308.92+0.12, \\
\text { RCW } 79\end{array}$ & 13 & 39 & 34.4 & -61 & 53 & 45 & -51 & 6.47 & - & - & $4.0^{2}$ & $\mathrm{~b}$ \\
\hline G $309.92+0.48$ & 13 & 47 & 12.5 & -61 & 20 & 38 & -58 & 6.24 & - & - & $4.0^{4}$ & $\mathrm{~g}$ \\
\hline G $311.94+0.18$ & 14 & 4 & 3.0 & -61 & 7 & 6 & -42 & - & - & - & & $\mathrm{b}$ \\
\hline G 316.37-0.37 & 14 & 39 & 26.3 & -60 & 4 & 33 & -3 & 8.30 & $(0.28) / 12.03$ & $(-2) /-76$ & $14.7^{1}$ & $\mathrm{c}$ \\
\hline G 316.64-0.08 & 14 & 40 & 30.0 & -59 & 42 & 18 & $(-19)^{\dagger}$ & 7.43 & $(1.58 / 10.78)$ & $(-2 /-15)$ & & \\
\hline G 316.77-0.02 & 14 & 41 & 10.4 & -59 & 35 & 50 & -41 & 6.58 & $3.12 /(9.26)$ & $-1 /(-3)$ & $2.5^{1}$ & $\mathrm{a}, \mathrm{g}$ \\
\hline G 316.81-0.06 & 14 & 41 & 41.7 & -59 & 36 & 53 & -39 & 6.66 & $2.95 /(9.45)$ & $-3 /(-10)$ & $2.5^{3}$ & $\mathrm{a}, \mathrm{g}$ \\
\hline G $318.05+0.09$ & 14 & 49 & 51.9 & -58 & 56 & 40 & -51 & 6.25 & $3.73 /(8.92)$ & $6 /(13)$ & & $\mathrm{j}$ \\
\hline G 323.74-0.25 & 15 & 27 & 54.6 & -56 & 20 & 55 & -50 & 6.04 & $3.50 /(10.20)$ & $-16 /(-47)$ & $3.0^{9}$ & $\mathrm{j}$ \\
\hline G $324.20+0.12$ & 15 & 29 & 1.2 & -55 & 46 & 12 & -88 & 4.95 & - & - & $6.9^{6}$ & $\mathrm{a}$ \\
\hline G $328.30+0.43$ & 15 & 50 & 15.3 & -53 & 2 & 46 & -93 & 4.64 & $(5.97) / 8.49$ & $44 /(63)$ & $8.5^{1}$ & $\mathrm{a}$ \\
\hline G 329.04-0.21 & 15 & 56 & 39.3 & -53 & 4 & 10 & -44 & 6.03 & $3.14 /(11.43)$ & $-11 /(-40)$ & & $\mathrm{j}$ \\
\hline G 331.00-0.19 & 16 & 6 & 3.4 & -51 & 47 & 30 & -92 & 4.49 & $5.65 /(9.21)$ & $-18 /(-30)$ & $6.4^{3}$ & $\mathrm{a}$ \\
\hline G 330.88-0.36 & 16 & 6 & 30.0 & -51 & 58 & 14 & -63 & 5.24 & $4.20 /(10.65)$ & $-27 /(-69)$ & $4.1^{1}$ & $\mathrm{a}, \mathrm{g}$ \\
\hline G 331.28-0.18 & 16 & 7 & 36.0 & -51 & 33 & 40 & -88 & 4.54 & $5.47 /(9.44)$ & $-18 /(-31)$ & & $\mathrm{b}$ \\
\hline $\begin{array}{l}\text { G } 332.65-0.63, \\
\text { RCW } 106\end{array}$ & 16 & 15 & 55.7 & -50 & 56 & 48 & -50 & 5.55 & $3.60 /(11.50)$ & $-38 /(-123)$ & $3.6^{1}$ & $\mathrm{a}, \mathrm{g}$ \\
\hline $\begin{array}{l}\text { G } 332.83-0.55, \\
\text { RCW } 106\end{array}$ & 16 & 16 & 23.7 & -50 & 45 & 45.5 & -57 & 5.29 & $3.97 /(11.15)$ & $-38 /(-107)$ & $4.2^{3}$ & $\mathrm{~b}$ \\
\hline G 333.13-0.43 & 16 & 17 & 16.8 & -50 & 28 & 17 & -52 & 5.44 & $3.73 /(11.44)$ & $-28 /(-87)$ & $3.8^{1}$ & $\mathrm{a}$ \\
\hline G $333.60-0.22$ & 16 & 18 & 22.4 & -49 & 59 & 27 & -48 & 5.54 & $3.56 /(11.66)$ & $-14 /(-45)$ & $3.5^{1}$ & $\mathrm{a}$ \\
\hline G $337.40-0.40$ & 16 & 35 & 8.1 & -47 & 22 & 23 & -41 & 5.55 & $3.36 /(12.34)$ & $-24 /(-87)$ & & $\mathrm{a}$ \\
\hline G 337.91-0.47 & 16 & 37 & 25.9 & -47 & 2 & 6 & -39 & 5.57 & $3.31 /(12.44)$ & $-28 /(-104)$ & $3.4^{1}$ & $\mathrm{a}, \mathrm{i}$ \\
\hline $\begin{array}{c}\text { G } 345.01+1.80 \\
\text { RCW } 116\end{array}$ & 16 & 53 & 17.3 & -40 & 9 & 23.2 & -14 & 6.45 & $2.14 /(14.28)$ & $67 /(447)$ & $3.0^{7}$ & $\mathrm{~d}, \mathrm{e}$ \\
\hline G 343.12-0.06 & 16 & 54 & 44.0 & -42 & 47 & 36.6 & -31 & 5.51 & $3.20 /(13.07)$ & $-4 /(-15)$ & & $\mathrm{a}, \mathrm{e}$ \\
\hline G $345.51+0.35$ & 17 & 0 & 53.6 & -40 & 40 & 18.5 & -17 & 6.11 & $2.50 /(13.96)$ & $15 /(85)$ & $2.1^{7}$ & $\mathrm{a}, \mathrm{e}, \mathrm{g}, \mathrm{i}$ \\
\hline G 345.00-0.23 & 17 & 1 & 40.1 & -41 & 24 & 58.5 & -27 & 5.49 & $3.18 /(13.24)$ & $-12 /(-52)$ & $3.2^{7}$ & $\mathrm{~d}, \mathrm{e}$ \\
\hline $\begin{array}{l}\text { G } 345.41-0.94, \\
\text { RCW } 117\end{array}$ & 17 & 6 & 2.2 & -41 & 32 & 6.3 & -22 & 5.81 & $2.82 /(13.63)$ & $-47 /(-225)$ & $2.8^{1}$ & $\mathrm{a}, \mathrm{e}$ \\
\hline G 348.55-0.97 & 17 & 15 & 53.1 & -39 & 0 & 57 & -15 & 5.78 & $2.80 /(13.86)$ & $-48 /(-237)$ & $2.1^{1}$ & $\mathrm{~d}, \mathrm{e}$ \\
\hline $\begin{array}{l}\text { G } 351.16+0.70, \\
\quad \text { RCW } 127, \\
\quad \text { NGC } 6334 \mathrm{~B}\end{array}$ & 17 & 16 & 36.1 & -35 & 54 & 51 & -6 & 6.45 & $2.08 /(14.72)$ & $25 /(180)$ & & $\mathrm{a}, \mathrm{e}, \mathrm{h}$ \\
\hline $\begin{array}{l}\text { G } 348.73-1.04, \\
\text { RCW } 122\end{array}$ & 17 & 16 & 39.8 & -38 & 54 & 13.6 & -12 & 6.14 & $2.43 /(14.25)$ & $-44 /(-259)$ & $2.1^{1}$ & $\mathrm{a}, \mathrm{e}, \mathrm{g}, \mathrm{i}$ \\
\hline $\begin{array}{c}\text { G } 351.41+0.64 \\
\text { NGC } 6334 \mathrm{I}\end{array}$ & 17 & 17 & 32.3 & -35 & 44 & 2.5 & -7 & 6.40 & $(2.13 / 14.68)$ & $24 /(165)$ & $1.7^{5}$ & $\mathrm{a}, \mathrm{e}, \mathrm{h}$ \\
\hline G $0.21-0.01$ & 17 & 42 & 57.0 & -28 & 44 & 5 & 25 & - & $7.36 /(9.64)$ & $0 /(0)$ & & $\mathrm{f}$ \\
\hline G 359.97-0.46 & 17 & 44 & 9.2 & -29 & 10 & 57.7 & 18 & - & $8.43 /(8.57)$ & $-67 /(-68)$ & & $\mathrm{d}, \mathrm{e}$ \\
\hline
\end{tabular}

Distance references: ${ }^{1}$ Caswell \& Haynes (1987), ${ }^{2}$ Henning et al. (1990), ${ }^{3}$ Lockman (1979), ${ }^{4}$ Moorwood et al. (1983), ${ }^{5}$ Neckel et al. (1978) ${ }^{6}$ Simpson et al. (1990), ${ }^{7}$ Testi et al. (1994), ${ }^{8}$ Zavagno et al. (1992).

Maser references: a) Batchelor et al. (1980), b) Braz \& Scalise (1982), c) Braz et al. (1989), d) Caswell et al. (1983), e) Forster \& Caswell (1989), f) Güsten \& Downes (1983), g) Kaufmann et al. (1977), h) Moran \& Rodriguez (1980), i) Scalise \& Braz (1980), j) Scalise et al. (1989).

$\uparrow$ Velocity of an $\mathrm{OH}$ maser. 
Table 3. CS and $\mathrm{C}^{34} \mathrm{~S}$ line areas and Gaussian line parameters for the central positions of the sources. Under the name are the offsets of the observed position relative to the positions given in Table 2. The numbers enclosed in brackets indicate the statistical uncertainties in the last digits as given by the fitting procedure for the Gaussian line parameters or as deduced from the baseline noise level in case of the integrated line temperature. Columns (7), (12) and (13) indicate some features of the spectra: blue and red wings are marked with $\mathrm{b}$ and $\mathrm{r}$ and strong absoption features with an a

\begin{tabular}{|c|c|c|c|c|c|c|c|c|c|c|c|c|}
\hline \multirow[b]{2}{*}{ Source } & \multirow[b]{2}{*}{$\mathrm{J}$} & \multicolumn{5}{|c|}{$\mathrm{C}^{34} \mathrm{~S}$} & \multicolumn{5}{|c|}{$\mathrm{CS}$} & \multirow{3}{*}{$\begin{array}{l}\mathrm{CO} \\
\text { wing } \\
\text { (13) }\end{array}$} \\
\hline & & $\begin{array}{l}\int T_{m b} \mathrm{dv} \\
(\mathrm{K} \mathrm{km} / \mathrm{s})\end{array}$ & $\begin{array}{l}\mathrm{T}_{m b} \\
(\mathrm{~K})\end{array}$ & $\begin{array}{l}V_{L S R} \\
(\mathrm{~km} / \mathrm{s})\end{array}$ & $\begin{array}{l}\Delta V \\
(\mathrm{~km} / \mathrm{s})\end{array}$ & wing & $\begin{array}{l}\int T_{m b} \mathrm{dv} \\
(\mathrm{K} \mathrm{km} / \mathrm{s})\end{array}$ & $\begin{array}{l}\mathrm{T}_{m b} \\
(\mathrm{~K})\end{array}$ & $\begin{array}{l}V_{L S R} \\
(\mathrm{~km} / \mathrm{s})\end{array}$ & $\begin{array}{l}\Delta V \\
(\mathrm{~km} / \mathrm{s})\end{array}$ & wing & \\
\hline (1) & (2) & (3) & (4) & (5) & (6) & (7) & (8) & (9) & (10) & (11) & & \\
\hline G308.00-0.25 & 2 & $2.38(0.13)$ & $0.58(0.18)$ & $-22.83(0.36)$ & $3.88(0.91)$ & & $20.41(0.20)$ & $3.93(0.07)$ & $-22.72(0.03)$ & $4.81(0.07)$ & & \\
\hline \multirow[t]{3}{*}{$(0,0)$} & 3 & $2.18(0.06)$ & $0.70(0.03)$ & $-22.35(0.04)$ & $2.92(0.10)$ & & $20.61(0.19)$ & $3.88(0.03)$ & $-22.31(0.01)$ & $4.92(0.03)$ & $\mathrm{br}$ & \\
\hline & 5 & $1.80(0.89)$ & $0.22(0.15)$ & $-23.58(2.20)$ & $8.44(4.33)$ & & $19.83(0.68)$ & $3.90(0.18)$ & $-22.22(0.06)$ & $4.45(0.17)$ & & \\
\hline & 7 & $-(-)$ & $-(-)$ & $-(-)$ & $-(-)$ & & $7.19(1.01)$ & $1.94(0.24)$ & $-22.16(0.16)$ & $3.41(0.32)$ & & \\
\hline G308.92+0.12 & 2 & $2.75(0.16)$ & $0.98(0.07)$ & $-51.03(0.07)$ & $2.82(0.14)$ & & $20.26(0.25)$ & $4.79(0.08)$ & $-50.85(0.02)$ & $3.83(0.05)$ & & $\mathrm{b}$ \\
\hline \multirow{3}{*}{$(0,0)$} & 3 & $5.11(0.06)$ & $1.42(0.03)$ & $-50.84(0.02)$ & $3.37(0.05)$ & & $25.04(0.15)$ & $5.81(0.03)$ & $-50.77(0.01)$ & $4.00(0.02)$ & b & \\
\hline & 5 & $3.33(0.31)$ & $0.98(0.13)$ & $-51.27(0.11)$ & $2.95(0.32)$ & & $22.39(0.58)$ & $5.17(0.19)$ & $-50.78(0.04)$ & $3.91(0.12)$ & & \\
\hline & 7 & $2.04(2.51)$ & $3.17(1.07)$ & $-48.52(0.13)$ & $0.68(0.15)$ & & $31.68(0.96)$ & $7.43(0.21)$ & $-50.92(0.04)$ & $4.00(0.09)$ & & \\
\hline G309.92+0.48 & 2 & $3.26(0.14)$ & $0.91(0.07)$ & $-58.43(0.08)$ & $3.14(0.19)$ & & $15.26(0.19)$ & $3.30(0.08)$ & $-58.44(0.03)$ & $4.30(0.08)$ & b & br \\
\hline \multirow[t]{3}{*}{$(0,0)$} & 3 & $3.94(0.08)$ & $1.04(0.03)$ & $-58.17(0.03)$ & $3.32(0.09)$ & & $18.29(0.25)$ & $3.77(0.03)$ & $-58.45(0.01)$ & $4.49(0.03)$ & $\mathrm{br}$ & \\
\hline & 5 & $0.49(0.29)$ & $0.93(0.20)$ & $-58.30(0.06)$ & $0.69(0.10)$ & & $7.70(0.64)$ & $2.14(0.20)$ & $-58.70(0.09)$ & $3.15(0.22)$ & & \\
\hline & 7 & $-(-)$ & $-(-)$ & $-(-)$ & $-(-)$ & & $-(-)$ & $-(-)$ & $-(-)$ & $-(-)$ & & \\
\hline G311.94+0.18 & 2 & $0.69(0.19)$ & $0.18(0.06)$ & $-36.93(0.54)$ & $3.28(0.66)$ & & $1.83(0.18)$ & $0.56(0.17)$ & $-42.18(0.26)$ & $3.12(0.74)$ & & \\
\hline \multirow[t]{3}{*}{$(0,0)$} & 3 & $-(-)$ & $-(-)$ & $-(-)$ & $-(-)$ & & $-(-)$ & $-(-)$ & $-(-)$ & $-(-)$ & & \\
\hline & 5 & $-(-)$ & $-(-)$ & $-(-)$ & $-(-)$ & & $-(-)$ & $-(-)$ & $-(-)$ & $-(-)$ & & \\
\hline & 7 & $-(-)$ & $-(-)$ & $-(-)$ & $-(-)$ & & $-(-)$ & $-(-)$ & $-(-)$ & $-(-)$ & & \\
\hline G316.37-0.37 & 2 & $1.27(0.14)$ & $0.12(0.05)$ & $-0.57(1.16)$ & $9.95(3.22)$ & & $3.79(0.13)$ & $0.71(0.05)$ & $-1.55(0.14)$ & $5.26(0.28)$ & & \\
\hline \multirow[t]{3}{*}{$(0,0)$} & 3 & $0.27(0.09)$ & $0.09(0.02)$ & $-1.88(0.52)$ & $4.40(0.80)$ & & $-(-)$ & $-(-)$ & $-(-)$ & $-(-)$ & & \\
\hline & 5 & $1.46(0.28)$ & $0.57(0.19)$ & $0.01(0.15)$ & $1.47(0.38)$ & & $-0.49(0.50)$ & $0.32(0.20)$ & $-2.60(0.35)$ & $1.21(0.57)$ & & \\
\hline & 7 & $-(-)$ & $-(-)$ & $-(-)$ & $-(-)$ & & $-(-)$ & $-(-)$ & $-(-)$ & $-(-)$ & & \\
\hline G316.64-0.08 & 2 & $0.02(0.07)$ & $0.29(0.16)$ & $-18.73(0.17)$ & $0.92(0.40)$ & & $0.34(0.17)$ & $0.52(0.05)$ & $-18.32(0.17)$ & $4.88(0.37)$ & & \\
\hline \multirow{3}{*}{$(-20,0)$} & 3 & $-0.05(0.03)$ & $0.19(0.06)$ & $0.24(0.05)$ & $0.37(0.08)$ & & $0.16(0.08)$ & $0.52(0.03)$ & $-18.03(0.08)$ & $4.53(0.19)$ & & \\
\hline & 5 & $-0.58(0.22)$ & $0.95(0.41)$ & $-20.76(0.05)$ & $0.38(0.13)$ & & $-0.22(0.32)$ & $0.43(0.11)$ & $-20.32(0.31)$ & $4.30(0.87)$ & & \\
\hline & 7 & $-(-)$ & $-(-)$ & $-(-)$ & $-(-)$ & & $-(-)$ & $-(-)$ & $-(-)$ & $-(-)$ & & \\
\hline \multirow{4}{*}{$\begin{array}{l}\text { G316.77-0.02 } \\
(20,20)\end{array}$} & 2 & $2.15(0.12)$ & $0.42(0.07)$ & $-40.84(0.23)$ & $4.60(0.58)$ & & $15.96(0.18)$ & $2.51(0.06)$ & $-39.74(0.04)$ & $5.87(0.10)$ & & b \\
\hline & 3 & $0.61(0.06)$ & $0.15(0.03)$ & $-39.64(0.22)$ & $3.95(0.51)$ & & $13.14(0.15)$ & $2.30(0.03)$ & $-39.93(0.02)$ & $5.18(0.05)$ & $\mathrm{b}$ & \\
\hline & 5 & $0.11(0.23)$ & $0.79(0.42)$ & $-40.44(0.05)$ & $0.38(0.16)$ & & $6.12(0.40)$ & $0.85(0.09)$ & $-39.62(0.21)$ & $6.87(0.54)$ & & \\
\hline & 7 & $-(-)$ & $-(-)$ & $-(-)$ & $-(-)$ & & $-(-)$ & $-(-)$ & $-(-)$ & $-(-)$ & & \\
\hline G316.81-0.06 & 2 & $2.83(0.11)$ & $0.73(0.07)$ & $-38.47(0.10)$ & $3.35(0.25)$ & & $18.96(0.23)$ & $3.91(0.07)$ & $-38.51(0.02)$ & $4.55(0.06)$ & & $\mathrm{b}$ \\
\hline \multirow[t]{3}{*}{$(0,20)$} & 3 & $2.39(0.07)$ & $0.69(0.03)$ & $-37.98(0.04)$ & $3.14(0.11)$ & & $22.69(0.15)$ & $4.82(0.03)$ & $-38.24(0.01)$ & $4.48(0.02)$ & & \\
\hline & 5 & $1.80(0.40)$ & $0.46(0.09)$ & $-37.55(0.27)$ & $3.83(0.58)$ & & $12.32(0.40)$ & $2.98(0.10)$ & $-38.08(0.04)$ & $3.87(0.10)$ & & \\
\hline & 7 & $-(-)$ & $-(-)$ & $-(-)$ & $-(-)$ & & $-(-)$ & $-(-)$ & $-(-)$ & $-(-)$ & & \\
\hline G318.05+0.09 & 2 & $3.21(0.15)$ & $0.98(0.09)$ & $-49.91(0.08)$ & $2.87(0.21)$ & & $22.76(0.38)$ & $5.04(0.08)$ & $-50.12(0.02)$ & $4.11(0.05)$ & & $\mathbf{r}$ \\
\hline \multirow[t]{3}{*}{$(20,0)$} & 3 & $3.92(0.08)$ & $1.18(0.03)$ & $-49.94(0.02)$ & $3.02(0.06)$ & & $26.68(0.40)$ & $5.64(0.04)$ & $-50.17(0.01)$ & $4.35(0.02)$ & & \\
\hline & 5 & $2.78(0.39)$ & $1.13(0.14)$ & $-49.58(0.09)$ & $2.20(0.21)$ & & $20.47(0.42)$ & $4.45(0.12)$ & $-50.07(0.03)$ & $4.20(0.09)$ & & \\
\hline & 7 & $-(-)$ & $-(-)$ & $-(-)$ & $-(-)$ & & $17.07(0.80)$ & $4.24(0.21)$ & $-50.21(0.06)$ & $3.78(0.14)$ & & \\
\hline G323.74-0.25 & 2 & $2.23(0.14)$ & $0.55(0.06)$ & $-49.57(0.16)$ & $4.17(0.32)$ & & $12.42(0.23)$ & $2.48(0.07)$ & $-49.15(0.04)$ & $4.51(0.09)$ & & \\
\hline \multirow[t]{3}{*}{$(0,20)$} & 3 & $1.98(0.08)$ & $0.46(0.04)$ & $-49.56(0.06)$ & $3.39(0.22)$ & & $13.25(0.20)$ & $2.40(0.04)$ & $-49.05(0.02)$ & $5.10(0.06)$ & b & \\
\hline & 5 & $-0.04(0.19)$ & $1.93(0.69)$ & $-51.73(0.02)$ & $0.16(0.04)$ & & $7.69(0.41)$ & $1.50(0.12)$ & $-49.50(0.11)$ & $4.67(0.32)$ & & \\
\hline & 7 & $-(-)$ & $-(-)$ & $-(-)$ & $-(-)$ & & $-(-)$ & $-(-)$ & $-(-)$ & $-(-)$ & & \\
\hline \multirow{4}{*}{$\begin{array}{l}\text { G324.20+0.12 } \\
(0,30)\end{array}$} & 2 & $4.45(0.11)$ & $0.87(0.06)$ & $-88.70(0.10)$ & $4.71(0.25)$ & & $24.79(0.30)$ & $3.98(0.07)$ & $-88.41(0.03)$ & $6.03(0.08)$ & & $\mathrm{r}$ \\
\hline & 3 & $5.33(0.11)$ & $1.04(0.03)$ & $-88.48(0.04)$ & $4.57(0.11)$ & b & $32.95(0.40)$ & $4.66(0.03)$ & $-88.26(0.01)$ & $7.43(0.04)$ & $b_{r}$ & \\
\hline & 5 & $5.11(0.41)$ & $1.00(0.14)$ & $-88.45(0.16)$ & $4.38(0.51)$ & & $25.98(0.53)$ & $3.74(0.09)$ & $-87.93(0.05)$ & $7.24(0.15)$ & b & \\
\hline & 7 & $-(-)$ & $-(-)$ & $-(-)$ & $-(-)$ & & $-(-)$ & $-(-)$ & $-(-)$ & $-(-)$ & & \\
\hline
\end{tabular}

above the galactic plane. The near and far kinematic distances were calculated by assuming a flat rotation curve for the Galaxy (Fich et al. 1989). For some sources the Col. (12) gives a distance estimate obtained from the literature. These distances, $d_{\text {ref }}$, are either more accurate than the calculated kinematic distances or represent the preferred kinematic distance used in some previous article. In cases where the kinematic distances had to be used we have adopted the one in Col. (10) which is not enclosed in parenthesis. For many sources the selection of the distance is based on the distance estimates of Lockman
(1979) and/or Caswell \& Haynes (1987). The kinematic distances are uncertain especially close to the galactic centre but even the estimates for the clouds G 0.21-0.01 and G 359.97-0.46 are still reasonable.

The first seven objects in Table 2 were taken from the initial selection of maser sources in the order of increasing right ascension. No selection criteria were applied to them. In one of these sources, G316.64-0.08, no $\mathrm{H}_{2} \mathrm{O}$ maser emission has been detected to our knowledge and the source is associated with an $\mathrm{OH}$ maser only. The maser 
Table 3. continued

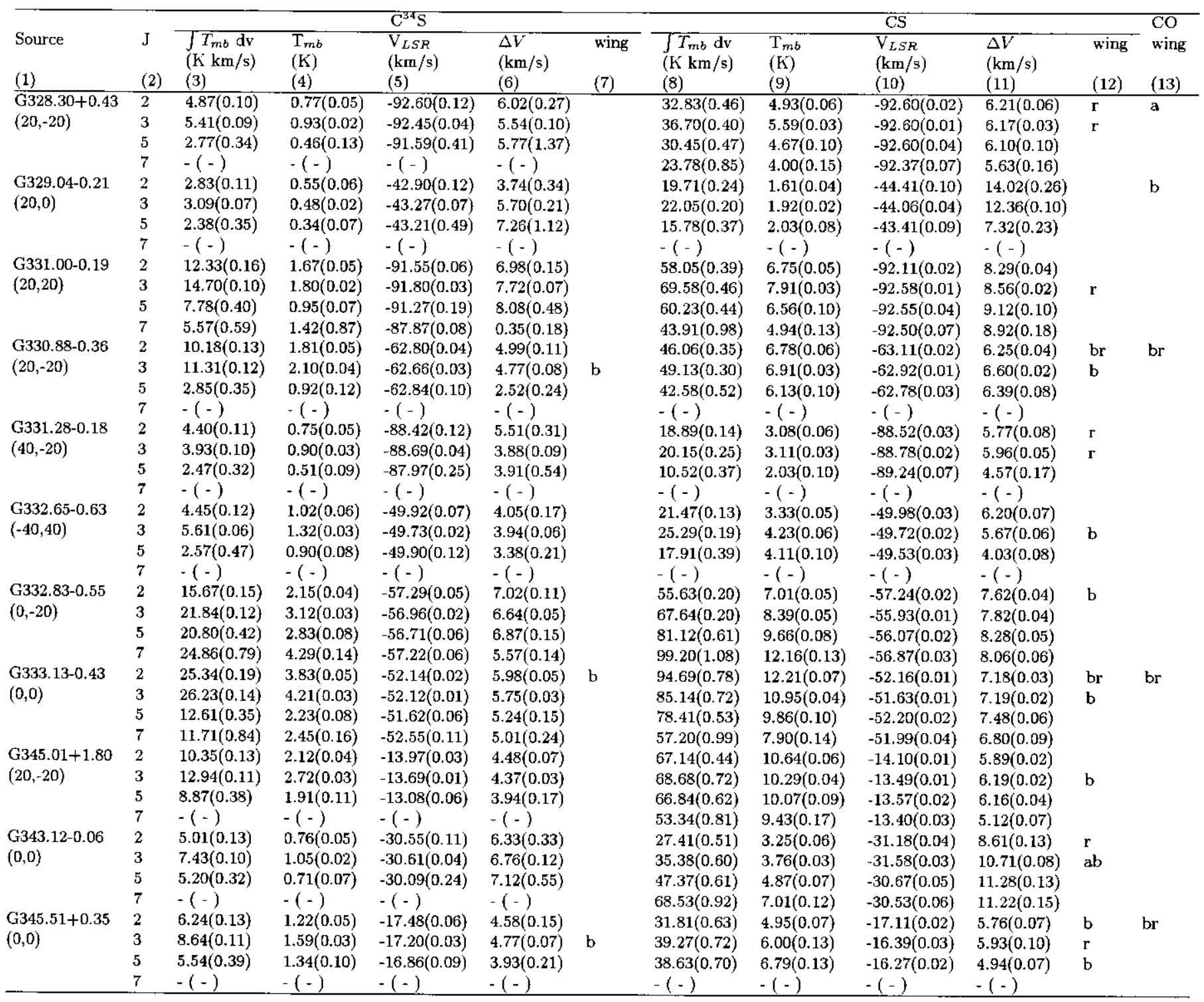

velocity quoted in Col. (8) of the table is that of the $\mathrm{OH}$ maser.

The rest of our sample satisfies the following criteria: (1) the $\mathrm{H}_{2} \mathrm{O}$ maser intensity is at least $9 \mathrm{Jy}$, (2) the source is associated with an IRAS source with an intensity greater than $1500 \mathrm{Jy}$ at $100 \mu \mathrm{m}$ and, (3) the projected distance between the maser and the infrared source is less than one arc minute. There are altogether some fourty sources satisfying these requirements in the given $(\alpha, \delta)$ range that were not already observed by Zinchenko et al. (1995). From this list we selected 22 sources which are associated with the brightest IRAS sources ( $I$ $(100 \mu \mathrm{m})>3500 \mathrm{Jy})$. The last three sources G 323.74-0.25, G 318.05+0.09 and G 329.04-0.21 have IRAS intensities of 3260,2210 and $1650 \mathrm{Jy}$ at $100 \mu \mathrm{m}$.
Many of the clouds are associated with several water maser sources. The last column in the table gives the references for the $\mathrm{H}_{2} \mathrm{O}$ maser observations that are used in this article.

Many of the sources in Table 2 have already been studied in different molecular lines: (1) the approximate positions of twelve of the clouds in our current sample have been observed in CS(1-0) by Gardner \& Whiteoak (1978); (2) there exist also detailed studies of several clouds made in $\mathrm{CO}(2-1)$ (see e.g. de Graauw et al. 1981; White \& Phillips 1983; Brand et al. 1984); (3) $\mathrm{CH}_{3} \mathrm{OH}$ absorption line measurements exist for eight clouds (Peng \& Whiteoak 1992) and, (4) $\mathrm{H}_{2} \mathrm{CO}$ absorption measurements for seventeen clouds (Whiteoak \& Gardner 1974; Gardner $\&$ Whiteoak 1984). Three cores from our sample were also 
Table 3. continued

\begin{tabular}{|c|c|c|c|c|c|c|c|c|c|c|c|c|}
\hline \multirow[b]{2}{*}{$\begin{array}{l}\text { Source } \\
\text { (1) }\end{array}$} & \multirow[b]{2}{*}{$\begin{array}{l}J \\
(2) \\
\end{array}$} & \multicolumn{5}{|c|}{$\mathrm{C}^{34} \mathrm{~S}$} & \multicolumn{5}{|c|}{$\mathrm{CS}$} & \multirow[b]{2}{*}{$\begin{array}{l}\mathrm{CO} \\
\text { wing } \\
\text { (13) }\end{array}$} \\
\hline & & $\begin{array}{l}\int T_{m b} \mathrm{dv} \\
(\mathrm{K} \mathrm{km} / \mathrm{s}) \\
(3)\end{array}$ & $\begin{array}{l}\mathrm{T}_{m b} \\
(\mathrm{~K}) \\
(4)\end{array}$ & $\begin{array}{l}V_{L S R} \\
(\mathrm{~km} / \mathrm{s}) \\
(5) \\
\end{array}$ & $\begin{array}{l}\Delta V \\
(\mathrm{~km} / \mathrm{s}) \\
(6) \\
\end{array}$ & $\begin{array}{l}\text { wing } \\
(7)\end{array}$ & $\begin{array}{l}\int T_{m b} \mathrm{dv} \\
(\mathrm{K} \mathrm{km} / \mathrm{s}) \\
(8)\end{array}$ & $\begin{array}{l}T_{m b} \\
\left(K^{\prime}\right) \\
(9) \\
\end{array}$ & $\begin{array}{l}V_{L S R} \\
(\mathrm{~km} / \mathrm{s}) \\
(10)\end{array}$ & $\begin{array}{l}\Delta V \\
(\mathrm{~km} / \mathrm{s}) \\
(11) \\
\end{array}$ & $\begin{array}{l}\text { wing } \\
\text { (12) } \\
\end{array}$ & \\
\hline G333.60-0.22 & 2 & $7.91(0.10)$ & $1.26(0.07)$ & $.48 .49(0.10)$ & $5.88(0.24)$ & & $55.74(0.28)$ & $7.51(0.06)$ & $-48.25(0.02)$ & $6.98(0.05)$ & & $\mathrm{br}$ \\
\hline \multirow[t]{3}{*}{$(20,0)$} & 3 & $9.31(0.08)$ & $1.26(0.04)$ & $-48.44(0.07)$ & $6.95(0.18)$ & & $53.28(0.23)$ & $6.85(0.03)$ & $-48.40(0.01)$ & $7.43(0.02)$ & & \\
\hline & 5 & $6.73(0.30)$ & $0.77(0.07)$ & $-49.44(0.29)$ & $9.00(0.65)$ & & $49.58(0.38)$ & $5.82(0.12)$ & $-48.21(0.05)$ & $8.34(0.13)$ & & \\
\hline & 7 & $-(-)$ & $-(-)$ & $-(-)$ & $-(-)$ & & $-(-)$ & $-(-)$ & $-(-)$ & $-(-)$ & & \\
\hline \multirow{4}{*}{$\begin{array}{l}\text { G337.40-0.40 } \\
(20,20)\end{array}$} & 2 & $11.45(0.14)$ & $2.25(0.05)$ & $-41.02(0.03)$ & $4.72(0.09)$ & & $50.58(0.37)$ & $8.32(0.05)$ & $-41.34(0.01)$ & $5.77(0.03)$ & & \\
\hline & 3 & $15.44(0.09)$ & $2.92(0.02)$ & $-40.96(0.01)$ & $4.88(0.03)$ & & $59.88(0.31)$ & $8.94(0.03)$ & $-40.98(0.01)$ & $6.36(0.02)$ & $\mathbf{r}$ & \\
\hline & 5 & $8.53(0.31)$ & $1.76(0.09)$ & $-40.72(0.07)$ & $4.28(0.16)$ & & $47.36(0.51)$ & $6.72(0.09)$ & $-41.27(0.03)$ & $6.69(0.07)$ & & \\
\hline & 7 & $-(-)$ & $-(-)$ & $-(-)$ & $-(-)$ & & $-(-)$ & $-(-)$ & $-(-)$ & $-(-)$ & & \\
\hline \multirow{4}{*}{$\begin{array}{l}\text { G337.91-0.47 } \\
(40,-20)\end{array}$} & 2 & $11.09(0.14)$ & $2.41(0.06)$ & $-39.52(0.03)$ & $4.10(0.08)$ & & $36.49(0.79)$ & $7.93(0.10)$ & $-40.33(0.02)$ & $3.83(0.04)$ & b & \\
\hline & 3 & $20.50(0.16)$ & $3.75(0.03)$ & $-39.14(0.01)$ & $4.93(0.03)$ & b & $51.90(0.88)$ & $8.49(0.06)$ & $-39.74(0.01)$ & $5.33(0.03)$ & $\mathrm{br}$ & \\
\hline & 5 & $12.67(0.34)$ & $2.32(0.09)$ & $-38.64(0.05)$ & $4.81(0.15)$ & & $76.11(0.68)$ & $10.19(0.10)$ & $-38.96(0.02)$ & $7.22(0.06)$ & $\mathrm{br}$ & \\
\hline & 7 & $22.62(1.01)$ & $3.98(0.21)$ & $-39.00(0.08)$ & $5.04(0.20)$ & & $68.23(1.09)$ & $9.08(0.16)$ & $-38.73(0.03)$ & $7.23(0.10)$ & & \\
\hline \multirow{4}{*}{$\begin{array}{l}\text { G345.00-0.23 } \\
(0,0)\end{array}$} & 2 & $5.26(0.11)$ & $0.60(0.04)$ & $-27.12(0.15)$ & $8.13(0.38)$ & & $25.14(0.45)$ & $1.78(0.03)$ & $-25.72(0.08)$ & $15.70(0.19)$ & a & \\
\hline & 3 & $8.49(0.09)$ & $0.98(0.02)$ & $-26.77(0.06)$ & $7.99(0.15)$ & & $47.15(0.56)$ & $3.65(0.02)$ & $-25.95(0.02)$ & $13.62(0.05)$ & a & \\
\hline & 5 & $6.04(0.36)$ & $0.96(0.08)$ & $-27.57(0.15)$ & $5.62(0.37)$ & & $48.09(0.59)$ & $5.35(0.07)$ & $-26.21(0.04)$ & $8.44(0.09)$ & $\mathrm{b}$ & \\
\hline & 7 & $-(-)$ & $-(-)$ & $-(-)$ & $-(-)$ & & $-(-)$ & $-(-)$ & $-(-)$ & $-(-)$ & & \\
\hline \multirow{4}{*}{$\begin{array}{l}\text { G345.41-0.94 } \\
(0,0)\end{array}$} & 2 & $11.32(0.17)$ & $2.82(0.06)$ & $-21.56(0.02)$ & $3.61(0.06)$ & & $45.45(0.26)$ & $11.02(0.07)$ & $-21.47(0.01)$ & $3.78(0.02)$ & & $\mathrm{r}$ \\
\hline & 3 & $16.94(0.16)$ & $4.31(0.04)$ & $-21.33(0.01)$ & $3.58(0.02)$ & & $63.12(0.42)$ & $13.61(0.04)$ & $-21.22(0.00)$ & $4.28(0.01)$ & & \\
\hline & 5 & $12.46(0.38)$ & $3.26(0.13)$ & $-21.34(0.04)$ & $3.37(0.11)$ & & $60.14(0.46)$ & $12.51(0.13)$ & $-21.19(0.01)$ & $4.46(0.03)$ & & \\
\hline & 7 & $7.94(0.90)$ & $2.12(0.22)$ & $-20.98(0.11)$ & $3.41(0.26)$ & & $49.40(0.98)$ & $10.28(0.17)$ & $-21.17(0.02)$ & $4.47(0.06)$ & & \\
\hline G348.55-0.97 & 2 & $5.10(0.28)$ & $0.85(0.10)$ & $-16.45(0.21)$ & $5.38(0.51)$ & & $-(-)$ & $-(-)$ & $-(-)$ & $-(-)$ & & \\
\hline \multirow[t]{3}{*}{$(0,0)$} & 3 & $-(-)$ & $-(-)$ & $-(-)$ & $-(-)$ & & $23.50(0.20)$ & $2.99(0.03)$ & $-16.21(0.02)$ & $7.30(0.05)$ & b & \\
\hline & 5 & $-(-)$ & $-(-)$ & $-(-)$ & $-(-)$ & & $7.09(0.88)$ & $1.76(0.36)$ & $-15.74(0.18)$ & $3.09(0.51)$ & & \\
\hline & 7 & $-(-)$ & $-(-)$ & $-(-)$ & $-(-)$ & & $-(-)$ & $-(-)$ & $-(-)$ & $-(-)$ & & \\
\hline \multirow{4}{*}{$\begin{array}{l}\text { G351.16+0.70 } \\
(-20,0)\end{array}$} & 2 & $11.28(0.15)$ & $2.33(0.06)$ & $-6.57(0.03)$ & $4.33(0.08)$ & b & $60.83(0.60)$ & $10.42(0.07)$ & $-6.34(0.01)$ & $5.41(0.03)$ & b & br \\
\hline & 3 & $14.76(0.17)$ & $2.90(0.03)$ & $-6.28(0.02)$ & 4.55(0.04) & b & $82.29(0.90)$ & $11.56(0.03)$ & $-5.89(0.01)$ & $6.80(0.01)$ & b & \\
\hline & 5 & $5.65(0.33)$ & $1.34(0.16)$ & $-6.07(0.09)$ & $3.41(0.34)$ & & $57.42(0.75)$ & $8.34(0.10)$ & $-6.10(0.02)$ & $6.57(0.06)$ & b & \\
\hline & 7 & $-(-)$ & $-(-)$ & $-(-)$ & $-(-)$ & & $43.40(1.08)$ & $7.04(0.18)$ & $-6.06(0.04)$ & $5.69(0.11)$ & & \\
\hline \multirow{4}{*}{$\begin{array}{l}\text { G348.73-1.04 } \\
(20,0)\end{array}$} & 2 & $14.69(0.16)$ & $2.90(0.05)$ & $-12.42(0.02)$ & $4.65(0.06)$ & & $66.04(0.31)$ & $11.01(0.07)$ & $-12.39(0.01)$ & $5.61(0.03)$ & $\mathbf{r}$ & $\mathrm{b}$ \\
\hline & 3 & $20.28(0.20)$ & $4.18(0.03)$ & $-12.29(0.01)$ & $4.47(0.03)$ & & $71.37(0.39)$ & $12.25(0.03)$ & $-12.54(0.00)$ & $5.43(0.01)$ & $r$ & \\
\hline & 5 & $16.55(0.43)$ & $2.91(0.09)$ & $-11.96(0.05)$ & $5.24(0.12)$ & & $68.12(0.59)$ & $12.21(0.12)$ & $-12.35(0.02)$ & $5.16(0.04)$ & & \\
\hline & 7 & $8.54(0.83)$ & $1.48(0.27)$ & $-11.68(0.18)$ & $5.03(0.76)$ & & $59.64(0.98)$ & $12.64(0.18)$ & $-12.31(0.02)$ & $4.37(0.05)$ & & \\
\hline \multirow{4}{*}{$\begin{array}{l}\text { G351.41+0.64 } \\
(0,0)\end{array}$} & 2 & $22.61(0.28)$ & $4.52(0.05)$ & $-6.63(0.02)$ & $4.55(0.04)$ & & $92.82(0.70)$ & $16.25(0.06)$ & $-7.39(0.01)$ & $5.37(0.02)$ & & $\mathrm{br}$ \\
\hline & 3 & $29.95(0.36)$ & $5.68(0.04)$ & $-6.67(0.01)$ & $4.86(0.03)$ & & $111.36(0.49)$ & $15.81(0.07)$ & $-7.01(0.01)$ & $6.64(0.02)$ & $\mathbf{r}$ & \\
\hline & 5 & $25.13(0.40)$ & $4.49(0.09)$ & $-6.82(0.03)$ & $5.17(0.08)$ & & $112.98(0.59)$ & $15.96(0.11)$ & $-6.97(0.01)$ & $6.66(0.04)$ & $\mathbf{r}$ & \\
\hline & 7 & $43.25(1.05)$ & $6.50(0.19)$ & $-6.76(0.06)$ & $6.28(0.14)$ & & $135.63(1.34)$ & $17.99(0.17)$ & $-6.69(0.02)$ & $7.18(0.05)$ & & \\
\hline \multirow{4}{*}{$\begin{array}{l}\text { G0.21-0.01 } \\
(0,0)\end{array}$} & 2 & $0.42(0.02)$ & $0.61(0.27)$ & $-2.72(0.04)$ & $0.26(0.08)$ & & $-(-)$ & $-(-)$ & $-(-)$ & $-(-)$ & & \\
\hline & 3 & $-(-)$ & $-(-)$ & $-(-)$ & $-(-)$ & & $-(-)$ & $-(-)$ & $-(-)$ & $-(-)$ & & \\
\hline & 5 & $-(-)$ & $-(-)$ & $-(-)$ & $-(-)$ & & $-0.05(0.42)$ & $1.53(0.66)$ & $-2.96(0.04)$ & $0.24(0.08)$ & & \\
\hline & 7 & $-(-)$ & $-(-)$ & $-(-)$ & $-(-)$ & & $-(-)$ & $-(-)$ & $-(-)$ & $-(-)$ & & \\
\hline \multirow{4}{*}{$\begin{array}{l}\text { G359.97-0.46 } \\
(0,0)\end{array}$} & 2 & $3.88(0.16)$ & $1.23(0.09)$ & $18.76(0.06)$ & $2.60(0.14)$ & & $-(-)$ & $-(-)$ & $-(-)$ & $-(-)$ & & \\
\hline & 3 & $2.06(0.07)$ & $0.40(0.03)$ & $18.81(0.10)$ & $4.41(0.24)$ & & $13.02(0.10)$ & $2.92(0.03)$ & $18.89(0.01)$ & $4.15(0.03)$ & & \\
\hline & 5 & $-(-)$ & $-(-)$ & $-(-)$ & $-(-)$ & & $19.40(0.80)$ & $3.47(0.18)$ & $19.10(0.09)$ & $5.16(0.21)$ & & \\
\hline & 7 & $-(-)$ & $-(-)$ & $-(-)$ & $-(-)$ & & $-(-)$ & $-(-)$ & $-(-)$ & $-(-)$ & & \\
\hline
\end{tabular}

included in the near infrared study of galactic masers by Testi et al. (1994).

The source G $351.41+0.64$ is probably the best known object in our sample. The object is better known as NGC 6334I (in the 'McBreen/Gezari convention', see Appendix in Kuiper et al. 1995) or NGC 6334F (see e.g. De Pree et al. 1995). The source has already been mapped in CO (Dickel et al. 1977; Bachiller \& Cernicharo 1990), $\mathrm{C}^{18} \mathrm{O}$ (Schwartz et al. 1989), $\mathrm{HCO}^{+}$(Batchelor et al. 1984) and $\mathrm{NH}_{3}$ (Kuiper et al. 1995).

CS has also been observed near NGC 6334I in transitions $J=5-4$ and $J=10-9$ (Hauschildt et al. 1993) but for the rest of our sample the present study comprises, to our knowledge, the first observations of CS transitions higher than $J=2-1$ as well as the first CS maps in any transition.

Since our sources are associated with both strong $\mathrm{H}_{2} \mathrm{O}$ maser emission and strong IRAS sources the cores are evidently regions of high mass star formation. As most sources coincide with known compact HII regions the hydrogen recombination lines have also been observed towards many of them (see e.g. Wilson 1970; Caswell \& Haynes 1987).

\subsection{Data reduction}

The basic data reduction was made using the GAG (Groupe d'Astrophysique de Grenoble) software which was also used for producing the maps. From the frequency switched spectra a baseline of order three to five was 
Table 4. The IRAS point sources associated with the observed CS cores. The second column gives the positional difference between the centre point of the CS core as indicated with a cross in the channel maps, and the IRAS source

\begin{tabular}{llllll}
\hline & & \multicolumn{3}{l}{ IRAS fluxes } \\
\cline { 4 - 6 } CS core & $\Delta\left(^{\prime \prime}\right)$ & $12 \mu \mathrm{m}$ & $25 \mu \mathrm{m}$ & $60 \mu \mathrm{m}$ & $100 \mu \mathrm{m}$ \\
\hline $308.00-0.25$ & 20 & 7.92 & 106 & 573 & 873 \\
$308.92+0.12$ & 18 & 251 & 601 & 2690 & 3570 \\
$309.92+0.48$ & 20 & 76.4 & 667 & 3930 & 4410 \\
$311.94+0.18$ & 126 & 22.6 & 79.7 & 1360 & 4470 \\
$316.37-0.37$ & 0 & 10.1 & 42.5 & 752 & 1470 \\
$316.64-0.08$ & 13 & 3.98 & 24.3 & 538 & 918 \\
$316.81-0.06$ & 50 & 140 & 766 & 6840 & 16100 \\
$318.05+0.09$ & 19 & 4.06 & 89.7 & 1130 & 2210 \\
$323.74-0.25$ & 44 & 23.7 & 167 & 1950 & 3260 \\
$324.20+0.12$ & 13 & 47.6 & 501 & 4820 & 6890 \\
$328.30+0.43$ & 20 & 142 & 1210 & 11600 & 12400 \\
$329.04-0.21$ & 58 & 6.31 & 4.24 & 332 & 1650 \\
$329.04-0.21$ & 12 & 6.31 & 4.16 & 332 & 1650 \\
$330.88-0.36$ & 19 & 20.8 & 237 & 6700 & 15100 \\
$331.00-0.19$ & 52 & 2.98 & 210 & 10600 & 19200 \\
$331.28-0.18$ & 34 & 36.2 & 237 & 2790 & 5720 \\
$332.65-0.63$ & 13 & 104 & 656 & 5240 & 12400 \\
$332.83-0.55$ & 24 & 105 & 1480 & 11400 & 20400 \\
$333.13-0.43$ & 33 & 144 & 1520 & 12400 & 26700 \\
$333.60-0.22$ & 33 & 2550 & 6810 & 5150 & 36400 \\
$337.40-0.40$ & 22 & 8.49 & 134 & 3690 & 8450 \\
$337.91-0.47$ & 50 & 192 & 1770 & 13300 & 24800 \\
$343.12-0.06$ & 178 & 1.98 & 62.3 & 2620 & 6470 \\
$343.12-0.06$ & 6 & 2.57 & 62.3 & 2620 & 6470 \\
$345.00-0.23$ & 14 & 3.12 & 241 & 3660 & 7000 \\
$345.01+1.80$ & 14 & 26.5 & 470 & 7140 & 13200 \\
$345.51+0.35$ & 29 & 68.5 & 538 & 2700 & 18300 \\
$345.41-0.94$ & 27 & 543 & 3880 & 12700 & 25800 \\
$348.55-0.97$ & 53 & 19.6 & 98.3 & 1660 & 4340 \\
$348.73-1.04$ & 19 & 328 & 1820 & 9910 & 35900 \\
$351.16+0.70$ & 8 & 3.73 & 805 & 10500 & 19900 \\
$351.41+0.64$ & 15 & 103 & 1400 & 11400 & 22100 \\
$359.97-0.46$ & 5 & 27.6 & 228 & 1750 & 3750 \\
$359.97-0.46$ & 154 & 2.4 & 4.83 & 1750 & 3750 \\
$0.21-0.01$ & 43 & 4.45 & 61.4 & 595 & 8740 \\
\hline & & & & &
\end{tabular}

subtracted before folding. In some cases the poor quality of the baselines clearly increases the uncertainty of the results, but this affects only some of the CS(5-4) maps. All measurements of the centre positions of the clouds were made using position switching or wide beam switching (beam offset about 12'). The subtraction of baselines of order one, or in some cases of order two, was sufficient.

\section{Observational results}

Figures 1 and 2 show the results of the mapping. Most sources were mapped in both $\mathrm{CS}(5-4)$ and $\mathrm{C}^{34} \mathrm{~S}(2-1)$, thirteen clouds were mapped in $\mathrm{CS}(2-1)$ and a few clouds in $\mathrm{CS}(3-2)$ as well. The velocity intervals and contour levels are given in the figures. The positions of the masers (filled triangles) and the IRAS sources (stars) are also indicated.

The results of the single point measurements are shown in Fig. 3. The figure contains all CS spectra measured at the centre positions of the clouds i.e. the points of maximum emission as determined on the basis of the mapping. The spectra have been smoothed to correspond to the resolution of the spectrometer, about $80 \mathrm{kHz}$. Most $\mathrm{CO}(1-0)$ spectra are also shown.

The spectra at the central positions of the clouds were fitted with only one Gaussian component each although in some cases the spectra are clearly not well described with such fits. Therefore the fit results are, for some sources and transitions, clearly only indicative and should be treated as such.

The results from the fitting of the central position spectra are given in Table 3 . The first column gives the offsets of the measured points with respect to the coordinates given in Table 2. The second column gives the $J$ value for the upper level of each transition. Table 3 includes also the line areas which were calculated by directly summing the channel values, i.e. they are not results of the Gauss fits. Table 3 contains also information on some non-gaussian features of the spectra. Wing emission that exceeds $2 \sigma$ noise level compared with the gaussian fit is marked with a letter $r$ in case of a red wing and with $b$ in case of a blue wing. Strong absorption features are indicated with letter $a$. The last column gives this information for the $\mathrm{CO}(1-0)$ line.

\section{IRAS associations}

The IRAS point source catalog was searched for infrared sources near the $\mathrm{H}_{2} \mathrm{O}$ maser locations. Table 4 lists the point sources, the projected distance between the CS cloud centre and the IRAS source in arc seconds as well as the source flux in the IRAS bands. Most cores are associated with very strong infrared sources as this was one of the selection criteria used in the case of 26 of the altogether 33 sources. Figure 4 shows two colour-colour plots based on the IRAS fluxes. The first frame shows $\log [S(60) / S(12)]$ as function of $\log [S(25) / S(12)]$ and the criteria for ultracompact HII regions as given by Wood \& Churchwell (1989). In the second frame the $\log [S(60) / S(25)]$ values are shown as the function of $\log [S(100) / S(60)]$. The selection criteria used by Richards et al. (1987) for compact molecular cores are indicated as a box. These figures show that most of our sources fulfill both given criteria. There are, however, also some exceptions, the most notable of which are G $329.04-0.21$ and G $333.60-0.22$. G $333.60-0.22$ is a well known compact HII region and is in infrared one of the most luminous ones in the Galaxy (see e.g. Storey et al. 1989; Natta \& Oliva 1985). G $329.04-0.21$ is also 
either a compact or ultra compact $\mathrm{H}$ II region (Habing \&Israel 1979). Source G $0.21-0.01$ is furthest above the box of compact molecular clouds of Richards et al. (1989) in Fig. 4b. This IRAS source is associated with an $\mathrm{NH}_{3}$ clump mapped by Güsten et al. (1981) but the observed $\mathrm{H}_{2} \mathrm{O}$ maser position is somewhat displaced from this.

\section{Data analysis}

\subsection{LTE-analysis}

The optical depths of all transitions $J=2-1, J=3-2$, $J=5-4$ and $J=7-6$ were first obtained in the usual manner from the ratio of the peak main beam temperatures assuming identical excitation temperatures and beam filling factors for both isotopes. By further assuming the terrestrial value $R=22.5$ for the abundance ratio between the two isotopes the optical depth of the rarer isotope $\tau_{\mathrm{p}}$ was calculated from

$$
\frac{T_{\mathrm{MB}}^{*}\left(\mathrm{C}^{34} \mathrm{~S}\right)}{T_{\mathrm{MB}}^{*}(\mathrm{CS})}=\frac{1-\mathrm{e}^{-\tau_{\mathrm{p}}}}{1-\mathrm{e}^{-\tau_{\mathrm{p}}} R} .
$$

If one takes into account the line broadening due to the optical depth (Phillips et al. 1979), the observed line width, $\Delta V$, can be expressed in terms of the line width of the optically thin line, $\Delta V_{0}$, as

$$
\Delta V=\frac{\Delta V_{0}}{\sqrt{\ln 2}} \sqrt{\ln \frac{\tau}{\ln \left[\frac{2}{1+\exp (-\tau)}\right]}} .
$$

This expression can be used to derive the optical depth from the ratio of the line area, $T_{\mathrm{MB}}^{*} \Delta V$, for the two isotopes. We denote this value of the optical depth as $\tau_{\mathrm{a}}$.

The CS column densities have been calculated from the integrated line areas using the LTE approximation. The broadening of the lines due to optical depth was also taken into account by using the formula

$$
N_{u}=\frac{3 h c}{8 \pi^{3} \nu \mu^{2}} \frac{\int \tau(\nu) \mathrm{d} \nu}{1-\mathrm{e}^{\frac{-h \nu}{k T}}}
$$

for the column density of molecules on the upper level of the transition. The integral of the optical depth was calculated from

$$
\int \tau(\nu) \mathrm{d} \nu=f \frac{\int T_{R} \mathrm{~d} v}{J\left(T_{\text {ex }}\right)-J\left(T_{\mathrm{bg}}\right)}
$$

with

$$
J(T)=1 /\left(\mathrm{e}^{\frac{h \nu}{k T}}-1\right)
$$

and the factor $f$ was estimated numerically assuming a Gaussian line profile.

Table 5 gives the results of the LTE calculations. The optical depths $\tau_{\mathrm{a}}$ and $\tau_{\mathrm{p}}$ were calculated separately for different transitions $J=2-1,3-2,5-4$ and $7-6$; similarly the column densities.
The densities and the cloud masses (see Table 6) were calculated by first estimating the cloud size from the $\mathrm{C}^{34} \mathrm{~S}(2-1)$ maps. The distances of the clouds were taken from Table 2 i.e. the values used are mostly kinematic distances calculated from the $\mathrm{C}^{34} \mathrm{~S}(2-1)$ line velocity using a flat rotation curve with $\Theta_{0}=220 \mathrm{~km} \mathrm{~s}^{-1}$ and $R_{0}=$ $8.5 \mathrm{kpc}$ (Fich et al. 1989). In some cases a value from the literature is used instead (see Table 2).

The adopted cloud sizes correspond to the area $A$ where the line integral of $\mathrm{C}^{34} \mathrm{~S}(2-1)$ exceeds one half of its maximum value. Using a cloud diameter $L$ derived from $L=\sqrt{4 A / \pi}$ the density was calculated as $n=N_{\mathrm{LTE}}\left(\mathrm{H}_{2}\right) / L$. The mass is given by the formula $M=\mu \mathrm{m} N_{\mathrm{LTE}}\left(\mathrm{H}_{2}\right) A$, where $m$ is the mass of a hydrogen molecule and $\mu \approx 1.36$ the ratio between the total gas mass (including helium) and the hydrogen mass.

The values of cloud densities and masses are given in Cols. (4) and (5) of Table 6. The masses of strongly selfabsorbed sources (e.g. G 345.00-0.23) are clearly underestimated.

The table also contains the virial masses that were calculated from the linewidths $\Delta V$ of $\operatorname{CS}(2-1)$ using the formula

$$
M_{\mathrm{vir}}=\frac{5}{3} \frac{\sigma^{2} R}{G}=\frac{5}{16 \ln 2} \frac{L(\Delta V)^{2}}{G}
$$

where $\sigma$ is the velocity dispersion and $G$ the gravitational constant. These values are in the last column of Table 6 .

\subsection{LVG models}

The observations were also analyzed using a spherical LVG model. A value of $\mu=1.96 \mathrm{D}$ was used for the electric dipole moment (Winnewisser \& Cook 1968). The source coupling coefficients were estimated from the $\mathrm{CS}(2-1)$, $\mathrm{C}^{34} \mathrm{~S}(2-1), \mathrm{CS}(5-4)$ and $\mathrm{C}^{34} \mathrm{~S}(5-4)$ maps by assuming a Gaussian beam with the beam widths given in The SEST Handbook (1993). These coefficients were interpolated for use with the $J=3-2$ transitions and extrapolated to $J=7-6$ transitions (see Table 2). For some sources an estimate for the kinetic temperature $T_{\mathrm{k}}$ is known from the literature. For the rest of the sources the $\mathrm{CO}(1-0)$ observations were used to get an approximate value for $T_{\mathrm{k}}$. Figure 5 shows an example of the LVG modeling of one cloud at the kinetic temperature deduced from the $\mathrm{CO}$ observations. The lines correspond to the temperatures of the different transitions and error limits at $1 \sigma$ due to statistical errors in deriving the peak temperatures. As in most cases the model errors exceed statistical errors i.e. there is no one unique solution within the error estimates. Furthermore the column density derived from the CS lines is systematically below the value derived from the $\mathrm{C}^{34} \mathrm{~S}$ lines.

Table 7 lists some results from the LVG modeling. Column (2) gives the adopted value of the kinetic temperature. These values have been estimated on the basis of the observed $\mathrm{CO}(1-0)$ antenna temperatures. For some 
Table 5. Results from the LTE analysis of the CS observations. The values have been calculated separately from different transitions of $\mathrm{CS}$ and $\mathrm{C}^{34} \mathrm{~S} . \tau_{\mathrm{a}}$ and $\tau_{\mathrm{p}}$ are the optical depths of $\mathrm{C}^{34} \mathrm{~S}$ calculated with different methods (see text). Column densities are calculated from the line integrals

\begin{tabular}{|c|c|c|c|c|c|}
\hline Source & $J$ & $T_{\text {ex }}(\mathrm{K})$ & $\tau_{\mathrm{p}}$ & $\tau_{\mathrm{a}}$ & $\log N_{\mathrm{L}}\left(\mathrm{C}^{34} \mathrm{~S}\right)$ \\
\hline \multirow[t]{4}{*}{$308.00-0.25$} & 2 & $7.2(0.2)$ & $0.15(0.03)$ & $0.23(0.09)$ & $12.59(0.06)$ \\
\hline & 3 & $7.5(0.0)$ & $0.20(0.01)$ & $0.19(0.01)$ & $12.39(0.01)$ \\
\hline & 5 & $11.4(9.0)$ & $0.08(0.06)$ & $0.25(0.20)$ & $12.60(0.71)$ \\
\hline & 7 & $-(-)$ & $-(-)$ & $-(-)$ & $-(-)$ \\
\hline \multirow[t]{4}{*}{$308.92+0.12$} & 2 & $8.0(0.1)$ & $0.23(0.01)$ & $0.33(0.03)$ & $12.66(0.02)$ \\
\hline & 3 & $9.5(0.0)$ & $0.28(0.00)$ & $0.54(0.02)$ & $12.71(0.00)$ \\
\hline & 5 & $10.1(0.2)$ & $0.21(0.02)$ & $0.30(0.06)$ & $12.69(0.03)$ \\
\hline & 7 & $14.0(0.2)$ & $0.56(0.12)$ & $0.09(0.05)$ & $12.62(0.10)$ \\
\hline \multirow[t]{4}{*}{$309.92+0.48$} & 2 & $6.4(0.1)$ & $0.32(0.02)$ & $0.52(0.06)$ & $12.80(0.02)$ \\
\hline & 3 & $7.3(0.0)$ & $0.32(0.01)$ & $0.54(0.03)$ & $12.70(0.01)$ \\
\hline & 5 & $6.5(0.2)$ & $0.58(0.10)$ & $0.16(0.05)$ & $12.50(0.09)$ \\
\hline & 7 & $-(-)$ & $-(-)$ & $-(-)$ & $-(-)$ \\
\hline \multirow[t]{4}{*}{$316.37-0.37$} & 2 & $3.6(0.1)$ & $0.18(0.05)$ & $0.90(0.47)$ & $12.82(0.10)$ \\
\hline & 3 & $-(-)$ & $-(-)$ & $-(-)$ & $-(-)$ \\
\hline & 5 & $5.3(2.2)$ & $0.91(0.47)$ & $0.64(0.53)$ & $14.41(0.57)$ \\
\hline & 7 & $-(-)$ & $-(-)$ & $-(-)$ & $-(-)$ \\
\hline \multirow[t]{4}{*}{$316.64-0.08$} & 2 & $3.5(0.4)$ & $0.78(0.43)$ & $0.33(0.34)$ & $11.43(0.48)$ \\
\hline & 3 & $3.6(0.5)$ & $0.58(0.38)$ & $0.11(0.14)$ & $-(-)$ \\
\hline & 5 & $6.5(3.4)$ & $0.94(0.46)$ & $0.49(0.45)$ & $-(-)$ \\
\hline & 7 & $-(-)$ & $-(-)$ & $-(-)$ & $-(-)$ \\
\hline \multirow[t]{4}{*}{$316.77-0.02$} & 2 & $5.6(0.1)$ & $0.18(0.02)$ & $0.27(0.06)$ & $12.62(0.04)$ \\
\hline & 3 & $7.8(1.0)$ & $0.04(0.01)$ & $0.03(0.02)$ & $11.81(0.06)$ \\
\hline & 5 & $5.1(0.4)$ & $1.13(0.21)$ & $0.08(0.06)$ & $12.26(0.44)$ \\
\hline & 7 & $-(-)$ & $-(-)$ & $-(-)$ & $-(-)$ \\
\hline \multirow[t]{4}{*}{$316.81-0.06$} & 2 & $7.1(0.1)$ & $0.20(0.01)$ & $0.28(0.04)$ & $12.68(0.02)$ \\
\hline & 3 & $8.6(0.0)$ & $0.15(0.00)$ & $0.17(0.01)$ & $12.36(0.01)$ \\
\hline & 5 & $7.6(0.1)$ & $0.16(0.02)$ & $0.34(0.09)$ & $12.80(0.06)$ \\
\hline & 7 & $-(-)$ & $-(-)$ & $-(-)$ & $-(-)$ \\
\hline \multirow[t]{4}{*}{$318.05+0.09$} & 2 & $8.2(0.1)$ & $0.22(0.01)$ & $0.28(0.04)$ & $12.71(0.02)$ \\
\hline & 3 & $9.3(0.0)$ & $0.23(0.00)$ & $0.31(0.01)$ & $12.57(0.01)$ \\
\hline & 5 & $9.2(0.1)$ & $0.29(0.03)$ & $0.27(0.04)$ & $12.70(0.03)$ \\
\hline & 7 & $-(-)$ & $-(-)$ & $-(-)$ & $-(-)$ \\
\hline \multirow[t]{4}{*}{$323.74-0.25$} & 2 & $5.5(0.1)$ & $0.25(0.02)$ & $0.54(0.08)$ & $12.68(0.03)$ \\
\hline & 3 & $5.8(0.0)$ & $0.21(0.01)$ & $0.25(0.03)$ & $12.52(0.01)$ \\
\hline & 5 & $7.2(0.6)$ & $1.23(0.00)$ & $0.04(0.03)$ & $10.87(0.50)$ \\
\hline & 7 & $-(-)$ & $-(-)$ & $-(-)$ & $-(-)$ \\
\hline \multirow[t]{4}{*}{$324.20+0.12$} & 2 & $7.1(0.1)$ & $0.25(0.01)$ & $0.40(0.04)$ & $12.89(0.01)$ \\
\hline & 3 & $8.3(0.0)$ & $0.25(0.01)$ & $0.28(0.01)$ & $12.74(0.01)$ \\
\hline & 5 & $8.4(0.1)$ & $0.31(0.03)$ & $0.37(0.08)$ & $13.11(0.03)$ \\
\hline & 7 & $-(-)$ & $-(-)$ & $-(-)$ & $-(-)$ \\
\hline \multirow[t]{4}{*}{$328.30+0.43$} & 2 & $8.2(0.1)$ & $0.16(0.01)$ & $0.32(0.03)$ & $12.90(0.01)$ \\
\hline & 3 & $9.3(0.0)$ & $0.18(0.00)$ & $0.32(0.01)$ & $12.71(0.01)$ \\
\hline & 5 & $10.6(0.8)$ & $0.09(0.03)$ & $0.15(0.07)$ & $12.54(0.09)$ \\
\hline & 7 & $-(-)$ & $-(-)$ & $-(-)$ & $-(-)$ \\
\hline \multirow[t]{4}{*}{$329.04-0.21$} & 2 & $4.6(0.0)$ & $0.42(0.04)$ & $0.14(0.03)$ & $12.83(0.02)$ \\
\hline & 3 & $5.2(0.0)$ & $0.29(0.01)$ & $0.21(0.01)$ & $12.80(0.01)$ \\
\hline & 5 & $6.4(0.1)$ & $0.18(0.03)$ & $0.39(0.11)$ & $13.25(0.06)$ \\
\hline & 7 & $-(-)$ & $-(-)$ & $-(-)$ & $-(-)$ \\
\hline \multirow[t]{4}{*}{$331.00-0.19$} & 2 & $9.9(0.0)$ & $0.28(0.01)$ & $0.55(0.02)$ & $13.33(0.01)$ \\
\hline & 3 & $11.7(0.0)$ & $0.26(0.00)$ & $0.54(0.01)$ & $13.13(0.00)$ \\
\hline & 5 & $11.8(0.1)$ & $0.15(0.01)$ & $0.25(0.03)$ & $12.89(0.02)$ \\
\hline & 7 & $11.3(0.5)$ & $0.35(0.16)$ & $-(-)$ & $-(-)$ \\
\hline \multirow[t]{4}{*}{$330.88-0.36$} & 2 & $10.0(0.0)$ & $0.31(0.01)$ & $0.58(0.03)$ & $13.25(0.01)$ \\
\hline & 3 & $10.6(0.0)$ & $0.36(0.00)$ & $0.61(0.02)$ & $13.04(0.00)$ \\
\hline & 5 & $11.3(0.1)$ & $0.16(0.01)$ & $0.05(0.02)$ & $12.46(0.03)$ \\
\hline & 7 & $-(-)$ & $-(-)$ & $-(-)$ & $-(-)$ \\
\hline
\end{tabular}


Table 5. continued

\begin{tabular}{|c|c|c|c|c|c|}
\hline Source & $J$ & $T_{\text {ex }}(\mathrm{K})$ & $\tau_{\mathrm{p}}$ & $\tau_{\mathrm{a}}$ & $\log N_{\mathrm{L}}\left(\mathrm{C}^{34} \mathrm{~S}\right)$ \\
\hline \multirow[t]{4}{*}{$\overline{331.28-0.18}$} & 2 & $6.2(0.0)$ & $0.28(0.01)$ & $0.68(0.08)$ & $12.96(0.02)$ \\
\hline & 3 & $6.6(0.0)$ & $0.34(0.01)$ & $0.47(0.02)$ & $12.75(0.01)$ \\
\hline & 5 & $6.3(0.1)$ & $0.29(0.04)$ & $0.60(0.17)$ & $13.32(0.05)$ \\
\hline & 7 & $-(-)$ & $-(-)$ & $-(-)$ & $-(-)$ \\
\hline \multirow{4}{*}{$332.65-0.63$} & 2 & $6.4(0.0)$ & $0.37(0.01)$ & $0.52(0.04)$ & $12.93(0.01)$ \\
\hline & 3 & $7.8(0.0)$ & $0.37(0.01)$ & $0.60(0.02)$ & $12.83(0.01)$ \\
\hline & 5 & $8.9(0.1)$ & $0.25(0.01)$ & $0.45(0.05)$ & $12.75(0.03)$ \\
\hline & 7 & $-(-)$ & $-(-)$ & $-(-)$ & $-(-)$ \\
\hline \multirow[t]{4}{*}{$332.83-0.55$} & 2 & $10.2(0.0)$ & $0.37(0.01)$ & $1.00(0.04)$ & $13.50(0.01)$ \\
\hline & 3 & $12.1(0.0)$ & $0.46(0.00)$ & $1.33(0.04)$ & $13.40(0.00)$ \\
\hline & 5 & $14.9(0.1)$ & $0.35(0.01)$ & $0.74(0.04)$ & $13.22(0.01)$ \\
\hline & 7 & $19.2(0.1)$ & $0.44(0.01)$ & $0.74(0.04)$ & $13.41(0.01)$ \\
\hline \multirow[t]{4}{*}{$333.13-0.43$} & 2 & $15.5(0.0)$ & $0.38(0.00)$ & $0.85(0.02)$ & $13.74(0.00)$ \\
\hline & 3 & $14.7(0.0)$ & $0.49(0.00)$ & $1.24(0.02)$ & $13.45(0.00)$ \\
\hline & 5 & $15.1(0.1)$ & $0.25(0.01)$ & $0.35(0.02)$ & $12.94(0.01)$ \\
\hline & 7 & $14.6(0.1)$ & $0.37(0.02)$ & $0.65(0.06)$ & $13.42(0.02)$ \\
\hline \multirow[t]{4}{*}{$333.60-0.22$} & 2 & $10.8(0.1)$ & $0.18(0.01)$ & $0.30(0.02)$ & $13.11(0.01)$ \\
\hline & 3 & $10.6(0.0)$ & $0.20(0.00)$ & $0.40(0.02)$ & $12.93(0.01)$ \\
\hline & 5 & $11.1(0.1)$ & $0.14(0.01)$ & $0.30(0.04)$ & $12.90(0.03)$ \\
\hline & 7 & $-(-)$ & $-(-)$ & $-(-)$ & $-(-)$ \\
\hline \multirow[t]{4}{*}{$337.40-0.40$} & 2 & $11.5(0.0)$ & $0.31(0.01)$ & $0.61(0.02)$ & $13.32(0.01)$ \\
\hline & 3 & $12.7(0.0)$ & $0.40(0.00)$ & $0.78(0.01)$ & $13.17(0.00)$ \\
\hline & 5 & $11.7(0.1)$ & $0.30(0.01)$ & $0.39(0.03)$ & $12.96(0.01)$ \\
\hline & 7 & $-(-)$ & $-(-)$ & $-(-)$ & $-(-)$ \\
\hline \multirow[t]{4}{*}{$337.91-0.47$} & 2 & $11.1(0.1)$ & $0.36(0.01)$ & $1.46(0.11)$ & $13.41(0.01)$ \\
\hline & 3 & $12.2(0.0)$ & $0.58(0.01)$ & $-(-)$ & $-(-)$ \\
\hline & 5 & $15.5(0.1)$ & $0.26(0.01)$ & $0.33(0.02)$ & $12.92(0.01)$ \\
\hline & 7 & $15.9(0.1)$ & $0.58(0.03)$ & $1.23(0.16)$ & $13.66(0.03)$ \\
\hline \multirow[t]{4}{*}{$345.01+1.80$} & 2 & $13.9(0.0)$ & $0.22(0.00)$ & $0.33(0.01)$ & $13.26(0.00)$ \\
\hline & 3 & $14.1(0.0)$ & $0.31(0.00)$ & $0.46(0.01)$ & $13.05(0.00)$ \\
\hline & 5 & $15.4(0.1)$ & $0.21(0.01)$ & $0.23(0.02)$ & $12.76(0.01)$ \\
\hline & 7 & $-(-)$ & $-(-)$ & $-(-)$ & $-(-)$ \\
\hline \multirow[t]{4}{*}{$343.12-0.06$} & 2 & $6.3(0.0)$ & $0.26(0.01)$ & $0.40(0.04)$ & $12.97(0.01)$ \\
\hline & 3 & $7.3(0.0)$ & $0.33(0.01)$ & $0.42(0.01)$ & $12.97(0.01)$ \\
\hline & 5 & $9.9(0.1)$ & $0.15(0.01)$ & $0.14(0.02)$ & $12.88(0.03)$ \\
\hline & 7 & $-(-)$ & $-(-)$ & $-(-)$ & $-(-)$ \\
\hline \multirow[t]{4}{*}{$345.51+0.35$} & 2 & $8.1(0.1)$ & $0.28(0.01)$ & $0.50(0.03)$ & $13.03(0.01)$ \\
\hline & 3 & $9.7(0.1)$ & $0.31(0.01)$ & $0.57(0.03)$ & $12.94(0.01)$ \\
\hline & 5 & $11.9(0.1)$ & $0.22(0.01)$ & $0.35(0.03)$ & $12.75(0.02)$ \\
\hline & 7 & $-(-)$ & $-(-)$ & $-(-)$ & $-(-)$ \\
\hline \multirow[t]{4}{*}{$345.00-0.23$} & 2 & $4.8(0.0)$ & $0.41(0.02)$ & $0.41(0.03)$ & $13.11(0.01)$ \\
\hline & 3 & $7.2(0.0)$ & $0.31(0.00)$ & $0.35(0.01)$ & $13.02(0.00)$ \\
\hline & 5 & $10.3(0.1)$ & $0.19(0.01)$ & $0.22(0.03)$ & $12.91(0.02)$ \\
\hline & 7 & $-(-)$ & $-(-)$ & $-(-)$ & $-(-)$ \\
\hline \multirow[t]{4}{*}{$345.41-0.94$} & 2 & $14.3(0.1)$ & $0.29(0.00)$ & $0.74(0.03)$ & $13.36(0.00)$ \\
\hline & 3 & $17.4(0.0)$ & $0.38(0.00)$ & $0.87(0.01)$ & $13.22(0.00)$ \\
\hline & 5 & $17.9(0.1)$ & $0.30(0.01)$ & $0.50(0.03)$ & $12.87(0.01)$ \\
\hline & 7 & $17.2(0.1)$ & $0.23(0.02)$ & $0.35(0.05)$ & $12.98(0.03)$ \\
\hline \multirow[t]{4}{*}{$351.16+0.70$} & 2 & $13.7(0.1)$ & $0.25(0.00)$ & $0.43(0.01)$ & $13.31(0.00)$ \\
\hline & 3 & $15.4(0.0)$ & $0.29(0.00)$ & $0.39(0.01)$ & $13.09(0.00)$ \\
\hline & 5 & $13.7(0.1)$ & $0.17(0.01)$ & $0.12(0.03)$ & $12.62(0.02)$ \\
\hline & 7 & $-(-)$ & $-(-)$ & $-(-)$ & $-(-)$ \\
\hline \multirow[t]{4}{*}{$348.73-1.04$} & 2 & $14.3(0.1)$ & $0.31(0.00)$ & $0.60(0.02)$ & $13.45(0.00)$ \\
\hline & 3 & $16.1(0.0)$ & $0.42(0.00)$ & $1.00(0.02)$ & $13.31(0.00)$ \\
\hline & 5 & $17.6(0.1)$ & $0.27(0.01)$ & $0.73(0.04)$ & $13.03(0.01)$ \\
\hline & 7 & $20.9(0.6)$ & $0.11(0.02)$ & $0.27(0.07)$ & $12.80(0.04)$ \\
\hline \multirow[t]{4}{*}{$351.41+0.64$} & 2 & $19.5(0.0)$ & $0.33(0.00)$ & $0.69(0.01)$ & $13.72(0.00)$ \\
\hline & 3 & $19.7(0.1)$ & $0.44(0.00)$ & $0.86(0.01)$ & $13.48(0.00)$ \\
\hline & 5 & $21.4(0.1)$ & $0.33(0.00)$ & $0.60(0.02)$ & $13.12(0.01)$ \\
\hline & 7 & $25.3(0.1)$ & $0.45(0.01)$ & $1.34(0.10)$ & $13.49(0.01)$ \\
\hline
\end{tabular}



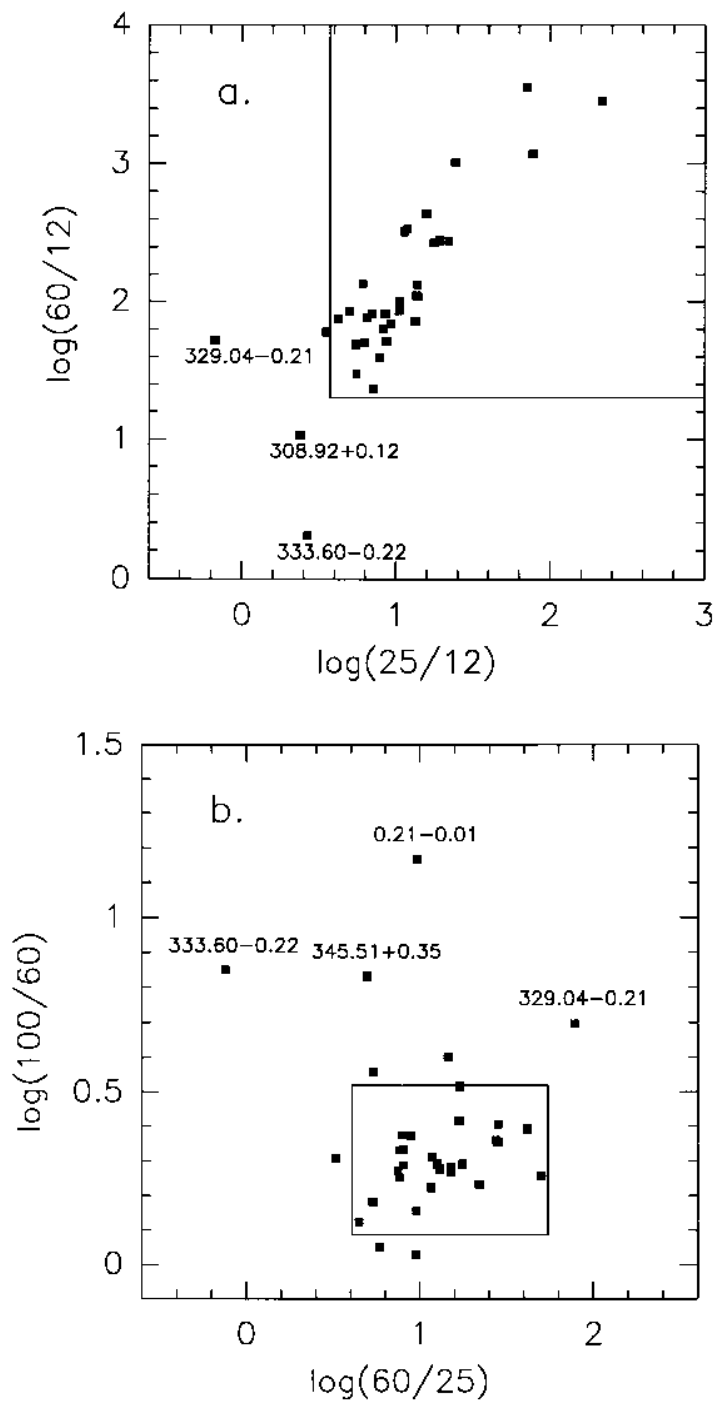

Fig. 4. The colour-colour diagrams of the IRAS sources associated with the CS cores. The figures contain all IRAS sources marked in the CS maps. a) The colour-colour diagram $(25-12) \times(60-12)$ of the IRAS sources. The selection criterion for ultra compact HII regions of Wood \& Churchwell (1989) is also indicated. b) The $(60-25) \times(100-60)$ colour-colour diagram. The box indicates the selection criteria for compact molecular clouds given by Richards et al. (1987)

sources the value is uncertain because of either the complexity or the poor quality of the CO spectrum. These are marked with a question mark in the table. The following columns give the total gas densities and the ${ }^{32} \mathrm{CS}$ column densities derived separately from the CS transitions $J=2-1$ and $J=5-4$ and the $\mathrm{C}^{34} \mathrm{~S}$ transitions $J=2-1$ and $J=5-4$.

The errors were estimated by adding $10 \%$ calibration error to the statistical errors of the temperature fits and drawing the corresponding error bands for all transitions in the $\left(n, N_{\mathrm{L}}\right)$ plane as shown in Fig. 5 . Since the error
Table 6. The densities and cloud masses calculated in LTE approximation from the lines $\mathrm{C}^{34} \mathrm{~S}(2-1)$ and $\mathrm{CS}(2-1)$. The last column gives the virial masses of the cores

\begin{tabular}{llllll}
\hline Source & $\begin{array}{l}d \\
(\mathrm{kpc})\end{array}$ & $\begin{array}{l}\text { Size } \\
\left({ }^{\prime \prime}\right)\end{array}$ & $\begin{array}{l}\log n \\
\mathrm{~cm}^{-3}\end{array}$ & $\begin{array}{l}M \\
\left(M_{\odot}\right)\end{array}$ & $\begin{array}{l}M_{\text {vir }} \\
\left(M_{\odot}\right)\end{array}$ \\
\hline G308.00-0.25 & 2.1 & 50.00 & 4.5 & 230 & 1213 \\
G308.92+0.12 & 4.0 & 54.90 & 4.2 & 1105 & 1635 \\
G309.92+0.48 & 4.0 & 69.70 & 4.3 & 2322 & 2618 \\
G316.37-0.37 & 12.0 & 30.00 & 3.9 & 2518 & 5072 \\
G316.77-0.02 & 3.1 & 96.55 & 3.9 & 1186 & 5279 \\
G316.81-0.06 & 3.0 & 85.45 & 4.0 & 1060 & 2655 \\
G318.05+0.09 & 3.7 & 74.55 & 4.0 & 1354 & 2392 \\
G323.74-0.25 & 3.5 & 85.80 & 3.9 & 1338 & 3105 \\
G324.20+0.12 & 6.9 & 53.90 & 4.4 & 8595 & 6877 \\
G328.30+0.43 & 8.5 & 70.70 & 4.0 & 12971 & 8281 \\
G329.04-0.21 & 3.1 & 59.45 & 4.5 & 1139 & 18646 \\
G331.00-0.19 & 5.7 & 62.65 & 4.8 & 18336 & 12366 \\
G330.88-0.36 & 4.2 & 71.50 & 4.8 & 11336 & 5966 \\
G331.28-0.18 & 5.5 & 73.10 & 4.6 & 14968 & 6759 \\
G332.65-0.63 & 3.6 & 72.90 & 4.4 & 3002 & 5120 \\
G332.83-0.55 & 4.0 & 61.35 & 5.0 & 9431 & 7195 \\
G333.13-0.43 & 3.7 & 58.00 & 5.3 & 12264 & 5672 \\
G333.60-0.22 & 3.6 & 79.80 & 4.4 & 3344 & 7025 \\
G337.40-0.40 & 3.4 & 69.35 & 4.9 & 6518 & 3943 \\
G337.91-0.47 & 3.3 & 66.40 & 4.9 & 5628 & 1642 \\
G345.01+1.80 & 2.1 & 78.10 & 4.9 & 2020 & 2945 \\
G343.12-0.06 & 3.2 & 40.00 & 5.0 & 1137 & 4824 \\
G345.51+0.35 & 2.5 & 57.85 & 4.8 & 1142 & 2441 \\
G345.00-0.23 & 3.2 & 54.50 & 4.7 & 1482 & 21706 \\
G345.41-0.94 & 2.8 & 61.05 & 4.9 & 2730 & 1251 \\
G351.16+0.70 & 2.1 & 72.10 & 5.1 & 2384 & 2227 \\
G348.73-1.04 & 2.4 & 66.95 & 5.2 & 4000 & 2602 \\
G351.41+0.64 & 1.7 & 92.80 & 5.2 & 3957 & 2310 \\
\hline & & & & &
\end{tabular}

limits were usually found to be small compared to the differences between results derived from different pairs of transitions the error estimates are given in Table 7 only when they exceed 0.1 units.

\section{Discussion}

Most CS cores appear almost spherical in our maps and most do not show strong velocity gradients. In G $351.41+0.64$ one can clearly see the velocity difference between NGC 6334I (the centre of the map) and NGC 6334I-N (Schwartz et al. 1989) in the northern part of the map. Among the other sources a change in radial velocity can be seen only in four cases: G $309.92+0.48$, G 316.77-0.02, G 316.81-0.06 and G 328.30+0.43. The lack of velocity gradients can be partly due to the limited sizes of our maps. The map G $351.41+0.64$ is the largest of them and in most other cases only the densest core is mapped.

The position of maximum emission is always the same for all observed lines, within $15^{\prime \prime}$. In some cases (e.g. 


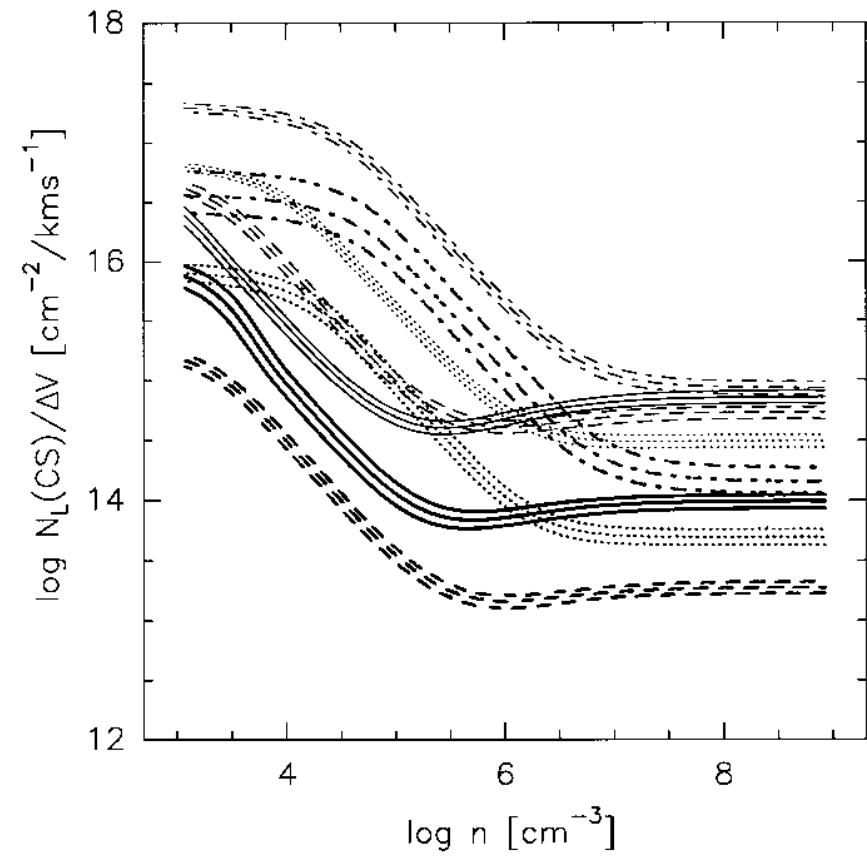

Fig. 5. An example (G 332.83-0.55) of the results from the LVG analysis. The different lines give the one $\sigma$ error bands (statistical errors plus $10 \%$ for calibration errors) for the radiation temperature measurements. In the figure the contours are drawn for $\mathrm{CS}(2-1)$ (thick continuous line), $\mathrm{CS}(3-2)$ (thick dashed line), CS(5-4) (thick dotted line), CS(7-6) (thick dash dotted line), $\mathrm{C}^{34} \mathrm{~S}(2-1)$ (thin line), $\mathrm{C}^{34} \mathrm{~S}(3-2)$ (thin dashed line), $\mathrm{C}^{34} \mathrm{~S}(5-4)$ (thin dotted line) and $\mathrm{C}^{34} \mathrm{~S}(7-6)$ (thin dotted line). An abundance ratio of 22.5 is assumed for the two isotopes

G 330.88-0.36) one can see a small displacement between the different transitions and isotopes but this is never more than only marginal.

The differences between the profiles of different lines are more clear. The lower CS transitions show in most cases some effects of the optical depth saturation ranging from slightly flattened line profiles (e.g. G 308.00-0.25) to strongly self absorbed lines as in G 329.04-0.21 or in G 345.00-0.23 where even the CS(5-4) line is clearly self-absorbed. The absorption features can exist either on the redshifted (e.g. G 337.91-0.47) or on the blueshifted side of the line (e.g. G 345.00-0.23). Many sources show also wide blue and red wings (e.g. G 309.92+0.48, G 324.20+0.12).

In Fig. 6 we present the distribution of the observed radial velocity differences between the water masers and the CS line emission. The data contain the velocities of those $\mathrm{H}_{2} \mathrm{O}$ masers that have been marked in our CS maps, and the center velocities of $\mathrm{C}^{34} \mathrm{~S}(2-1)$ from Gauss fits. The distribution seems to be asymmetric with respect to zero in the sense that the maser radial velocities are mainly smaller than the velocity of the CS cloud. The difference could be due to beaming effects as suggested by Zinchenko
Table 7. Results from the LVG analysis. Total gas density and the column density of the main isotope have been calculated from $\mathrm{CS}$ and $\mathrm{C}^{34} \mathrm{~S}$ observations separately. Numbers in parenthesis indicate the uncertainty of the last digit when it exceeds 1

\begin{tabular}{|c|c|c|c|c|c|}
\hline \multirow[b]{2}{*}{ Source } & \multirow[b]{2}{*}{$\begin{array}{l}T_{\text {kin }} \\
(\mathrm{K})\end{array}$} & \multicolumn{2}{|c|}{$\mathrm{CS}$} & \multicolumn{2}{|c|}{$\mathrm{C}^{34} \mathrm{~S}$} \\
\hline & & $\begin{array}{l}\log n \\
\left(\mathrm{~cm}^{-3}\right)\end{array}$ & $\begin{array}{l}\log N_{\mathrm{L}} \\
\left(\mathrm{cm}^{-2}\right)\end{array}$ & $\begin{array}{l}\log n \\
\left(\mathrm{~cm}^{-3}\right)\end{array}$ & $\begin{array}{l}\log N_{\mathrm{L}} \\
\left(\mathrm{cm}^{-2}\right)\end{array}$ \\
\hline $308.00-0.25$ & 30 & 5.8 & 13.5 & $5.5(3)$ & $14.1(2)$ \\
\hline $308.92+0.12$ & 40 & 5.8 & 13.7 & 5.7 & 14.3 \\
\hline $309.92+0.48$ & 20 & 6.0 & 13.5 & 6.3 & 14.3 \\
\hline $311.94+0.18$ & - & - & - & - & - \\
\hline $316.37-0.37$ & $10 ?$ & $>6.0$ & 12.8 & - & - \\
\hline 316.64-0.08 & $15 ?$ & $6.5(3)$ & 12.7 & - & - \\
\hline $316.77-0.02$ & 30 & 5.4 & 13.3 & $6.3(4)$ & $13.9(2)$ \\
\hline $316.81-0.06$ & 35 & 5.7 & 13.4 & 5.7 & 14.1 \\
\hline $318.05+0.09$ & 35 & 5.8 & 13.7 & 5.8 & 14.2 \\
\hline $323.74-0.25$ & 20 & 6.0 & 13.2 & - & - \\
\hline $324.20+0.12$ & - & - & - & - & - \\
\hline $328.30+0.43$ & 40 & 5.8 & 13.6 & 5.6 & 14.0 \\
\hline $329.04-0.21$ & 15 & 6.9 & 13.1 & 6.3 & 14.1 \\
\hline $331.00-0.19$ & 30 & 5.9 & 13.8 & 5.7 & 14.6 \\
\hline $330.88-0.36$ & 45 & 5.7 & 13.8 & 5.4 & 14.7 \\
\hline $331.28-0.18$ & 20 & 6.1 & 13.3 & 6.0 & 14.3 \\
\hline $332.65-0.63$ & 35 & 6.0 & 13.4 & 5.8 & 14.3 \\
\hline $332.83-0.55$ & 30 & 6.3 & 13.8 & 6.1 & 14.7 \\
\hline $333.13-0.43$ & 50 & 5.5 & 14.2 & 5.3 & 14.8 \\
\hline $333.60-0.22$ & 50 & 5.5 & 13.7 & 5.5 & 14.2 \\
\hline $337.40-0.40$ & 20 & 6.0 & 14.1 & 6.1 & 14.7 \\
\hline $337.91-0.47$ & $10 ?$ & - & - & - & - \\
\hline $345.01+1.80$ & 45 & 5.7 & 14.0 & 5.7 & 14.6 \\
\hline $343.12-0.06$ & 25 & 6.5 & 13.4 & 6.0 & 14.4 \\
\hline $345.51+0.35$ & 35 & 6.1 & 13.7 & 5.8 & 14.4 \\
\hline $345.00-0.23$ & $10 ?$ & - & - & - & - \\
\hline $345.41-0.94$ & 55 & 5.7 & 14.1 & 5.7 & 14.7 \\
\hline $348.55-0.97$ & - & - & - & - & - \\
\hline $351.16+0.70$ & 45 & 5.6 & 14.0 & 5.4 & 14.7 \\
\hline $348.73-1.04$ & 60 & 5.7 & 14.1 & 5.7 & 14.8 \\
\hline $351.41+0.64$ & 55 & 5.7 & 14.2 & 5.7 & 14.8 \\
\hline $0.21-0.01$ & - & - & - & - & - \\
\hline $359.97-0.46$ & - & - & - & - & - \\
\hline
\end{tabular}

et al. (1995) or due to obscuration of the maser sources behind the cloud core. However, the difference between the velocities of $\mathrm{CS}$ emission and $\mathrm{H}_{2} \mathrm{O}$ masers is statistically not very significant in this sample. The probability that the mean of $V_{\mathrm{H}_{2} \mathrm{O}}-V_{\mathrm{CS}}$ is less than zero is only $59 \%$. Moreover, the $\mathrm{H}_{2} \mathrm{O}$ emission usually contains many maxima with widely varying velocities. Since we have only considered the velocity of the strongest component the result does not necessarily reflect the distribution of all maser sources associated with the molecular core.

The LVG calculation gives clearly different results depending on the transitions used. Of course, one cannot 


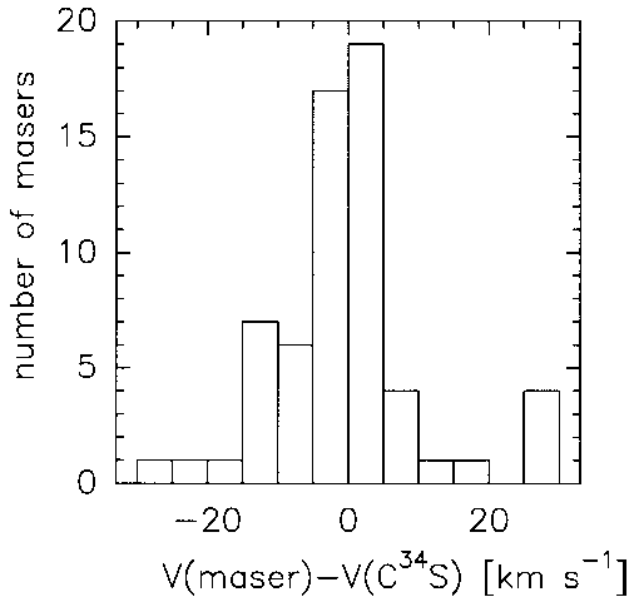

Fig. 6. The distribution of the velocity differences between $\mathrm{H}_{2} \mathrm{O}$ masers and the CS emission as determined from the $\mathrm{C}^{34} \mathrm{~S}(2-1)$ lines

expect similar results since different transitions probe different volumes of the emitting gas. The isotope $\mathrm{C}^{34} \mathrm{~S}$ gives, however, systematically higher values for the total column density than CS. Since the terrestrial value of $R=22.5$ was used as the abundance ratio between the isotopes, the results of the LVG analysis seem to indicate a smaller ratio, in fact less than 5.0. This can be only partly attributed to underestimated kinetic temperatures and uncertainties in the determination of the source coupling coefficients. There is already some evidence for a lower value e.g. Mundy et al. (1986) obtained values $R=9-17$.

\section{Summary and conclusions}

1. We have observed 33 southern molecular cores associated with $\mathrm{H}_{2} \mathrm{O}$ masers in several $\mathrm{CS}$ and $\mathrm{C}^{34} \mathrm{~S}$ lines. The clouds have been mapped mainly in $\mathrm{CS}(2-1)$, $\mathrm{CS}(5-4)$ and $\mathrm{C}^{34} \mathrm{~S}(2-1)$. All central positions of the clouds have been observed in both isotopes in transitions $J=3-2$ and $J=5-4$ as well as in $\mathrm{C}^{34} \mathrm{~S}(2-1)$. Some selected clouds were also mapped in $\mathrm{CS}(3-2)$. $\mathrm{CS}(7-6)$ was observed in 14 and $\mathrm{C}^{34} \mathrm{~S}(7-6)$ in seven clouds.

2. The maps of emission from different transitions and from different isotopes show a closely similar distribution. The positional differences in the peak emission do not exceed $15^{\prime \prime}$.

3. We have calculated the optical depths of the $\mathrm{C}^{34} \mathrm{~S}$ lines and the column densities in the LTE approximation. All observations have also been analysed through LVG modeling. The total column densities calculated with LVG models using the $\mathrm{C}^{34} \mathrm{~S}$ isotope exceed the values calculated from the main isotope when an isotope ratio $R=22.5$ (terrestrial value) has been assumed. The results give support to a much lower value, $R<10$.
4. The masses calculated with the LTE approximation are mainly in agreement with the virial masses. The mean density of the gas along the line of sight is typically $10^{4}-10^{5} \mathrm{~cm}^{-3}$. The LVG models do not produce clearly increasing values for density with higher transitions.

This paper has presented the observations and the basic analysis of the CS observations. The data will also be analysed with the aid of three dimensional Monte Carlo simulation. The effects of the clumpy structure of the emitting gas will be of special interest during this analysis.

Acknowledgements. We thank A. Lapinov for providing the program used in the LVG model calculations.

\section{References}

Bachiller R., Cernicharo J., 1990, A\&A 239, 276

Batchelor R.A., Caswell J.L., Goss W.M., et al., 1980, Aust. J. Phys. 33, 139

Batchelor R.A., Robinson B.J., McCulloch M.G., 1984, Proc. Astron. Soc. Aust. 5, 363

Booth R.S., Delgado G., Hagström M., et al., 1989, A\&A 216, 315

Brand J., van der Bij M.D.P., de Vries C.P., et al., 1984, A\&A 139, 181

Braz M.A., Epchtein N., 1983, A\&AS 54, 167

Braz M.A., Scalise E. Jr., 1982, A\&A 107, 272

Braz M.A., Scalise E. Jr., Gregorio Hetem J.C., Monteiro do Vale J.L., Gaylard M., 1989, A\&AS 77, 465

Caswell J.L., Batchelor R.A., Forster J.R., Wellington K.J., 1983, Aust. J. Phys. 36, 401

Caswell J.L., Haynes R.F., 1987, A\&A 171, 261

Churchwell E., 1991, Newly Formed Massive Stars. In: Lada C.F., Kylafis N.D. (eds.), The Physics of Star Formation and Early Stellar Evolution. Kluwer Academic Publishers, Dordrecht

Dickel H.R., Dickel J.R., Wilson W.J., 1977, ApJ 217, 56

Fich M., Blitz L., Stark A.A., 1989, ApJ 342, 272

Forster J.R., Caswell J.L., 1989, A\&A 213, 339

Gardner F.F, Whiteoak J.B., 1978, MNRAS 183, 711

Gardner F.F., Whiteoak J.B., 1984, MNRAS 210, 23

de Graauw T., Lidholm S., Fitton B., et al., 1981, A\&A 102, 257

Genzel R., 1991, Physical Conditions and Heating/Cooling Processes in High Mass Star Formation Regions. In: Lada C.J., Kylafis N.D. (eds.), The Physics of Star Formation and Early Stellar Evolution. Kluwer Academic Publishers, Dordrecht

Güsten R., Downes D., 1983, A\&A 117, 343

Güsten R., Walmsley C.M., Pauls T., 1981, A\&A 103, 197

Habing H.J., Israel F.P., 1979, Compact HII regions and OB star formation, ARA\&A 17, 345

Hauschildt H., Güsten R., Phillips T.G., Schilke P., Serabyn E., Walker C.K., 1993, A\&A 273, L23

Henning Th., Pfau W., Altenhoff W.J., 1990, A\&A 227, 542

Kaufmann P., Zisk S., Scalise E. Jr., Schaal R.E., Gammon R.H., 1977, AJ 82, 577 
Kuiper T.B.H., Peters III W.L., Foster J.R., Gardner F.F., Whiteoak J.B., 1995, ApJ 446, 692

Lockman F., 1979, ApJ 232, 761

Moran J.M., Rodriguez L.F., 1980, ApJ 236, L159

Moorwood A.F.M., Salinari P., 1983, A\&A 125, 342

Mundy L.G., Snell R.L., Evans N.J II, Goldsmith P.F., Bally J., 1986, ApJ 306, 670

Natta A., Oliva E., 1985, A\&A 152, 300

Neckel T., 1978, A\&A 69, 51

Peng R.S., Whiteoak J.B., 1992, MNRAS 254, 301

Phillips T.G., Huggins P.J., Wannier P.G., Scoville N.Z., 1979, ApJ 231, 720

de Pree C.G., Rodríguez L.F., Dickel H.R., Goss W.M., 1995, ApJ 447, 220

Richards P.J., Little L.T., Toriseva M., Heaton B.D., 1987, MNRAS 228, 43

Scalise E. Jr., Braz M.A., 1980, A\&A 85, 149

Scalise E. Jr., Rodriguez L.F., Mendoza-Torres E., 1989, A\&A 221,105
Schwartz P.R., Snell R.L., Schloerb F.P., 1989, ApJ 336, 519

Simpson J.P., Rubin R.H., 1990, ApJ 354, 165

Storey J.W.V., Harnett J.I., Lugten J.B., et al., 1989, MNRAS 237, 1001

Testi L., Felli M., Persi P., Roth M., 1994, A\&A 288, 634

The SEST Handbook 1993. Operating Manual No. 19, European Southern Observatory

White G.J., Phillips J.P., 1983, MNRAS 202, 255

Whiteoak J.B., Gardner F.F., 1974, A\&A 37, 389

Whyborn N., Nyman L.-A., Wild W., Delgado G., 1992, ESO Messenger 68, 45

Wilson T.L., Mezger P.G., Gardner F.F, Milne D.K., 1970, A\&A 6, 364

Winnewisser G., Cook R.L., 1968, J. Mol. Spectrosc. 28, 266

Wood D.O.S, Churchwell E., 1989, ApJ 340, 265

Zavagno A., Cox P., Baluteau J.-P., 1992, A\&A 259, 241

Zinchenko I., Mattila K., Toriseva M., 1995, A\&AS 111, 95 


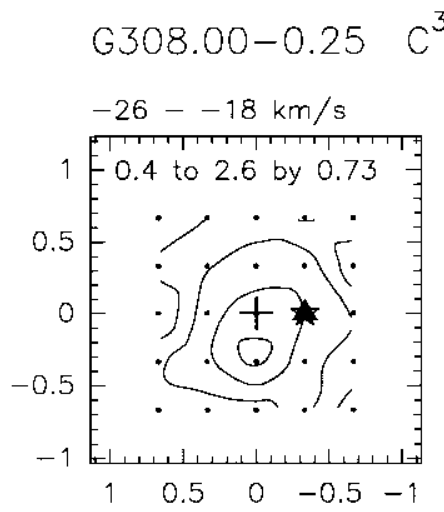

$$
C^{34} S(2-1)
$$
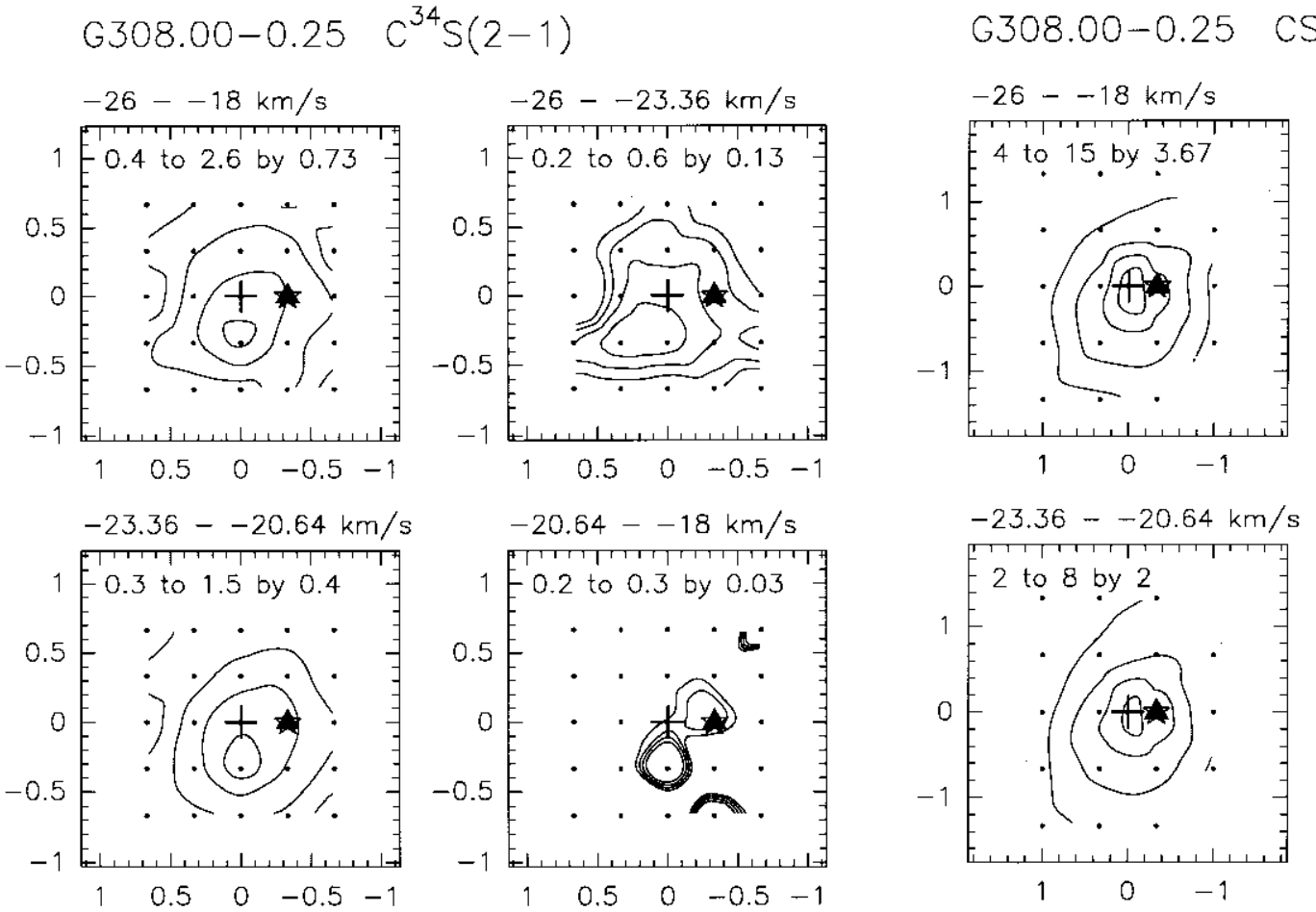

$\mathrm{CS}(2-1)$
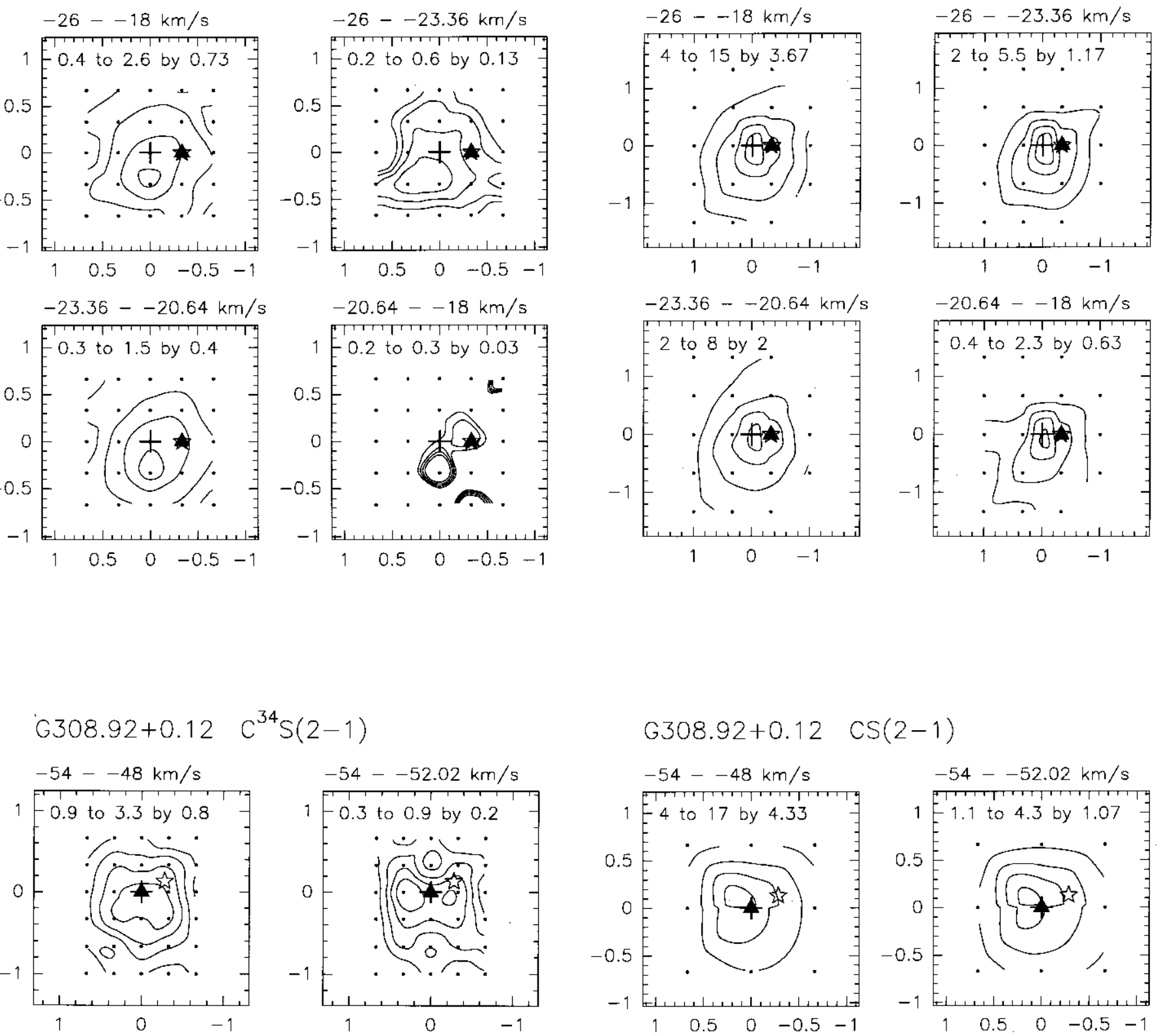

$$
C^{34} S(2-1)
$$
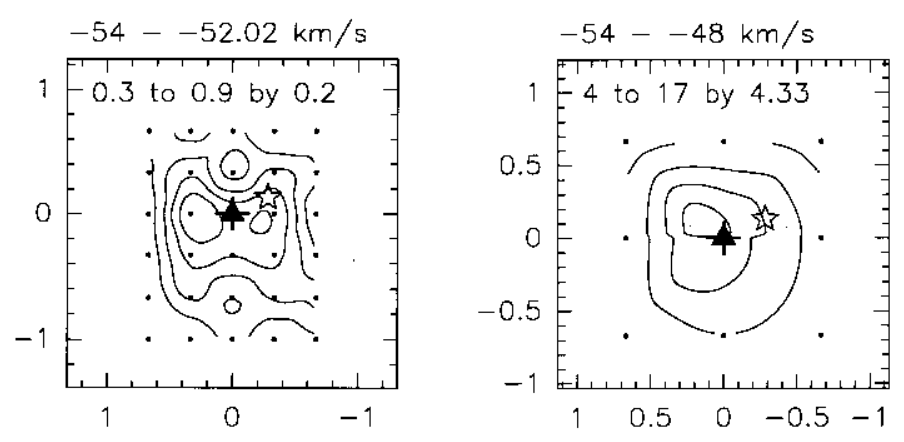

$$
\operatorname{cs}(2-1)
$$
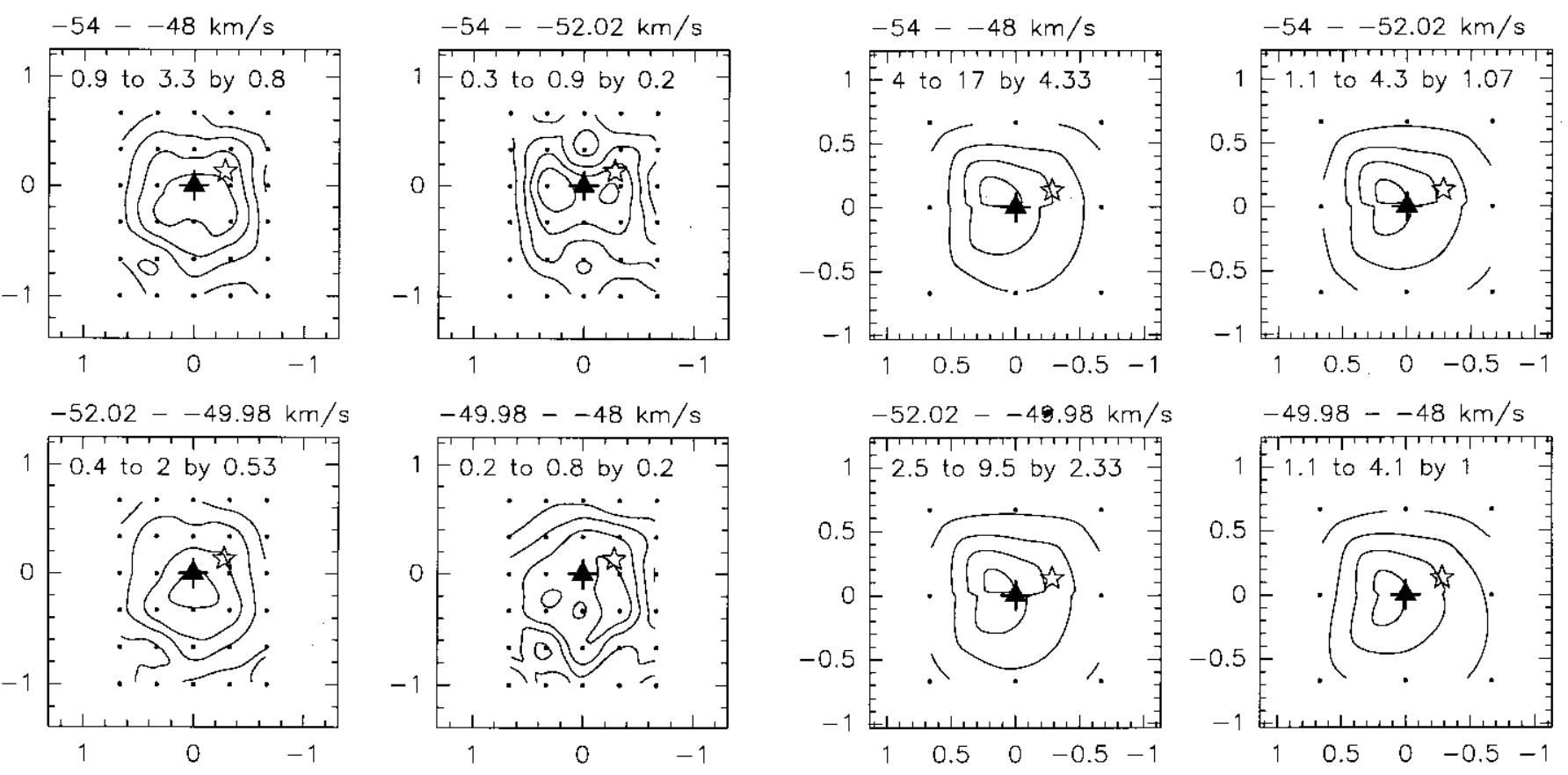

Fig. 1. The maps of integrated main beam temperature for transitions $\mathrm{CS}(2-1), \mathrm{CS}(3-2)$ and $\mathrm{C}^{34} \mathrm{~S}(2-1)$. The source name and the line are indicated above each group of four figures. The integrated velocity interval is given above each frame and the contour levels in units of $\mathrm{K} \mathrm{km} \mathrm{s}^{-1}$ are indicated inside the frames. $\mathrm{H}_{2} \mathrm{O}$-maser positions are marked with triangles and IRAS point sources with stars. A cross marks the position used for further one point measurements 


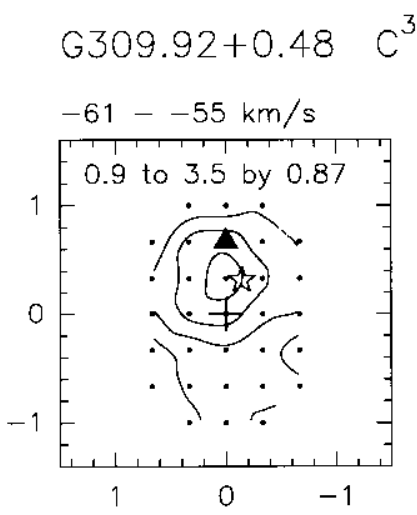

$C^{34} S(2-1)$

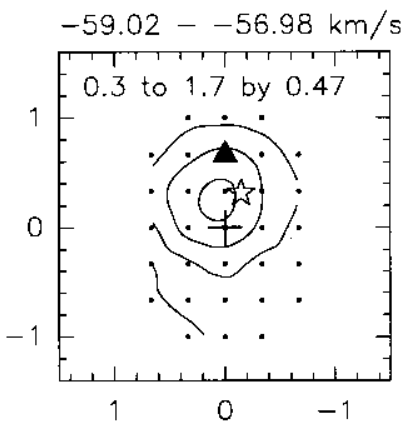

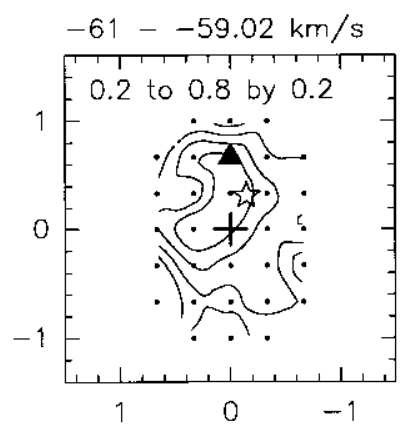

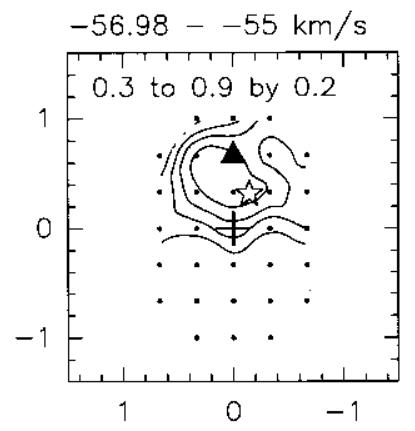

G309.92+0.48 CS(2-1)
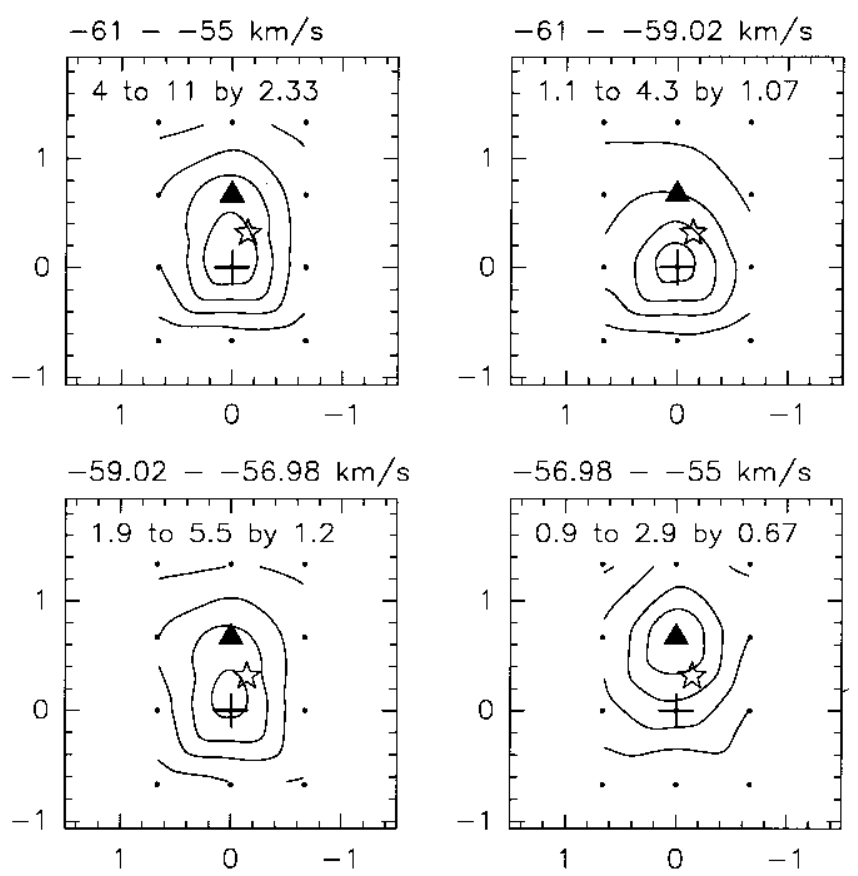

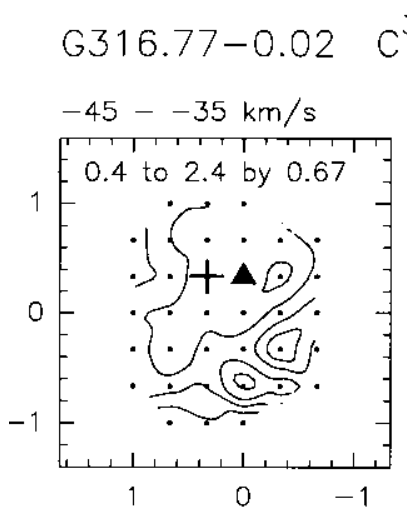

$C^{34} S(2-1)$
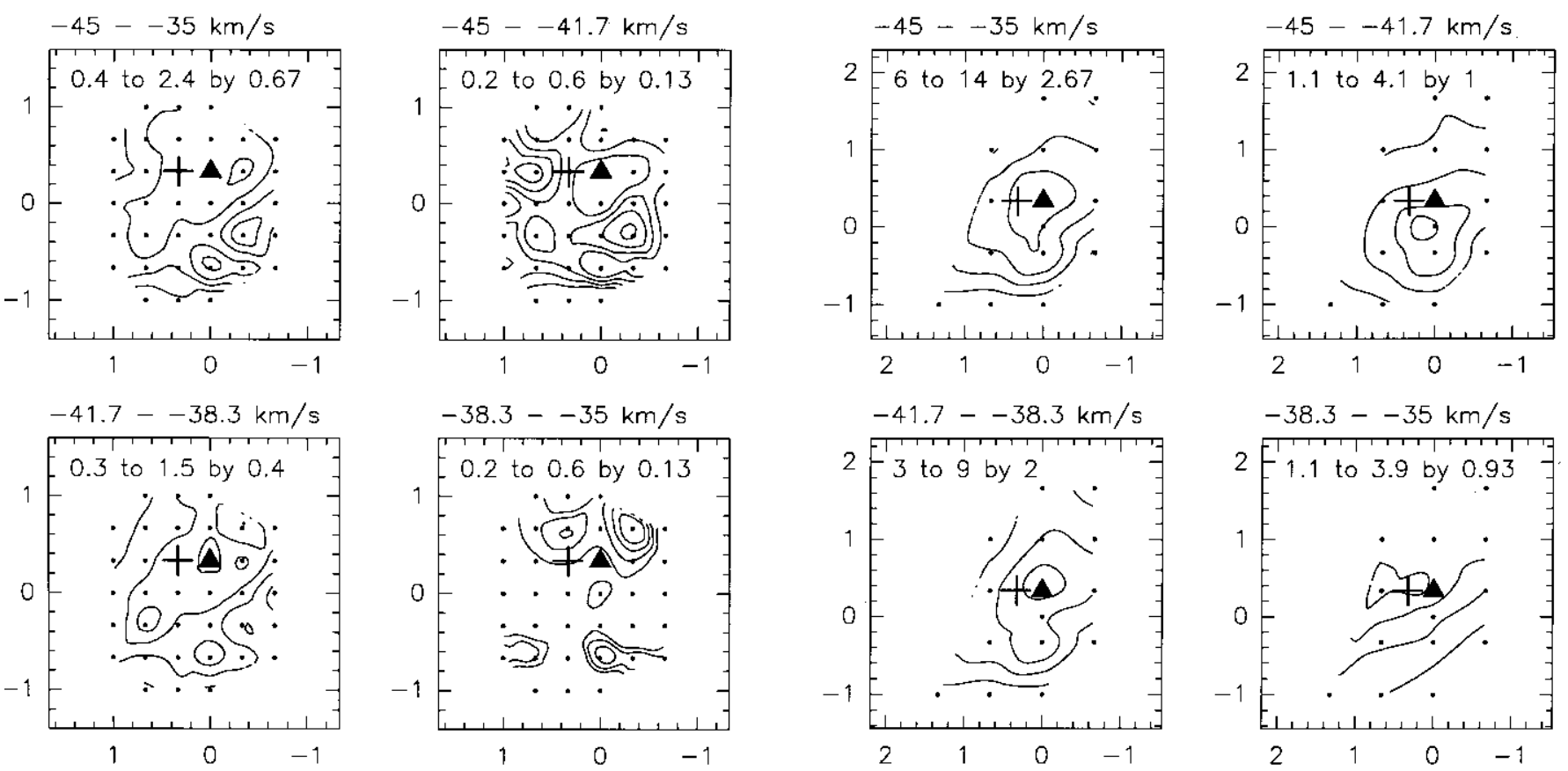

Fig. 1. continued 


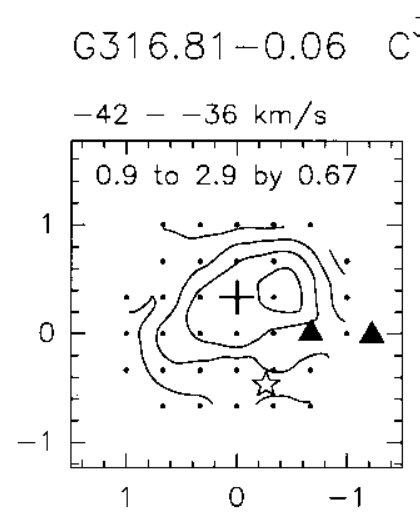

$$
C^{34} S(2-1)
$$
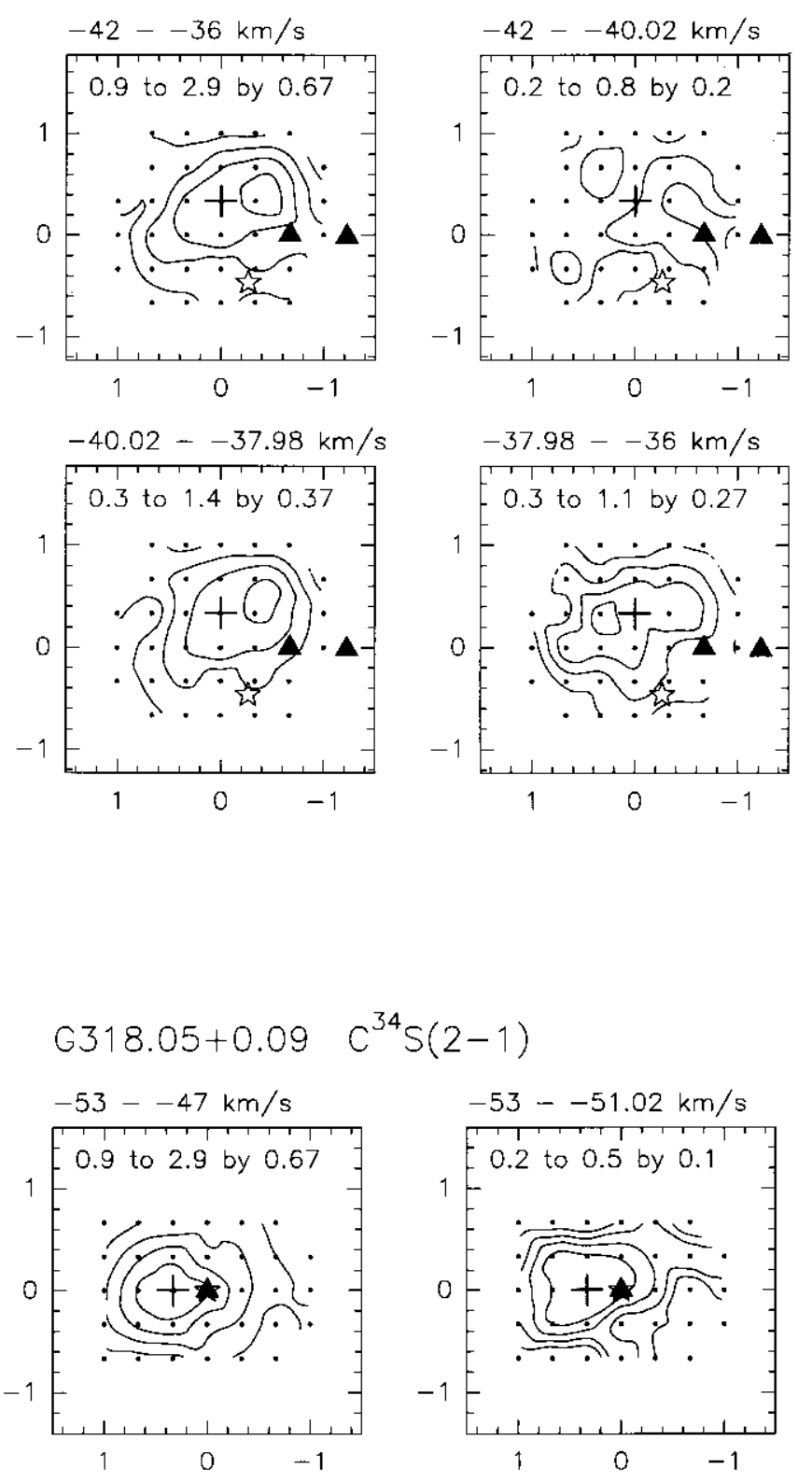

$C^{34} S(2-1)$
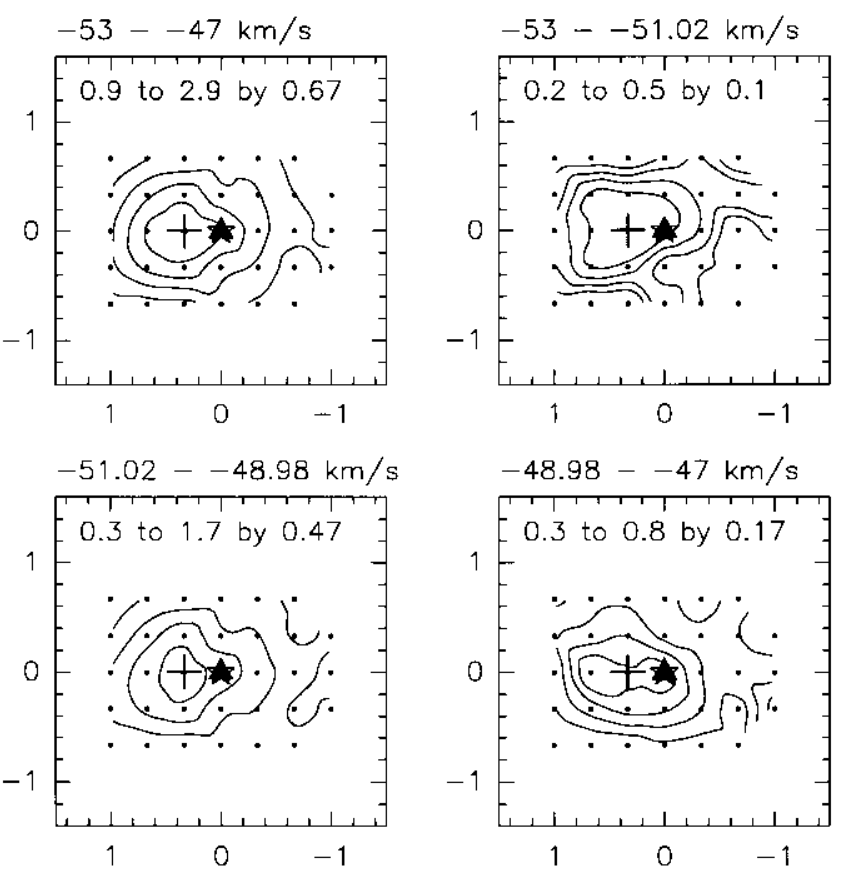
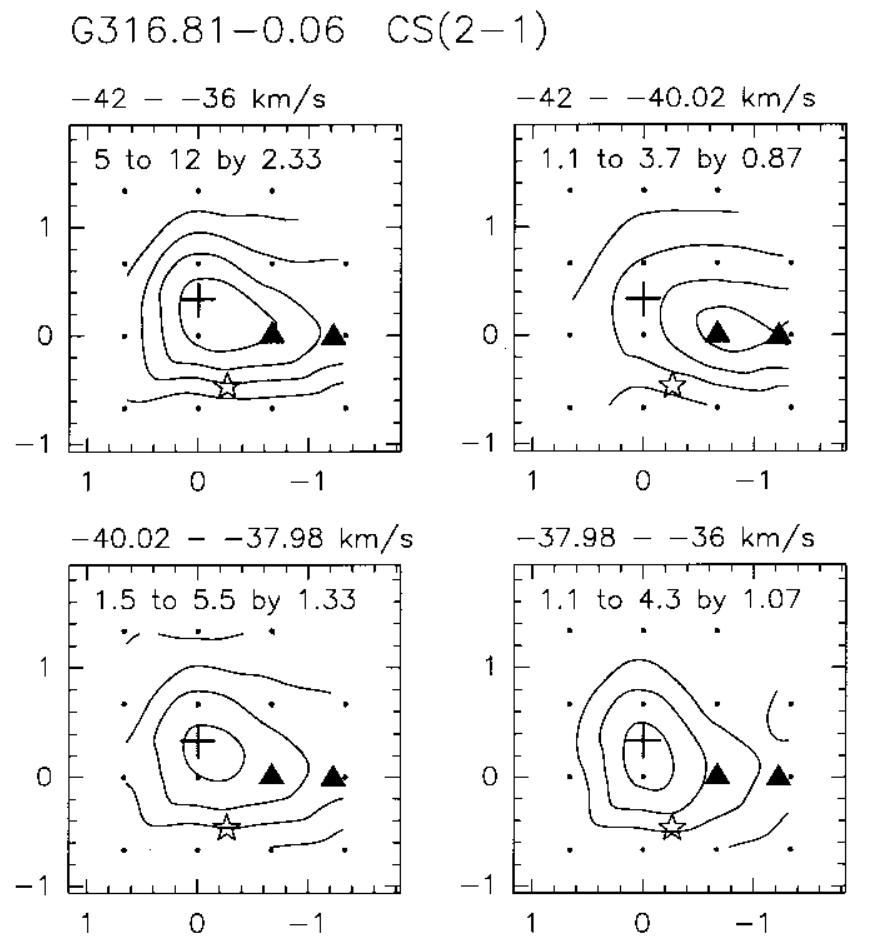

\section{G318.05+0.09 CS(2-1)}
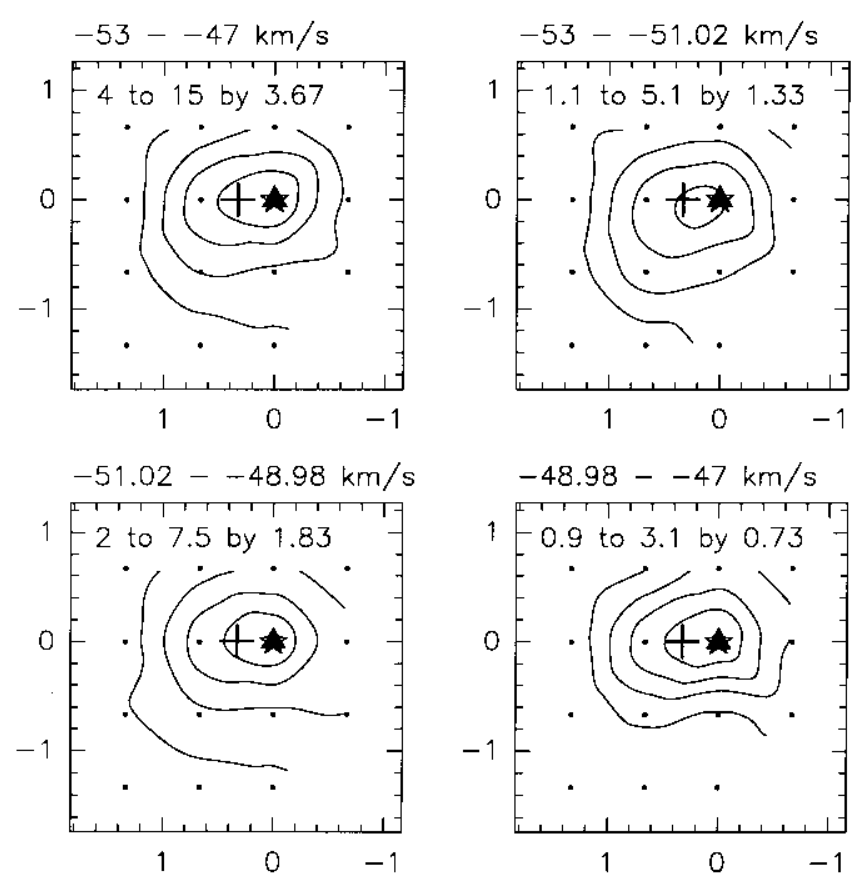

Fig. 1. continued 


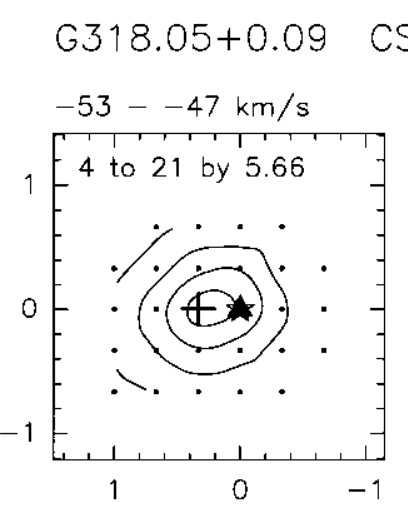

$\operatorname{CS}(3-2)$
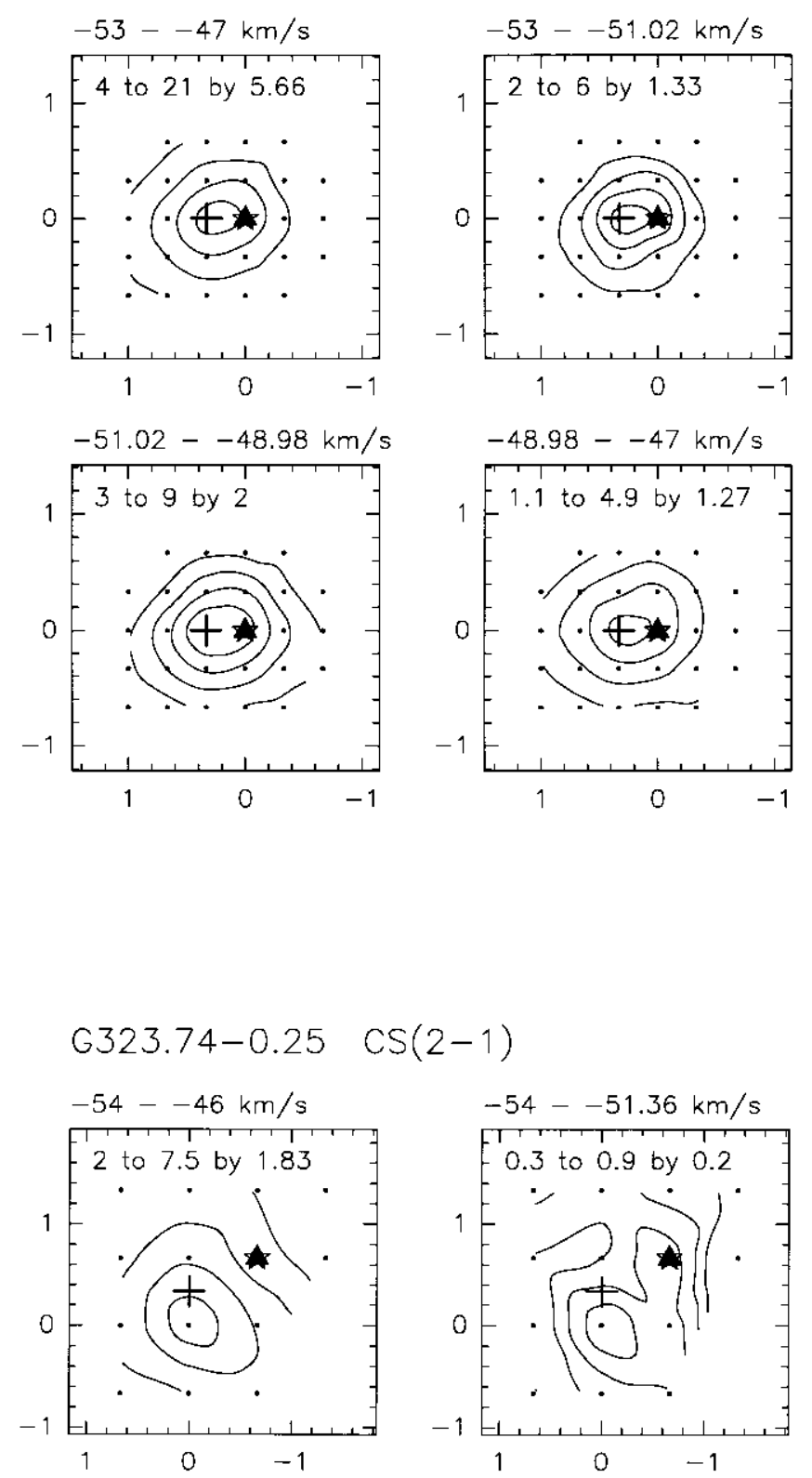

\section{$\operatorname{cs}(2-1)$}
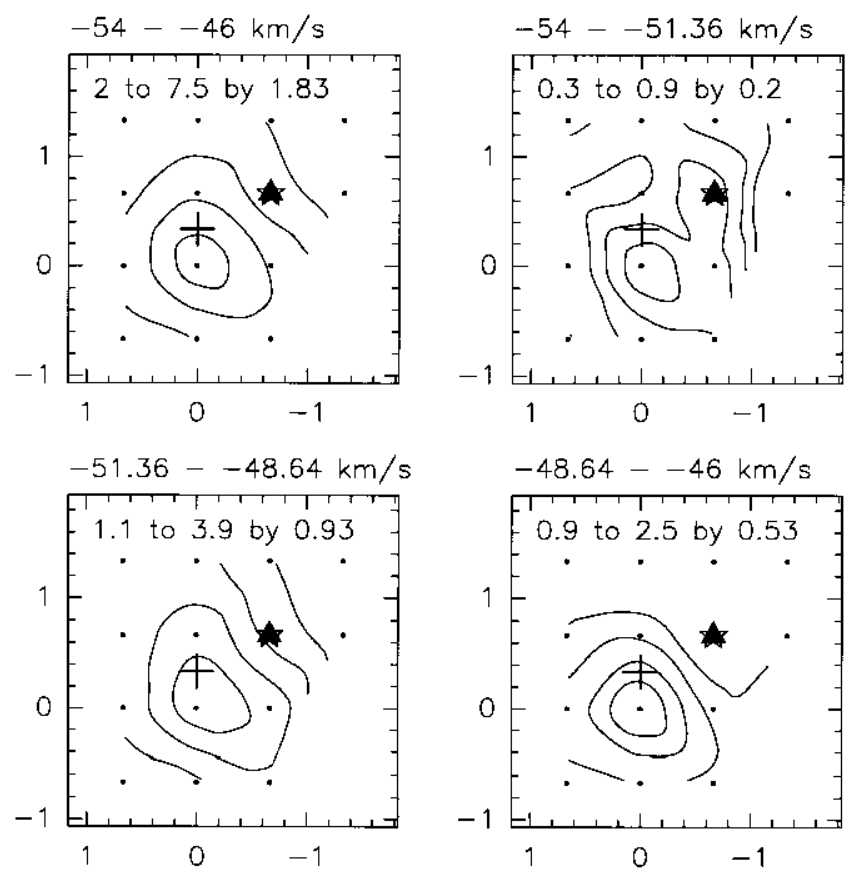

$$
\text { G323.74-0.25 } C^{34} S(2-1)
$$
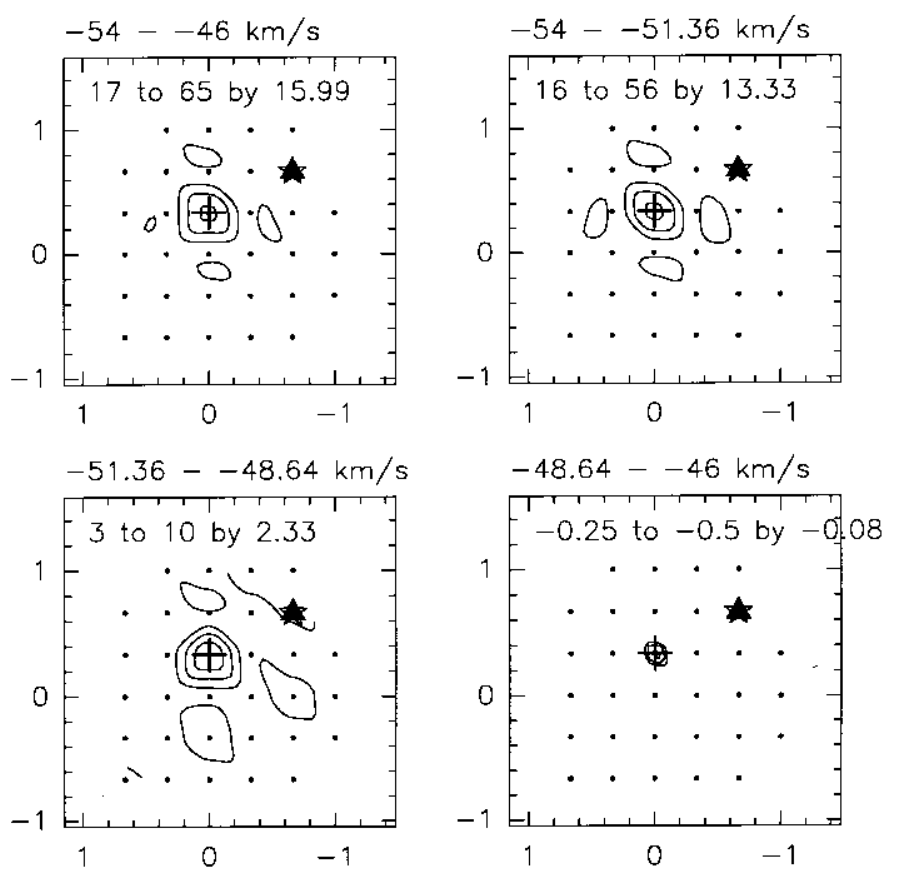

$G 324.20+0.12 \quad C^{34} S(2-1)$
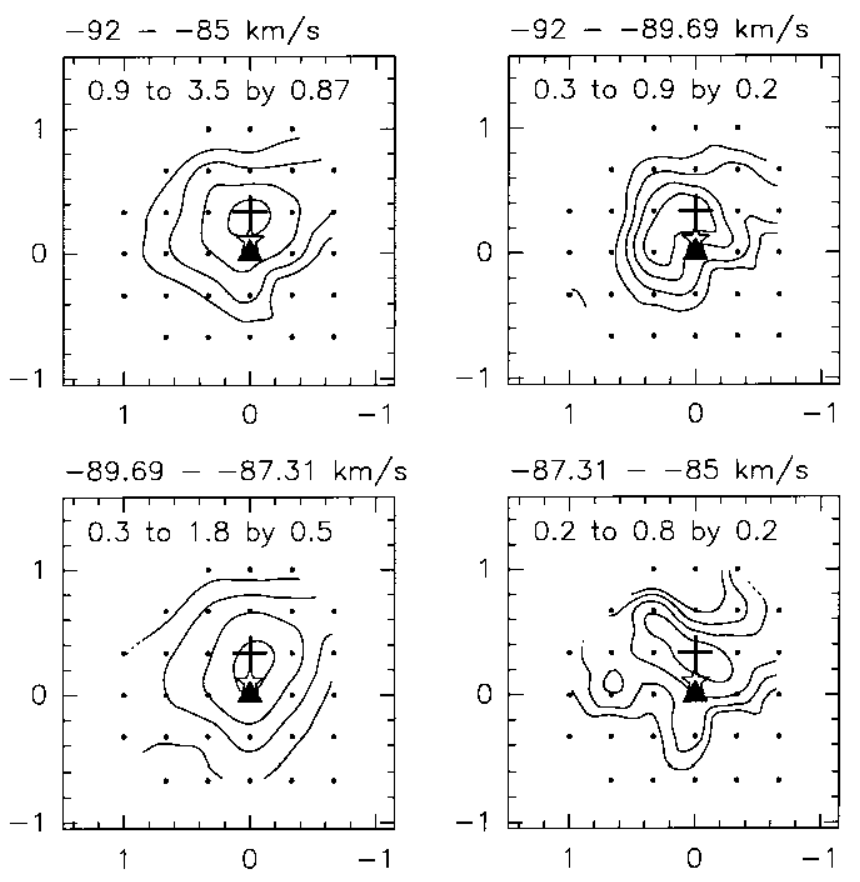

Fig. 1. continued 


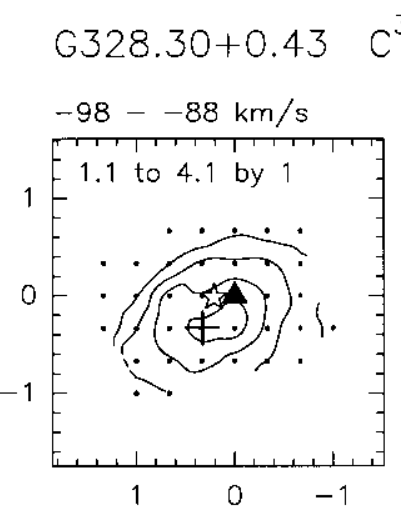

$C^{34} S(2-1)$
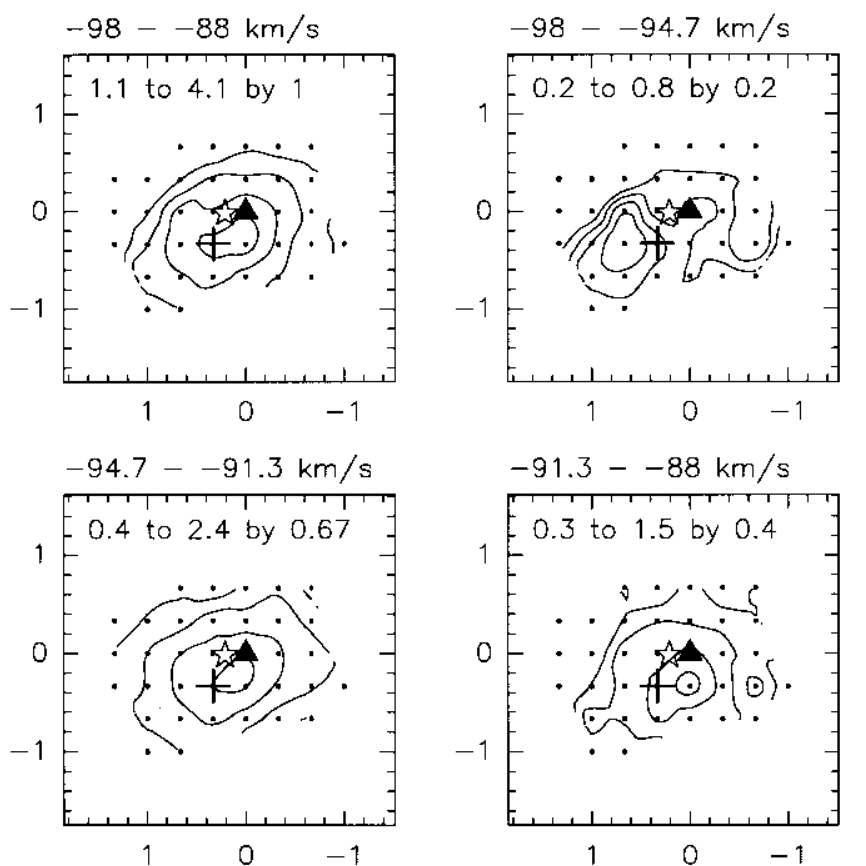

$6328.30+0.43 \operatorname{CS}(2-1)$
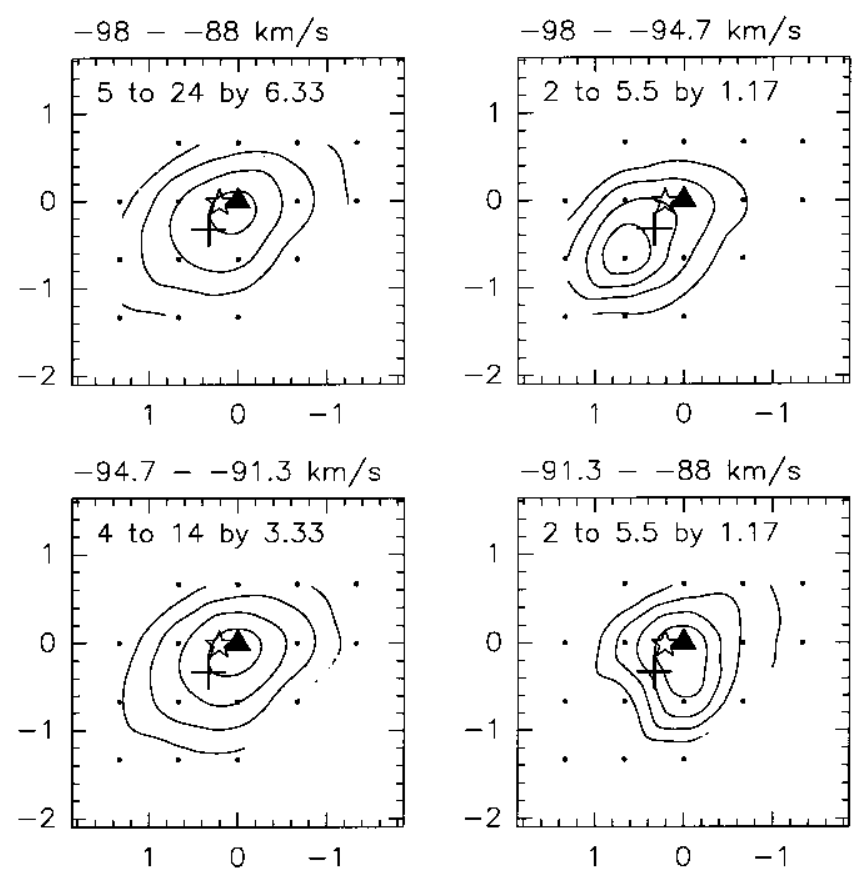

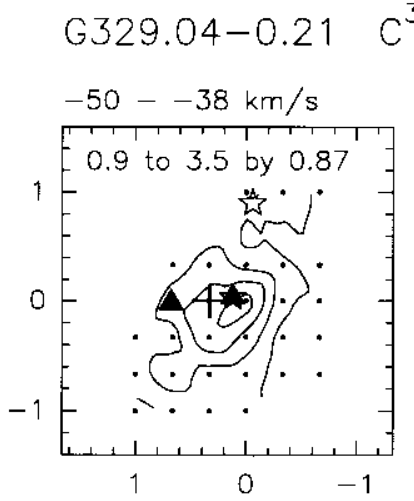

$S(2-1)$
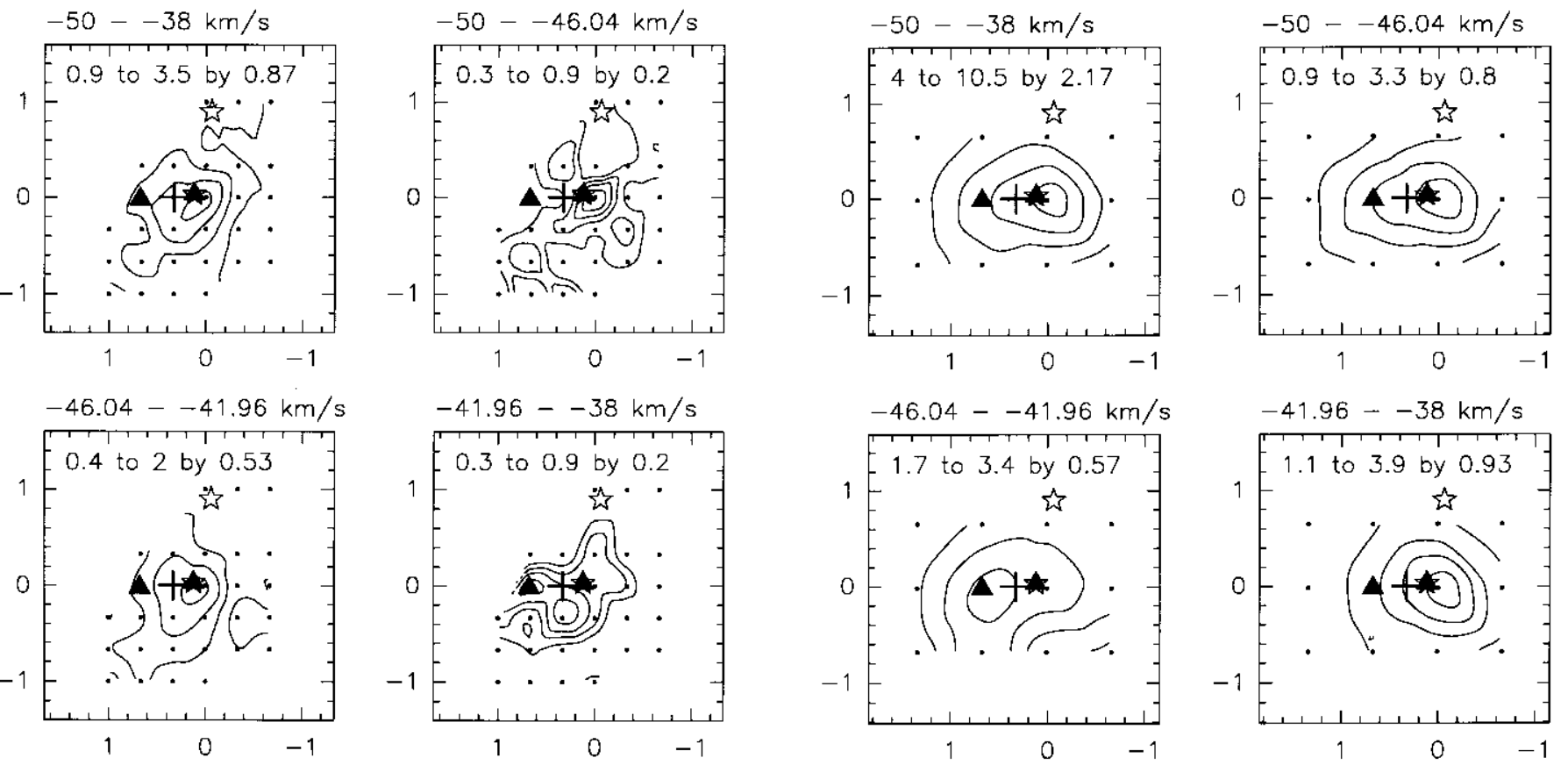

Fig. 1. continued 


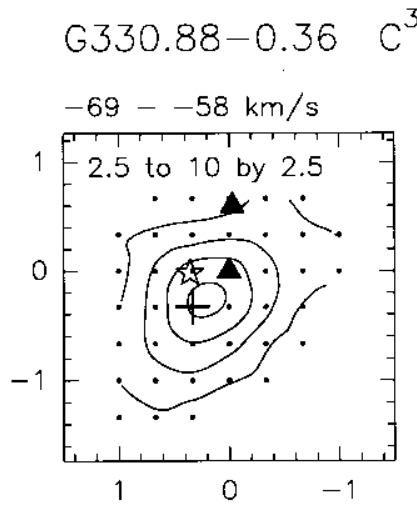

$$
C^{34} S(2-1)
$$
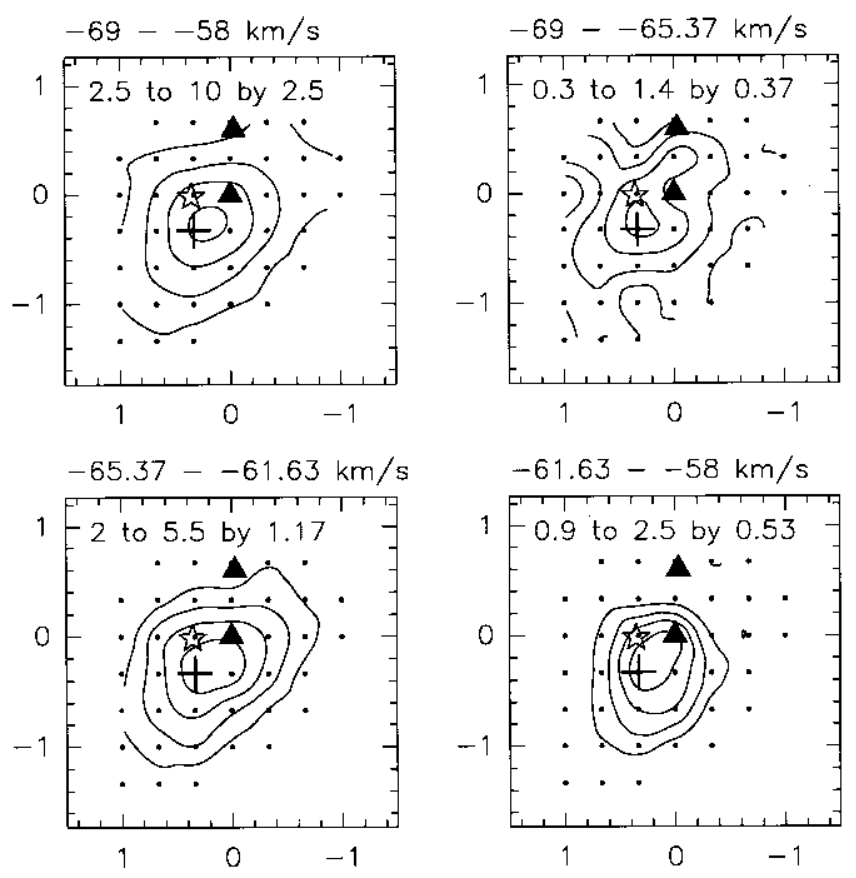

G331.00-0.19 C C $3(2-1)$
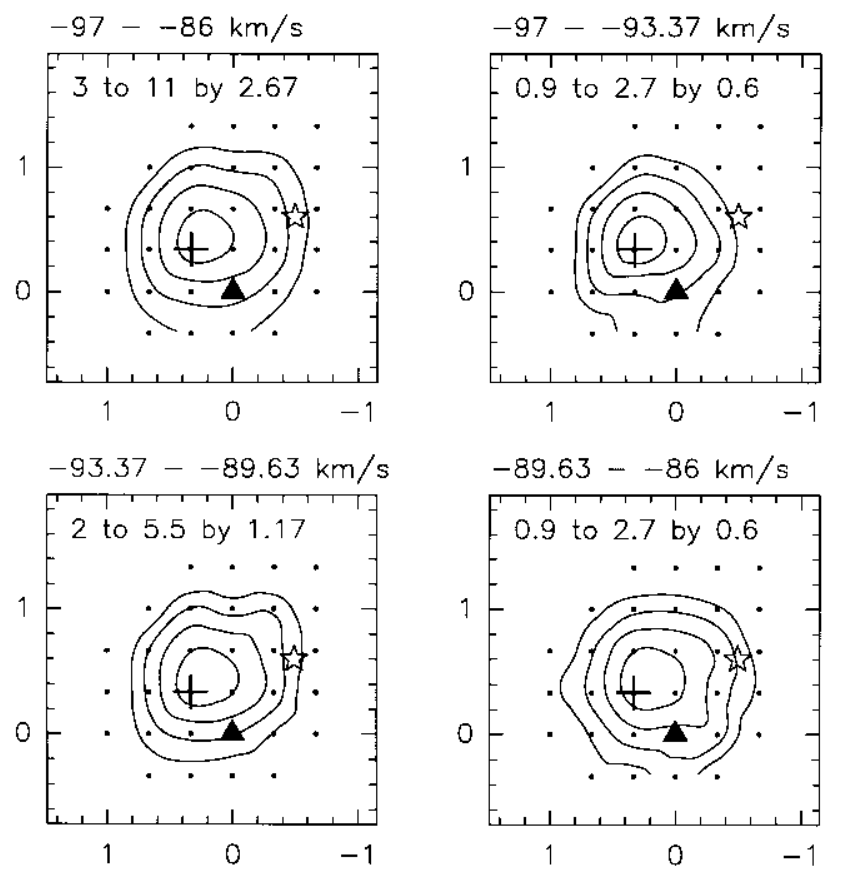

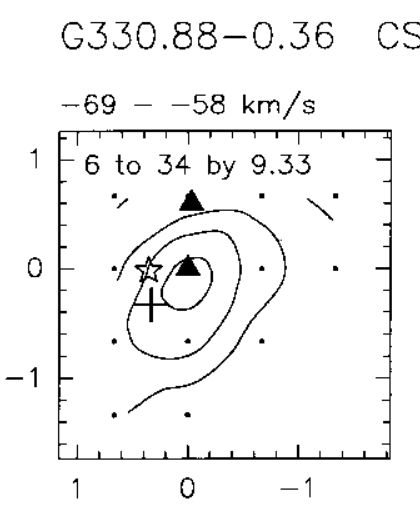

$$
S(2-1)
$$
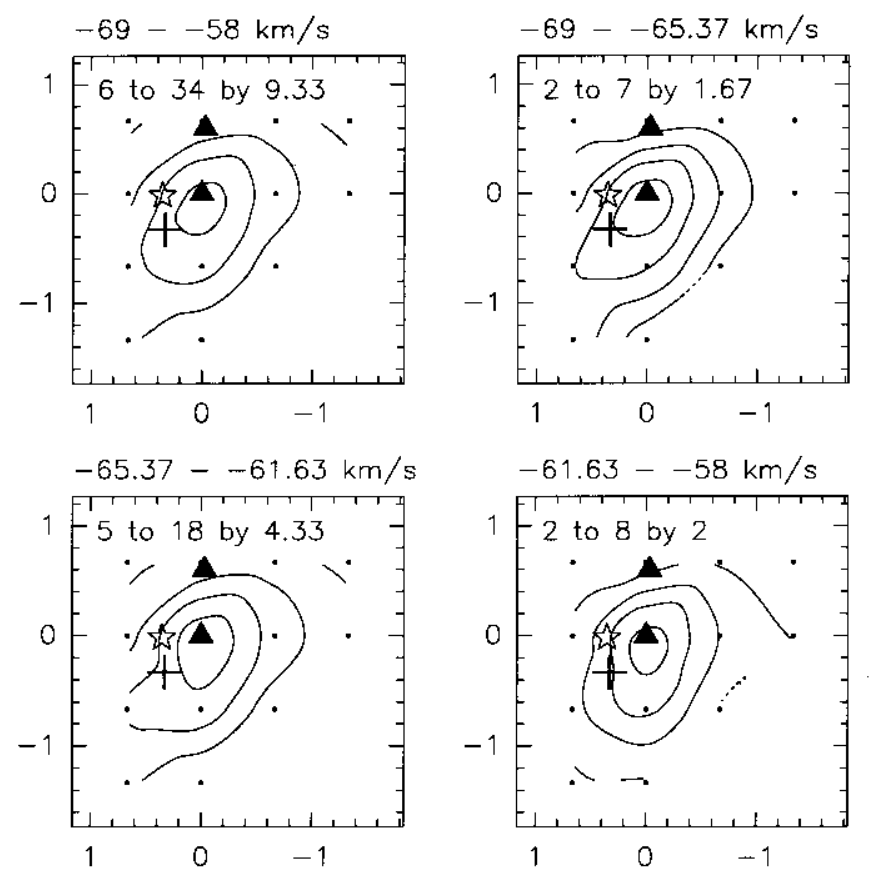

G331.00-0.19 CS(3-2)
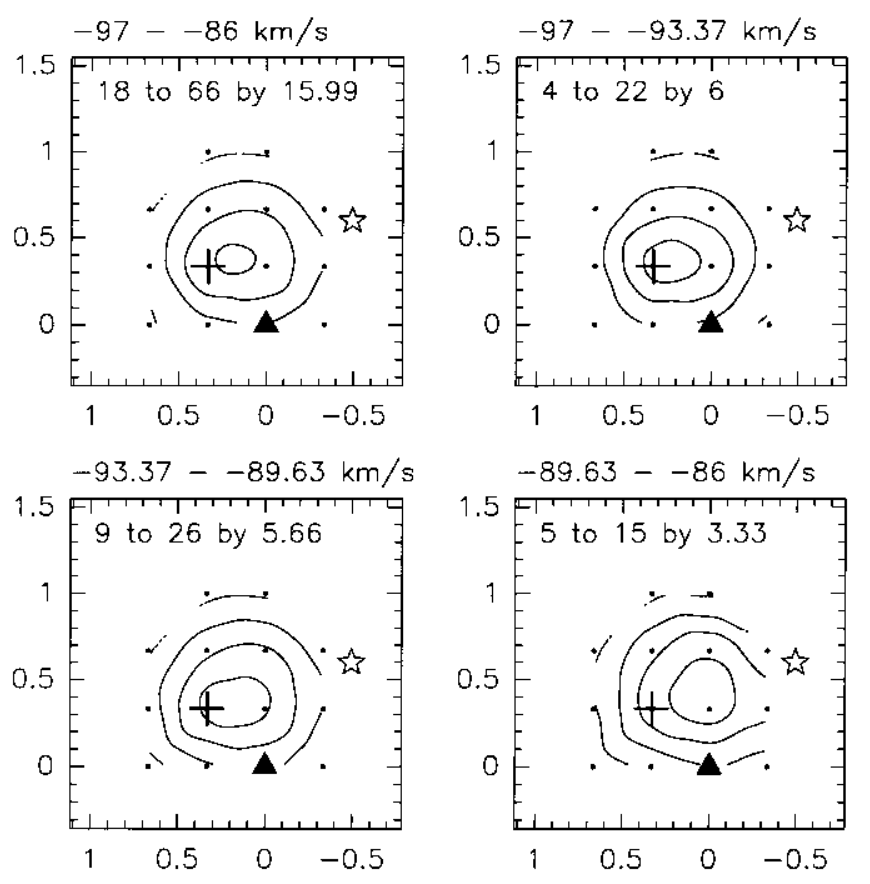

Fig. 1. continued 


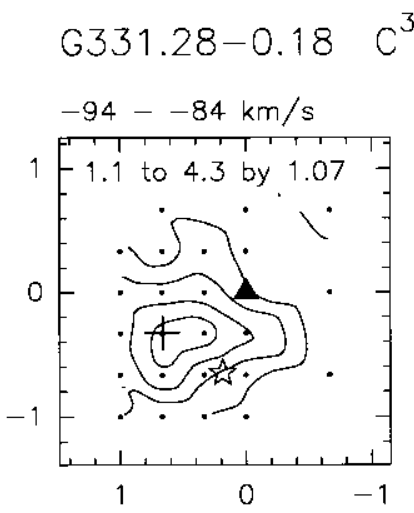

$$
C^{34} S(2-1)
$$
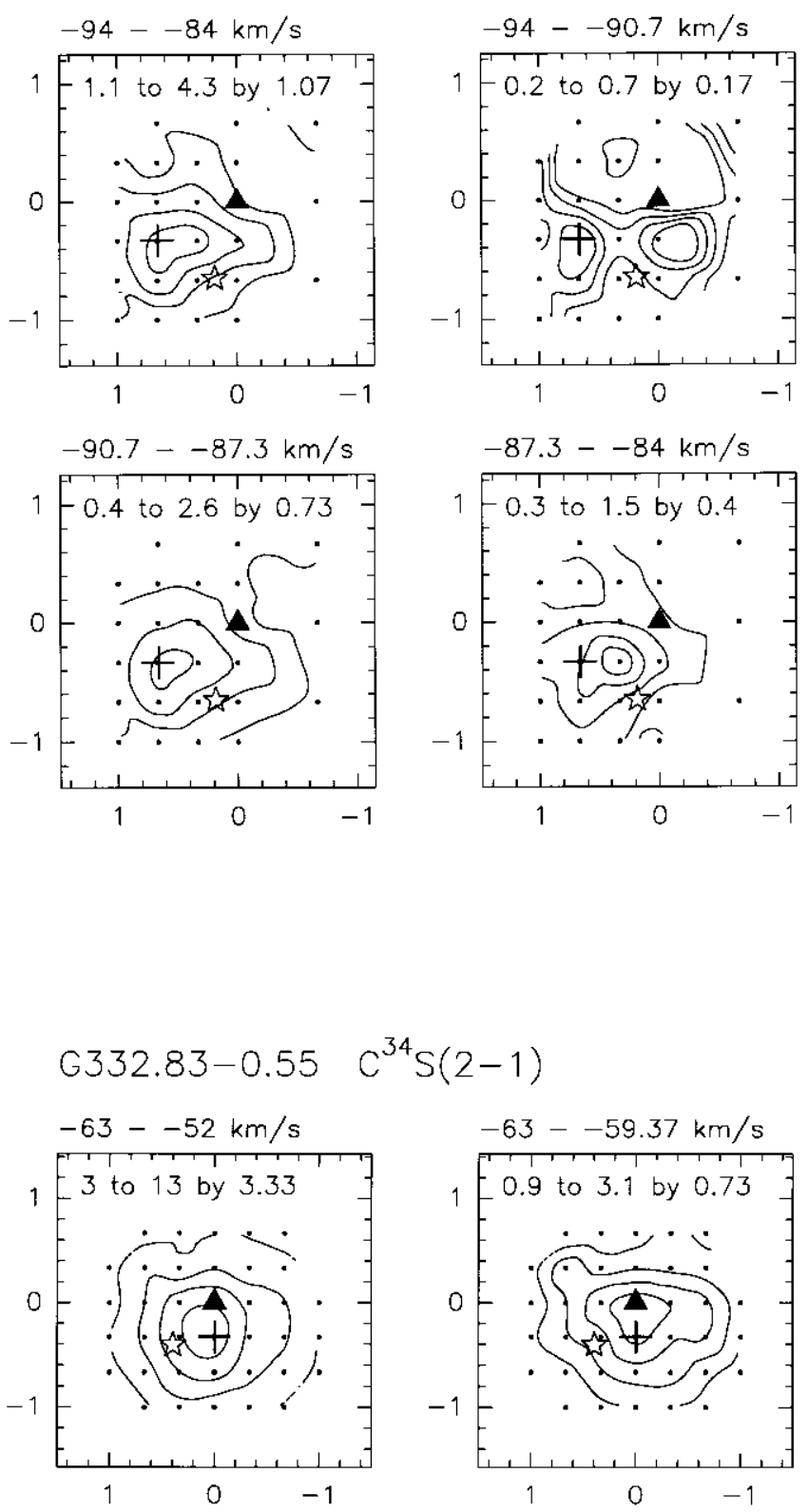

$C^{34} S(2-1)$
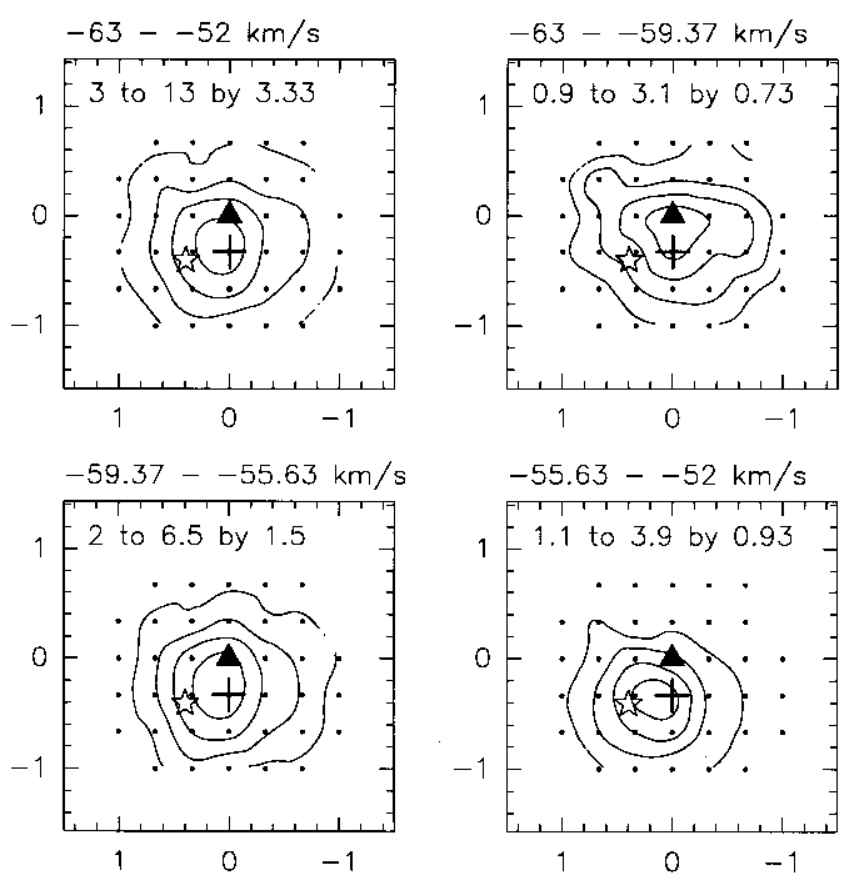

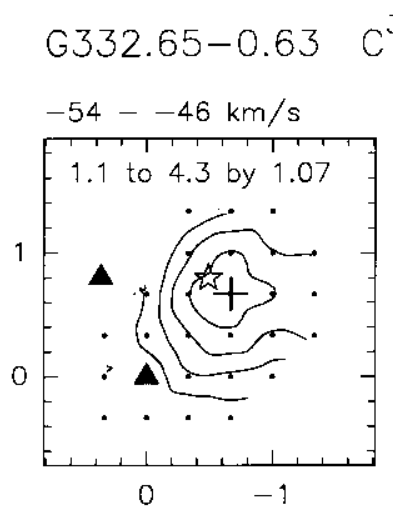

$$
{ }^{34} S(2-1)
$$
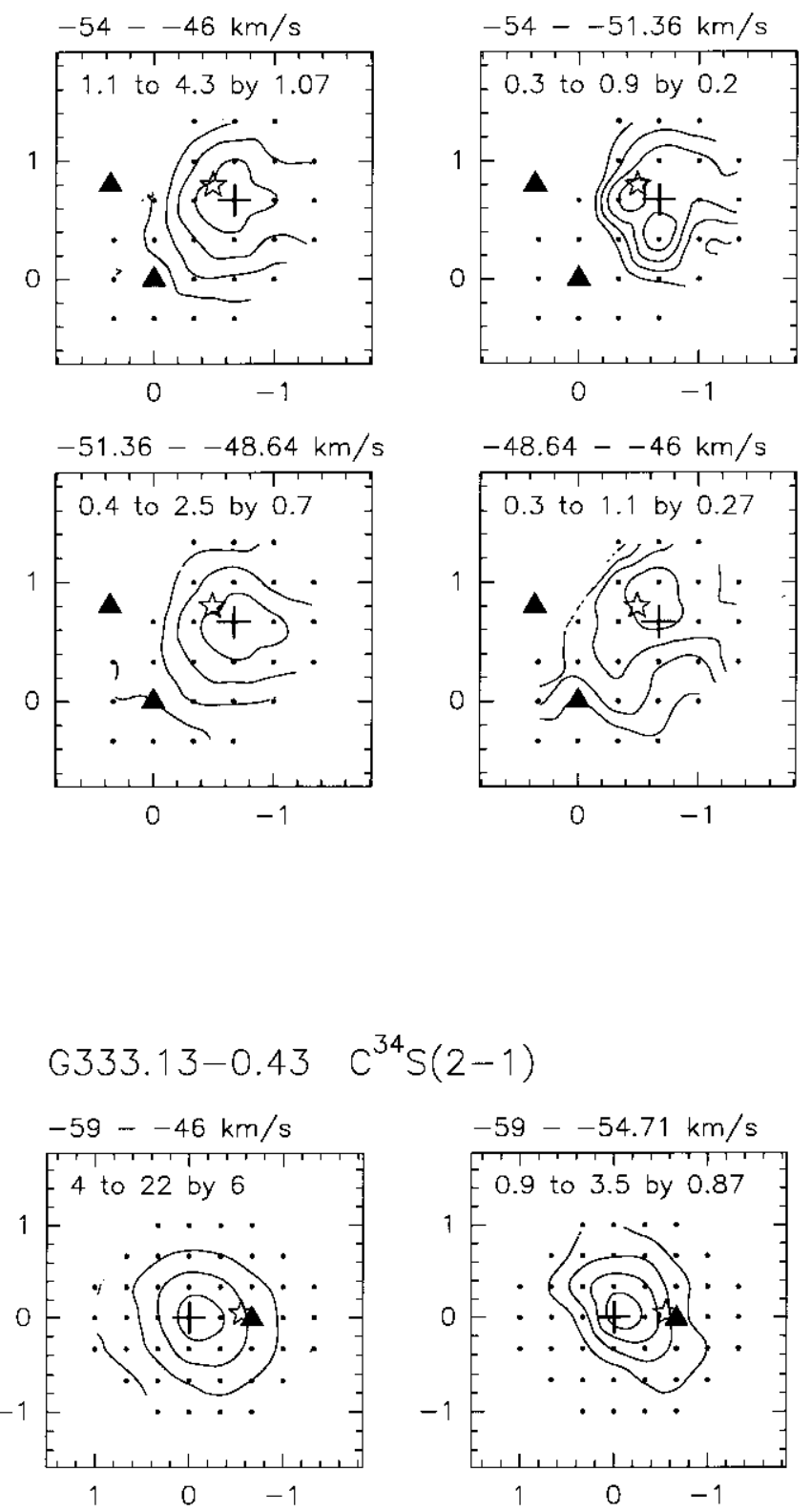

$$
S(2-1)
$$
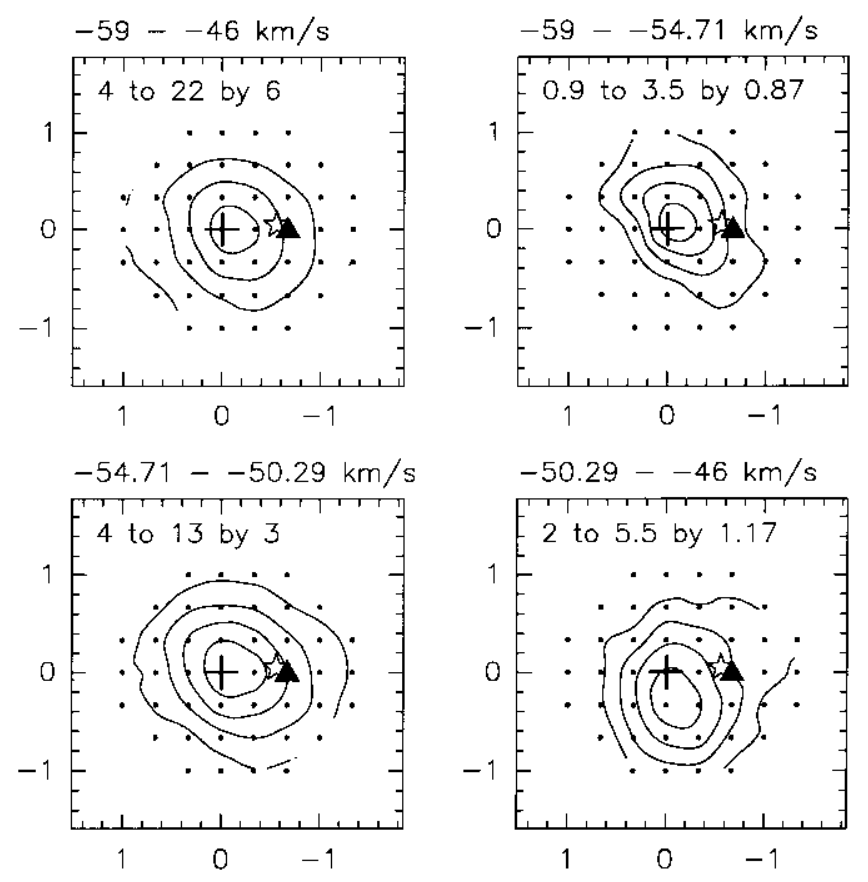

Fig. 1. continued 


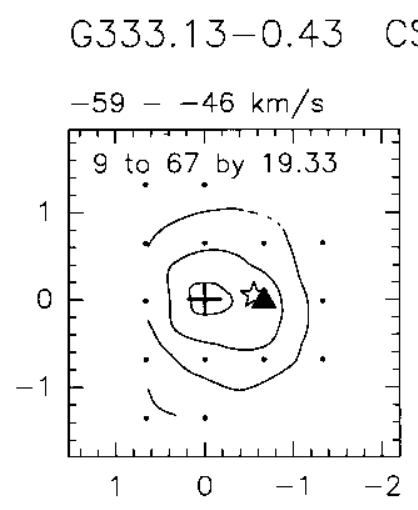

\section{$\operatorname{CS}(2-1)$}
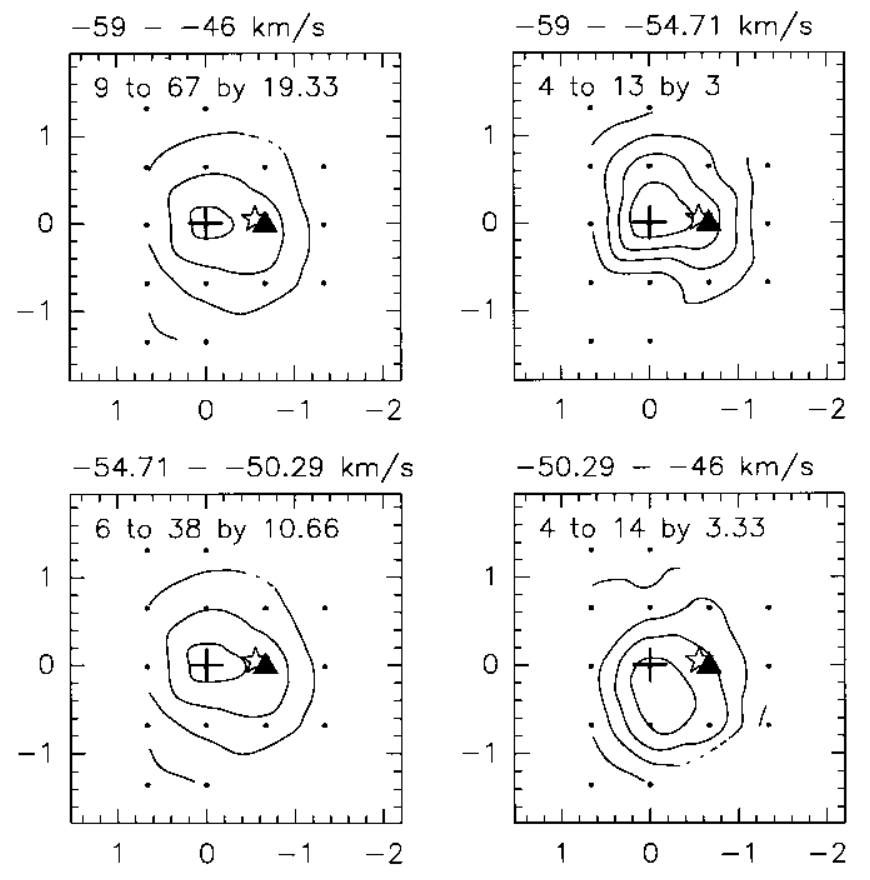

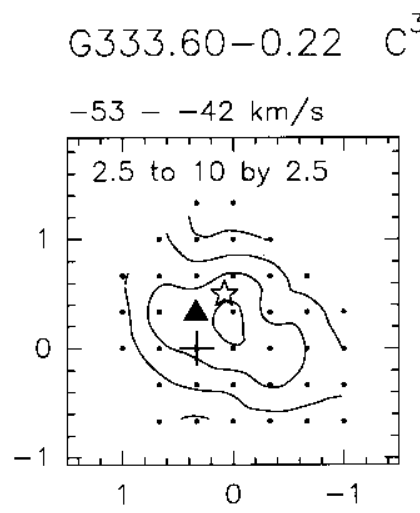

$C^{34} S(2-1)$
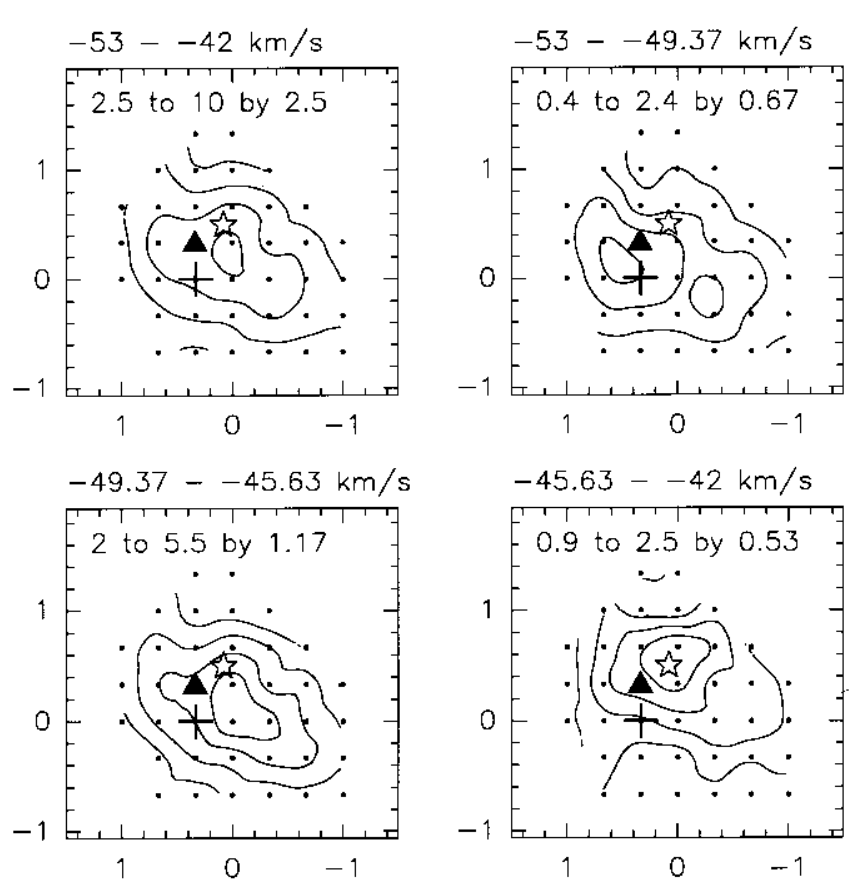

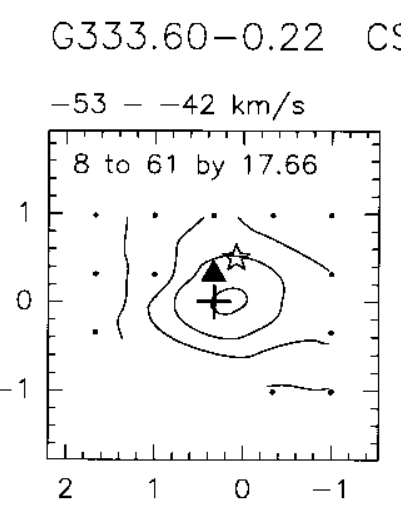

$\operatorname{CS}(2-1)$
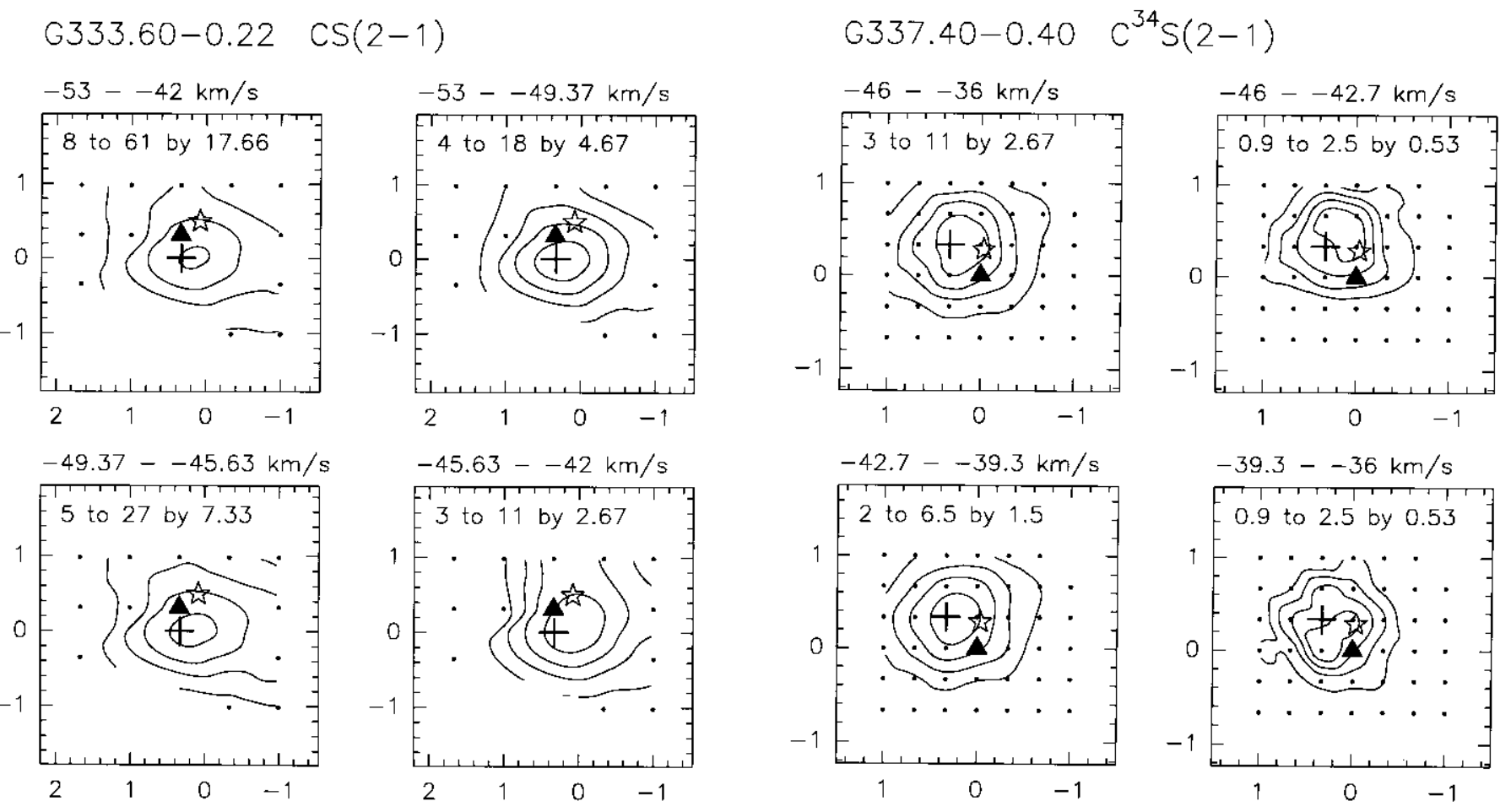

Fig. 1. continued 


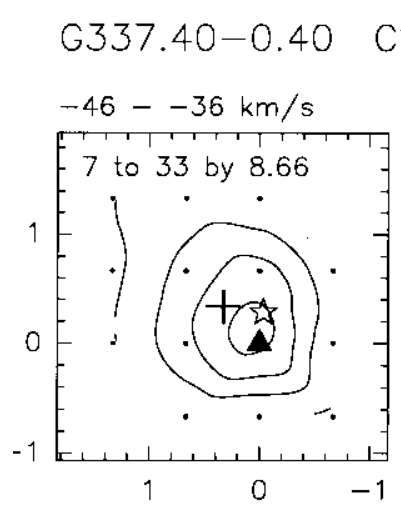

$\operatorname{CS}(2-1)$
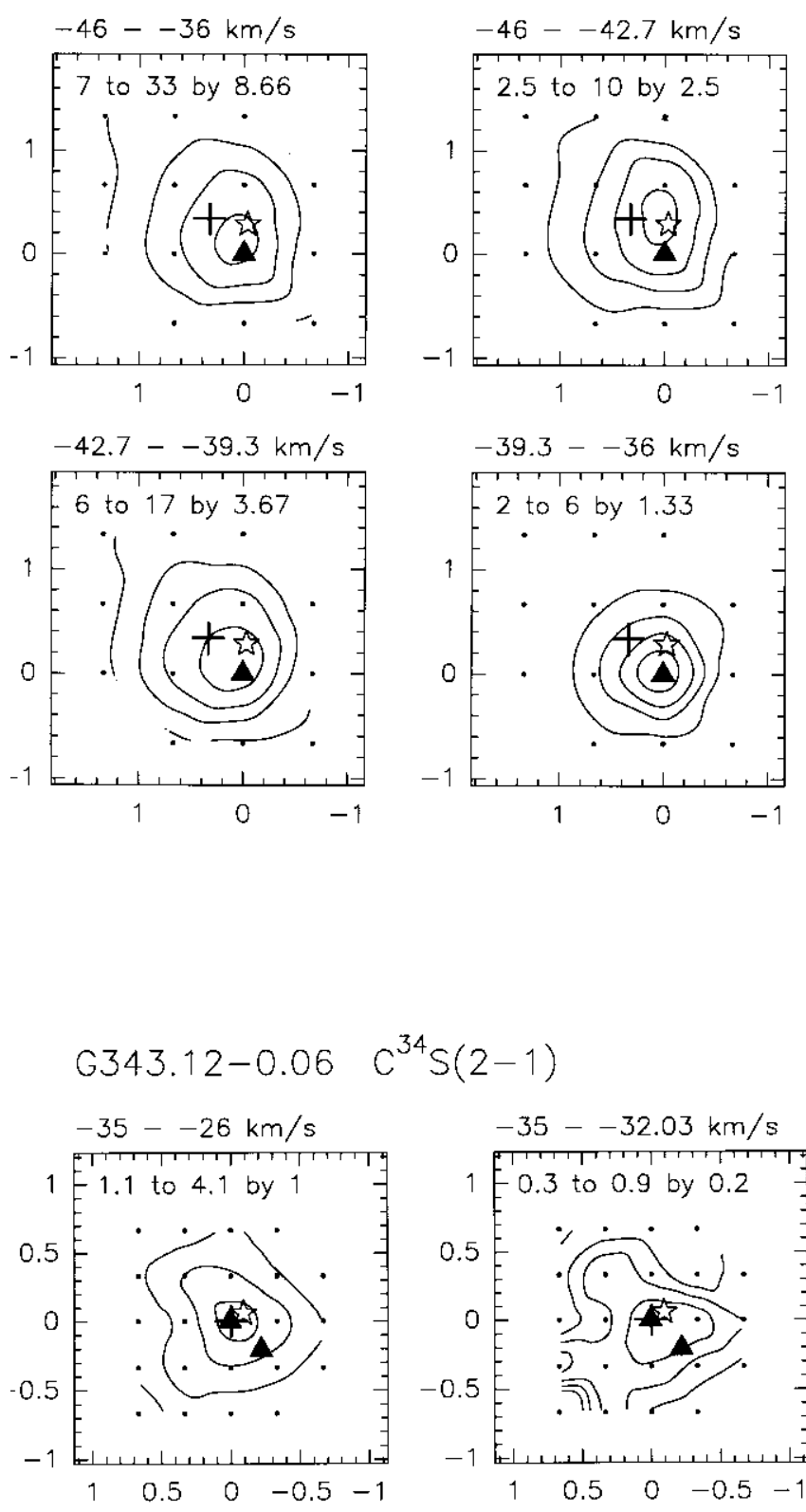

$$
C^{34} S(2-1)
$$
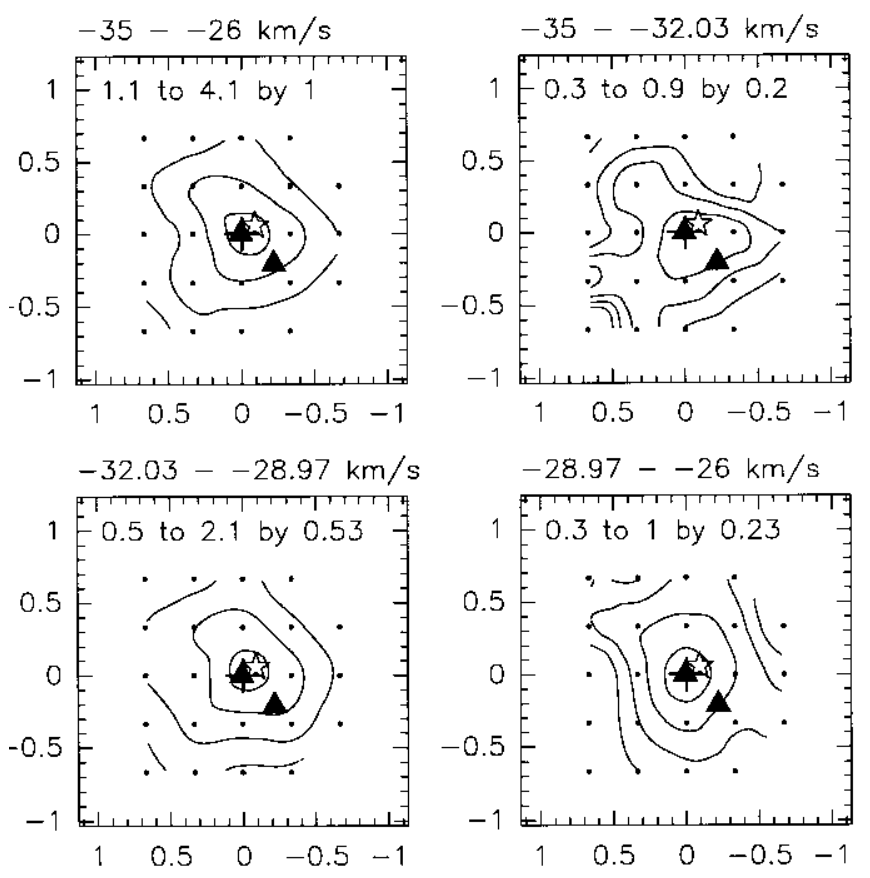

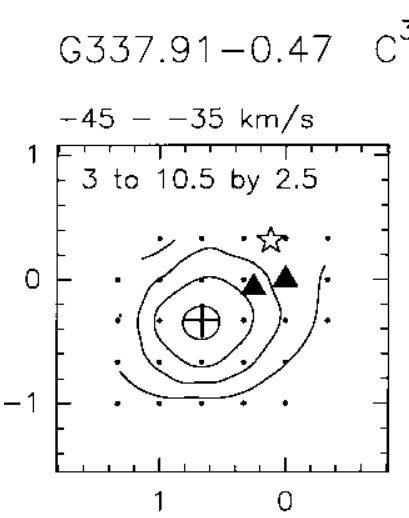

$C^{34} S(2-1)$
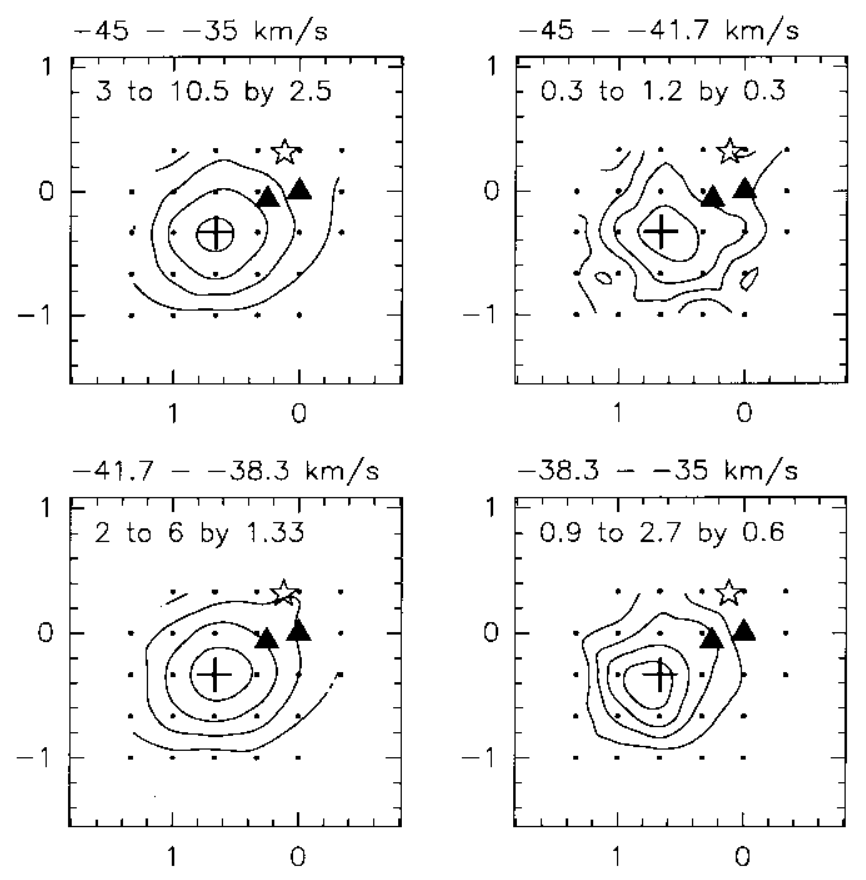

G343.12-0.06 CS(3-2)
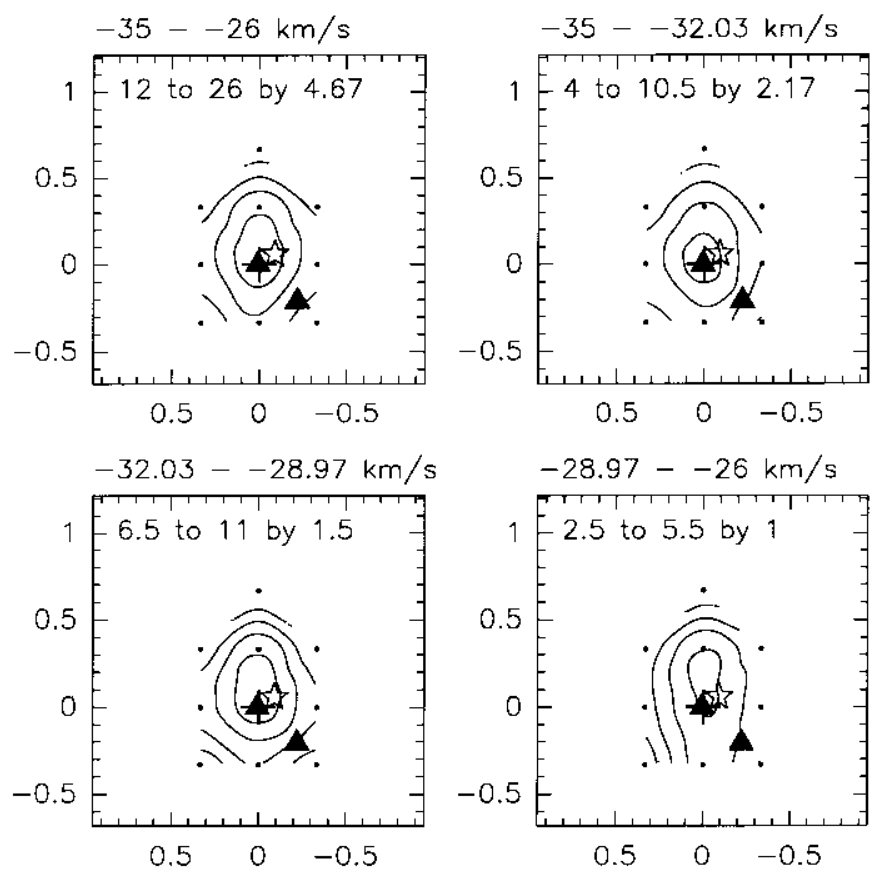

Fig. 1. continued 


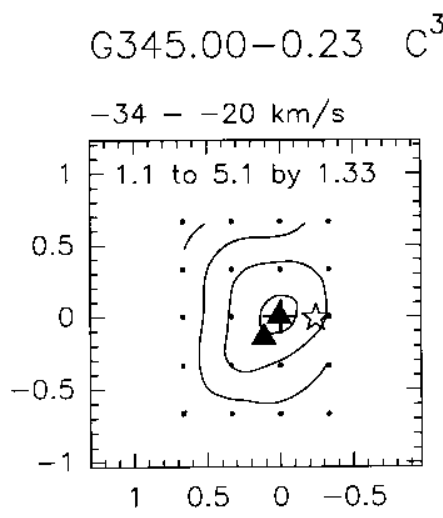

$$
{ }^{34} S(2-1)
$$
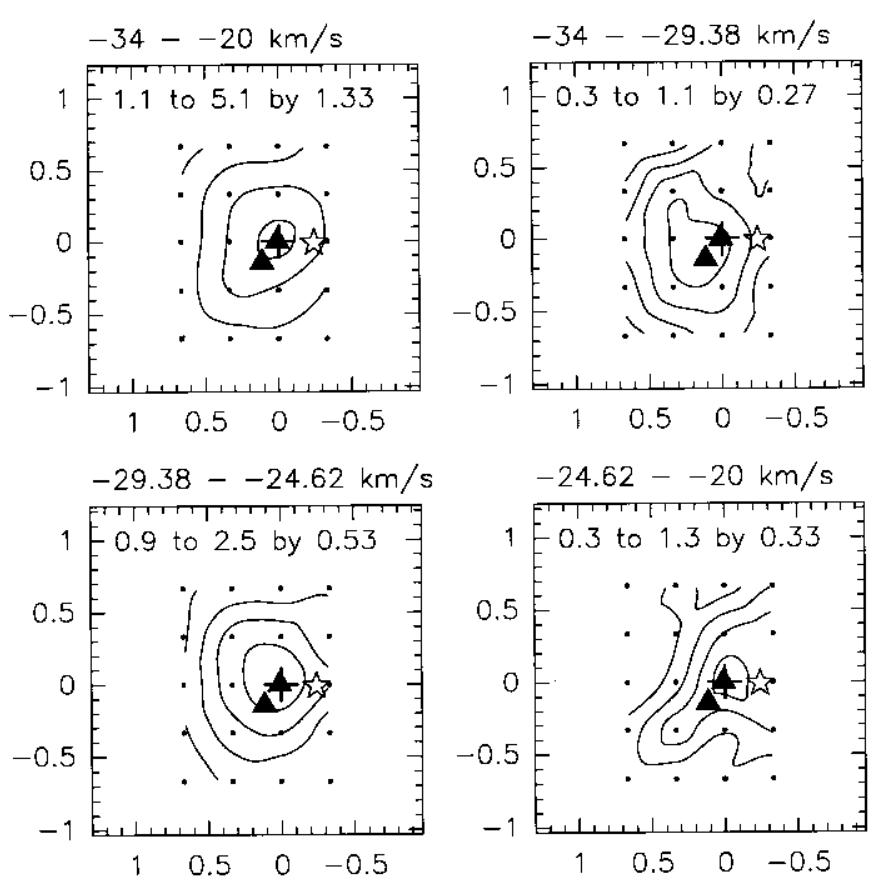

$6345.01+1.80 \quad C^{34} S(2-1)$
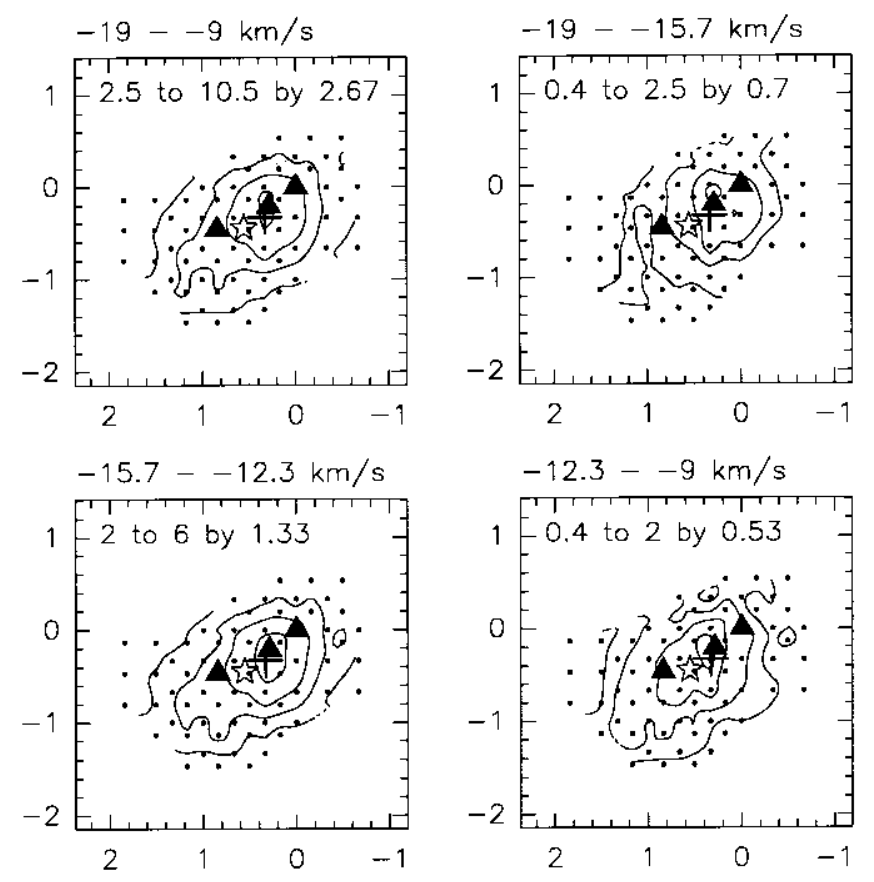
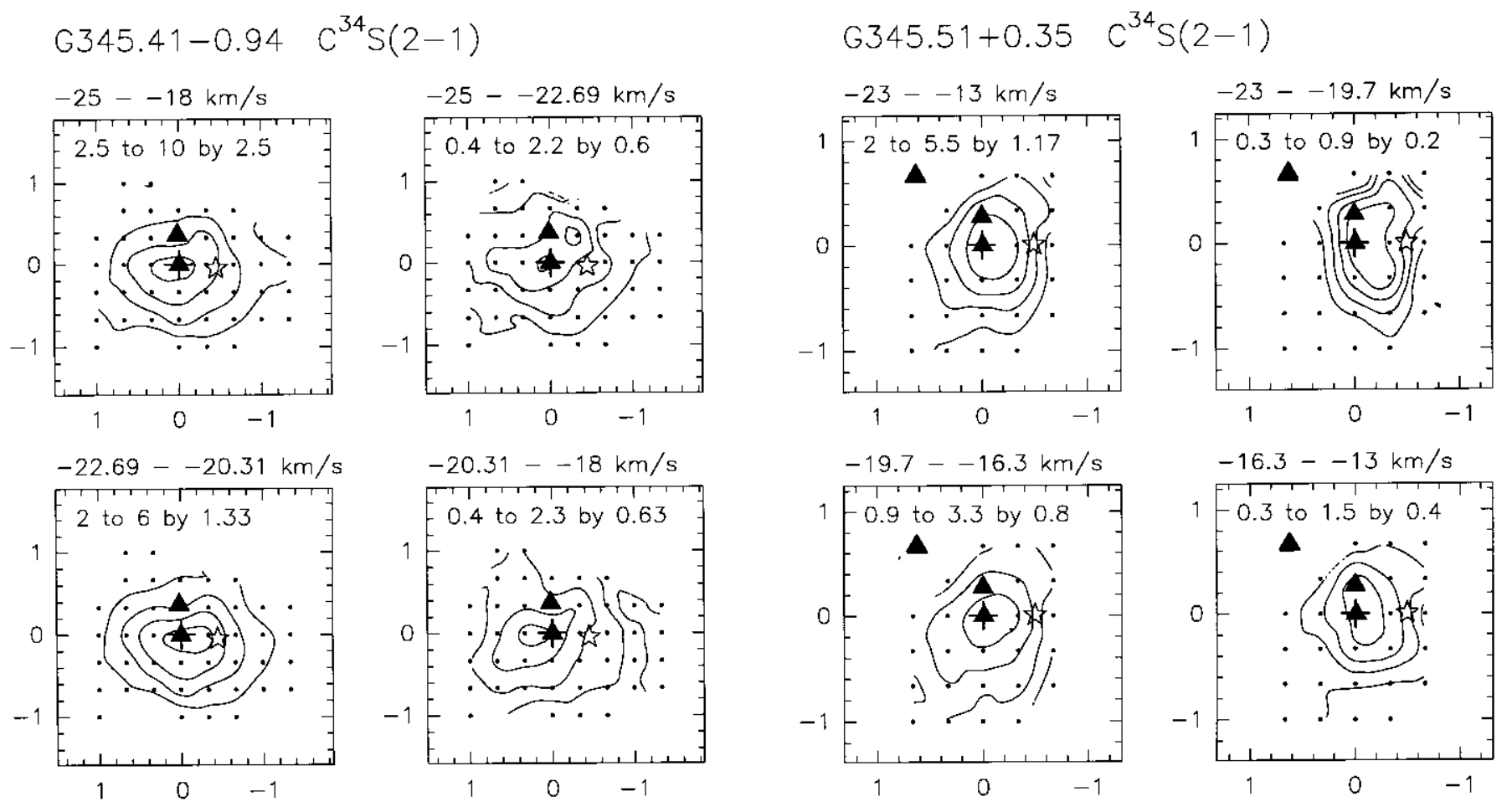

Fig. 1. continued 


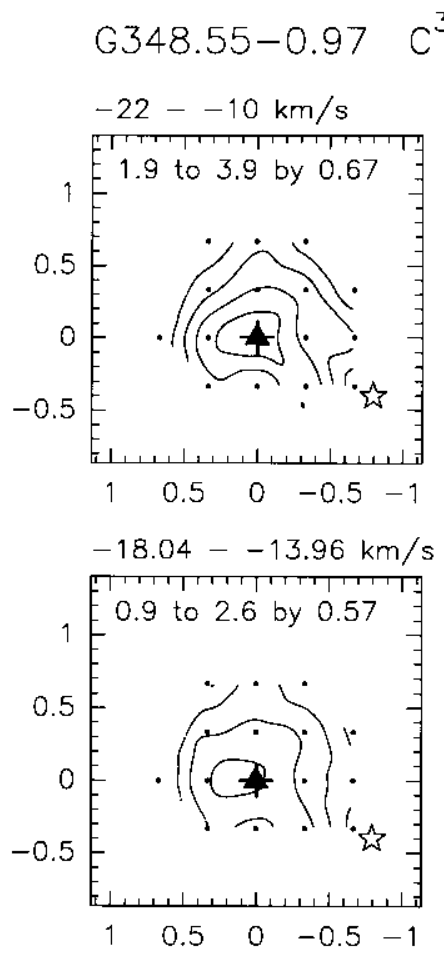

$$
C^{34} S(2-1)
$$
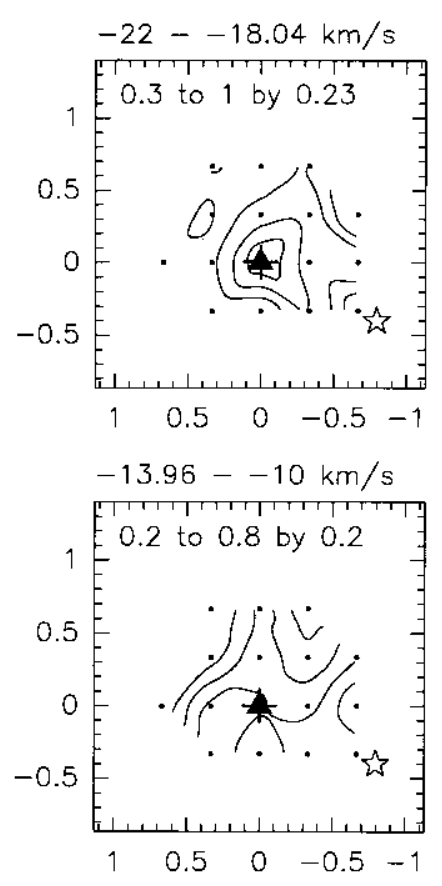

G348.73-1.04 $\mathrm{C}^{34} \mathrm{~S}(2-1)$
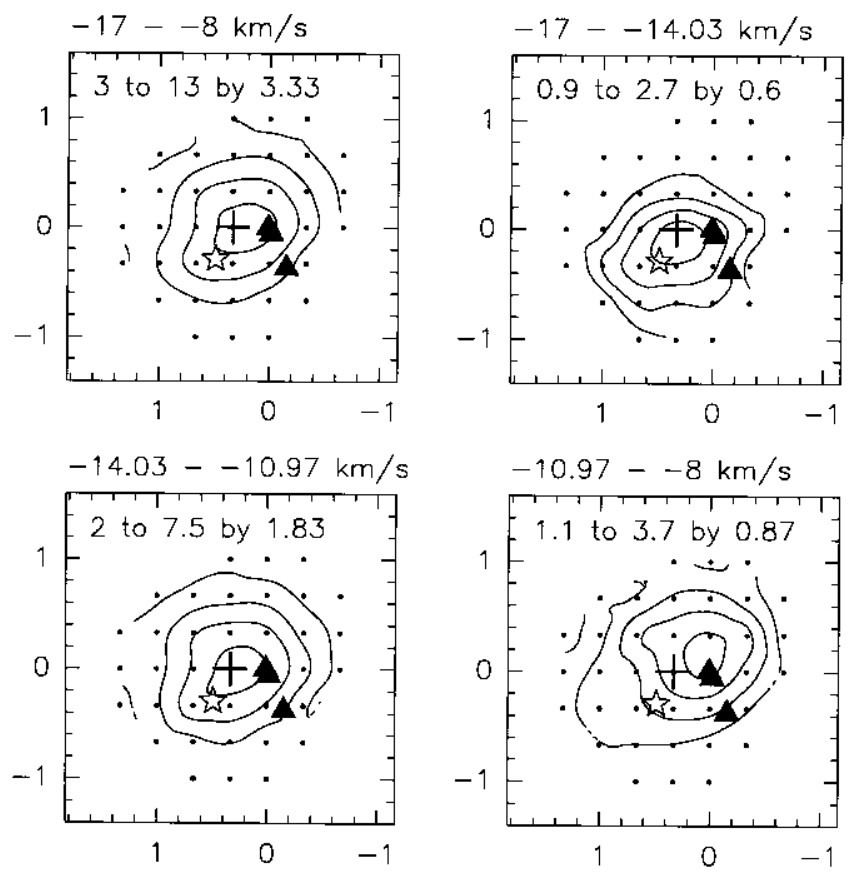

G348.55-0.97 CS(3-2)
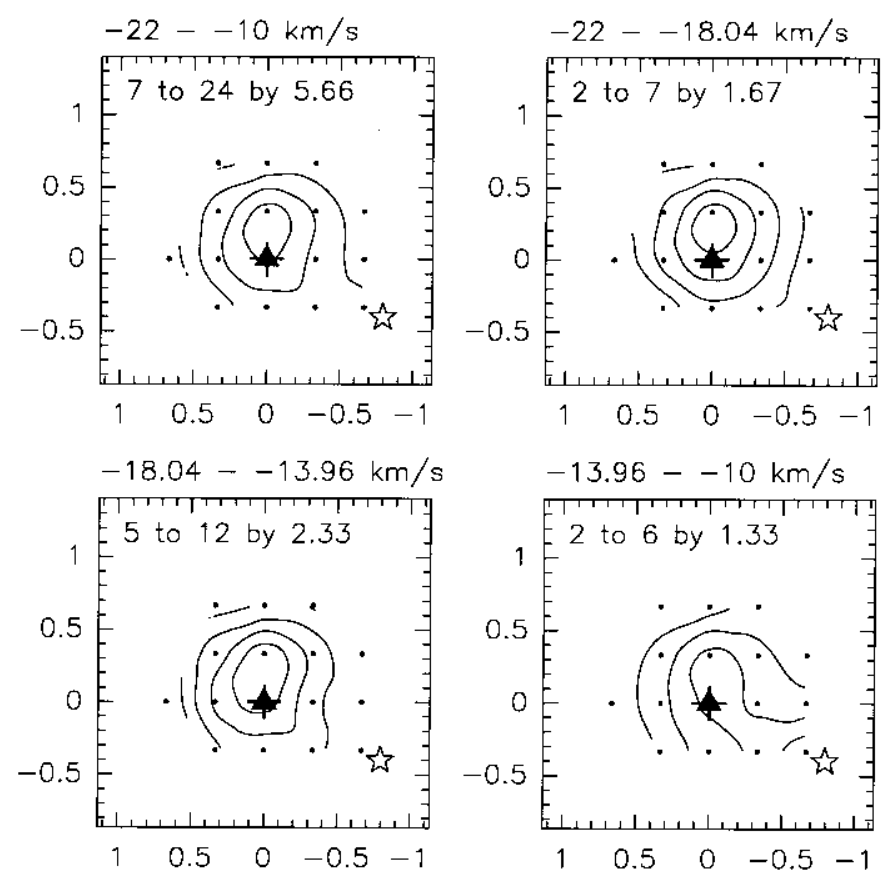

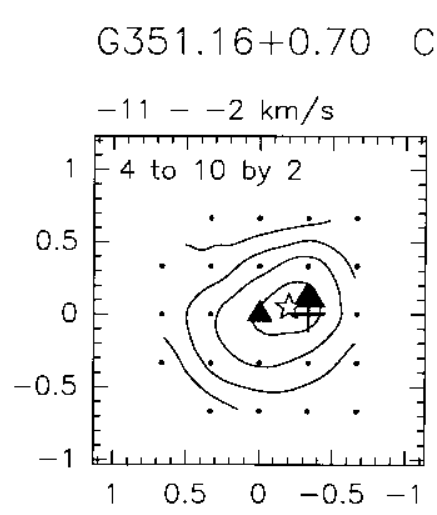

$C^{34} S(2-1)$
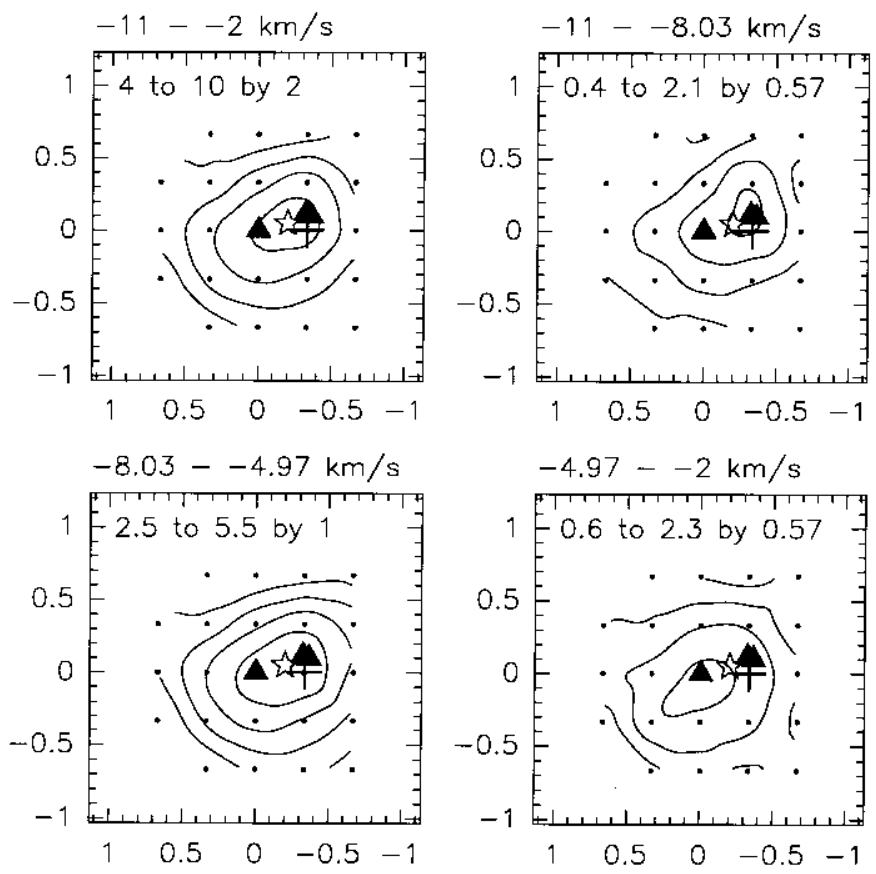

Fig. 1. continued 


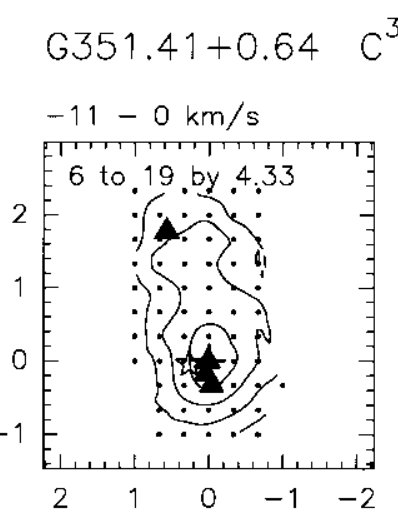

$$
C^{34} S(2-1)
$$
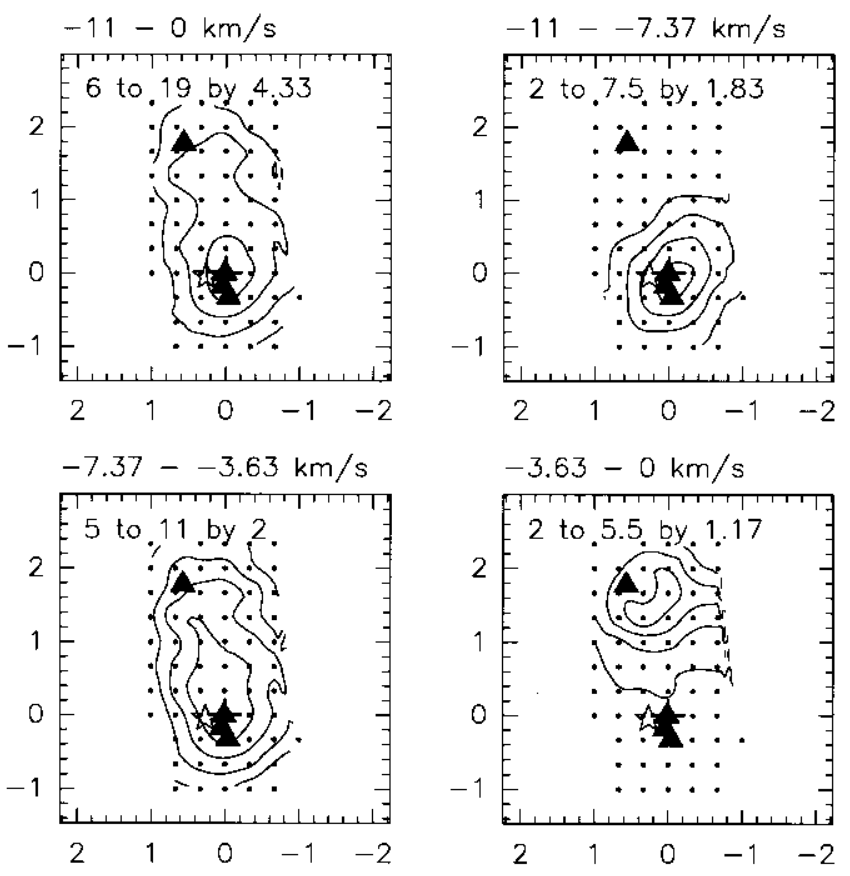

G359.97-0.46 $C^{34} S(2-1)$
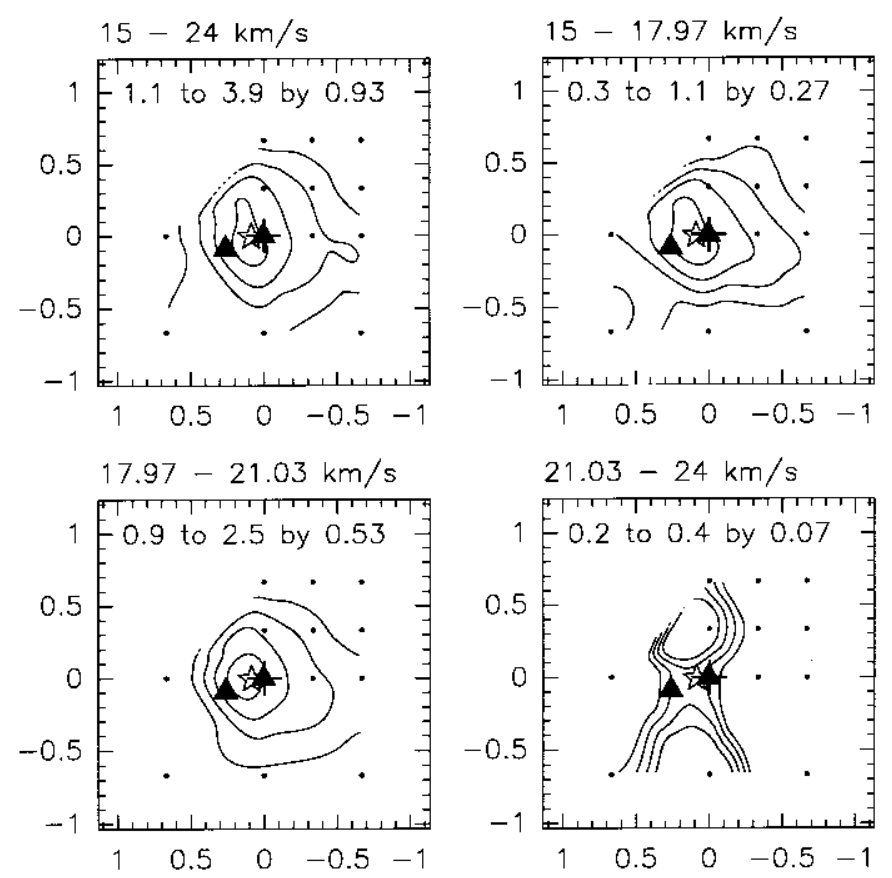

Fig. 1. continued
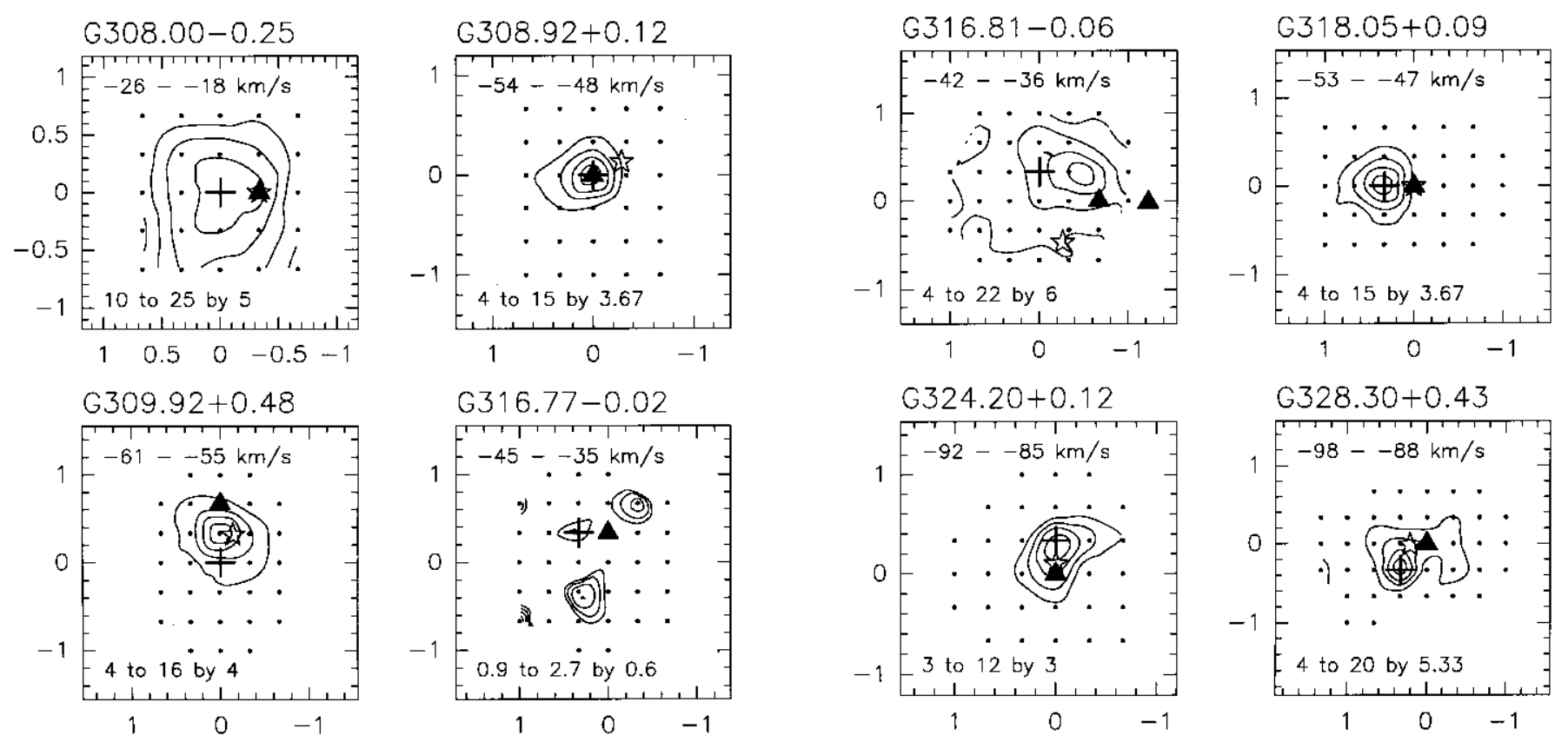

Fig. 2. The maps of integrated main beam temperature for the transition CS(5-4). The integrated velocity intervals and the contour values in units of $\mathrm{K} \mathrm{km} \mathrm{s}^{-1}$ are indicated inside the frames. $\mathrm{H}_{2} \mathrm{O}$-maser positions are marked with triangles and IRAS point sources with stars. A cross marks the position used for further one point measurements 

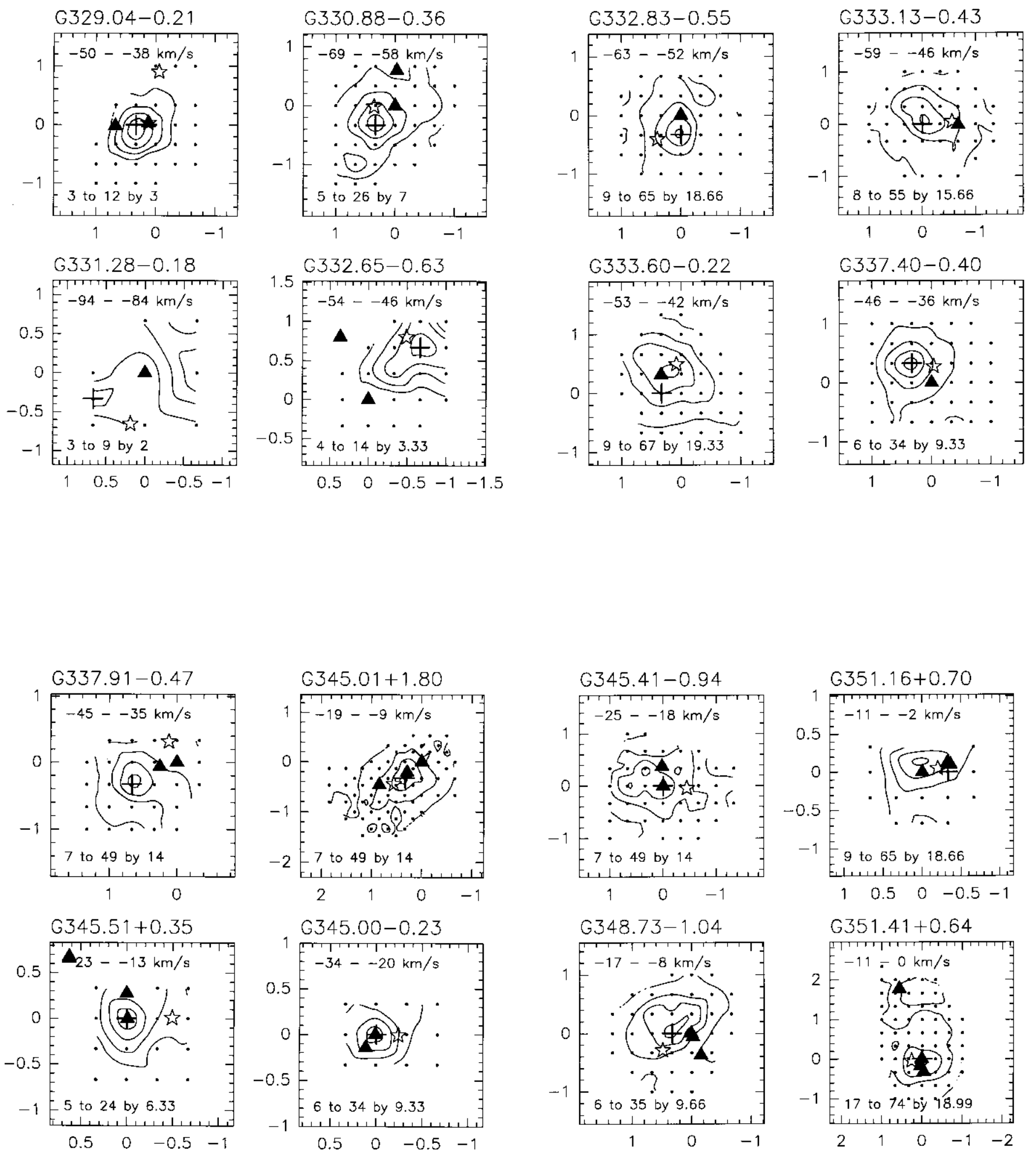

Fig. 2. continued 


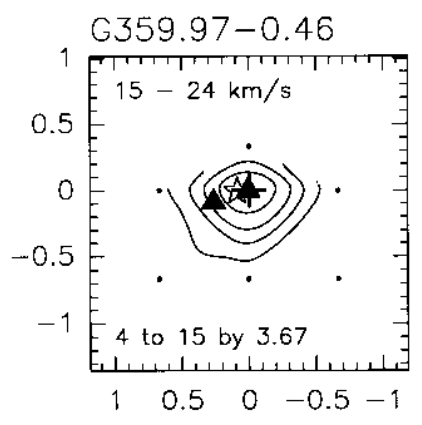

Fig. 2. continued
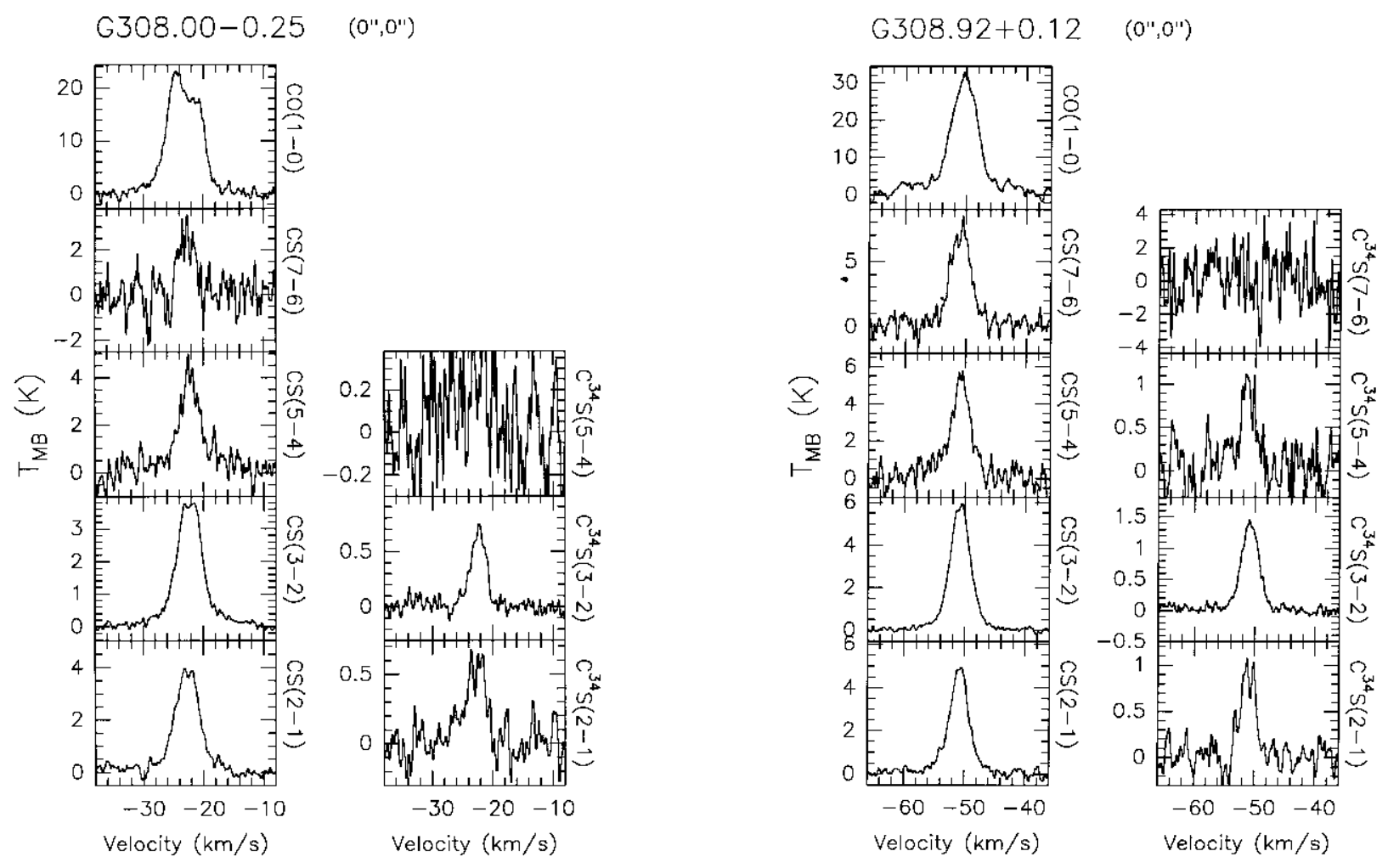

Fig. 3. The observed CS and $\mathrm{C}^{34} \mathrm{~S}$ spectra towards the positions of peak emission. Positions differ from the zero offset positions given in Table 2. The offsets from these coordinates are given in the figure and the positions are also indicated with crosses in Figs. 1 and 2 


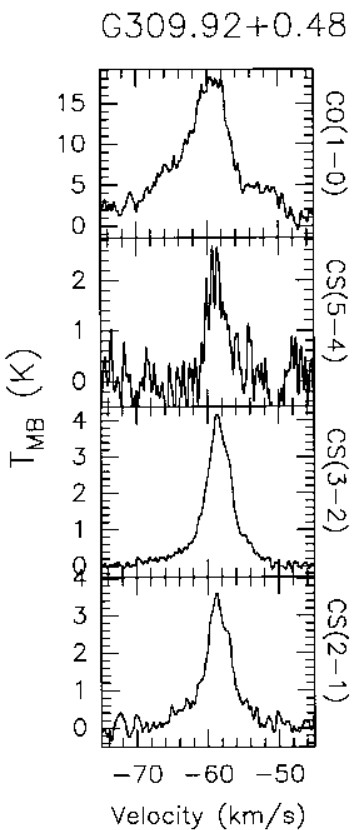

$\left(0^{\prime \prime}, 0^{\prime \prime}\right)$
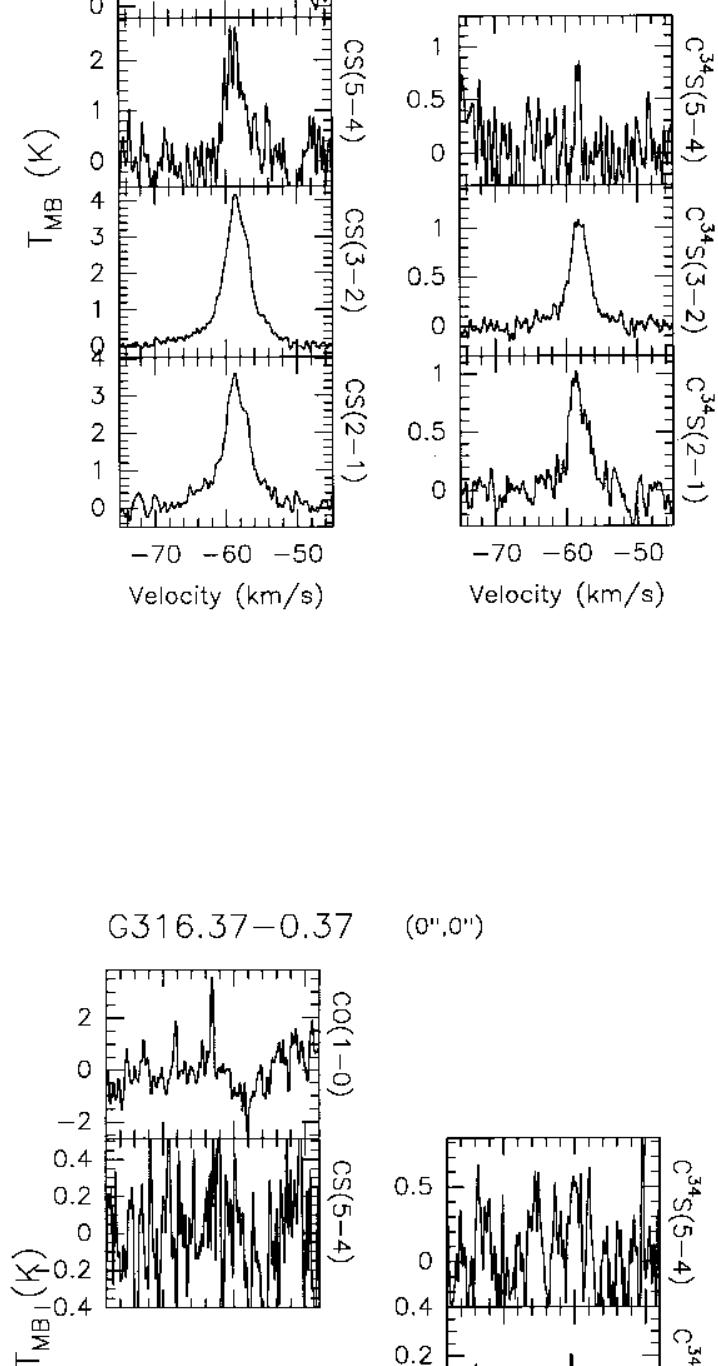

$\left(0^{\prime \prime}, 0^{\prime \prime}\right)$
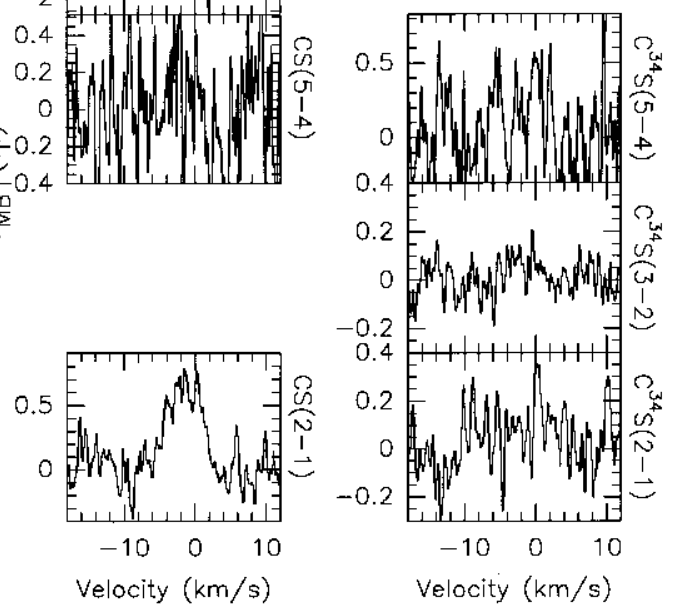
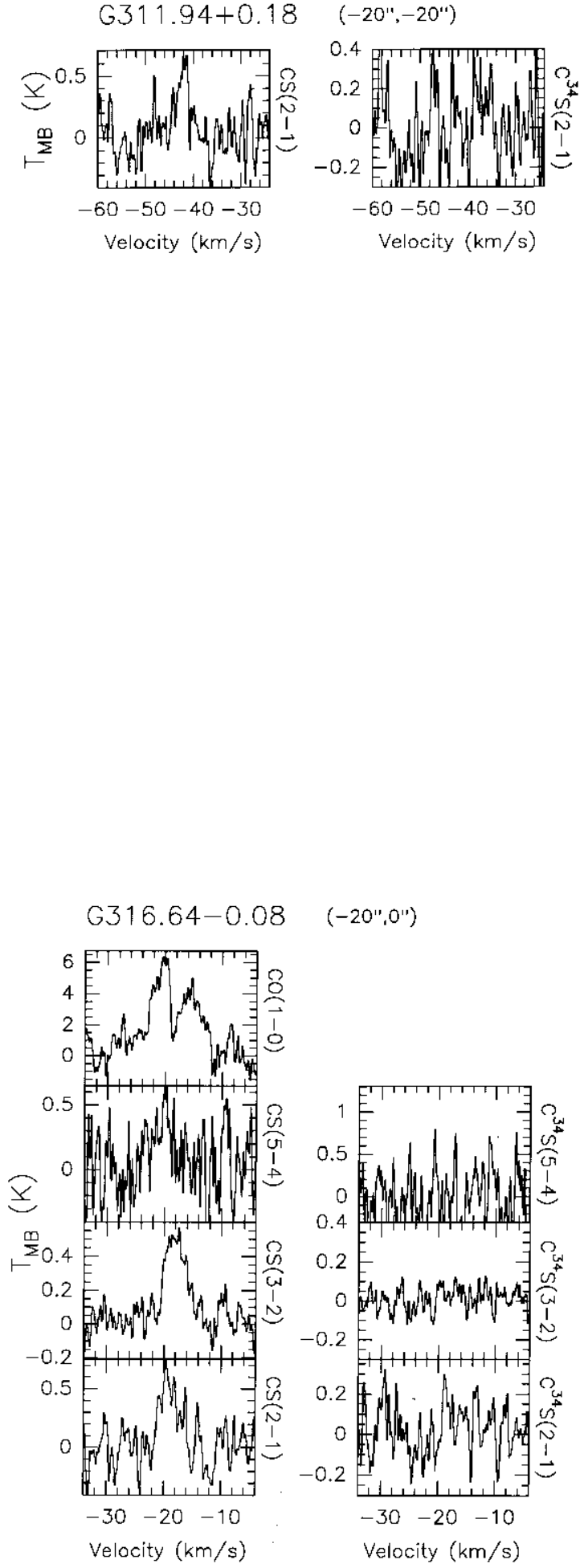

Fig. 3. continued 

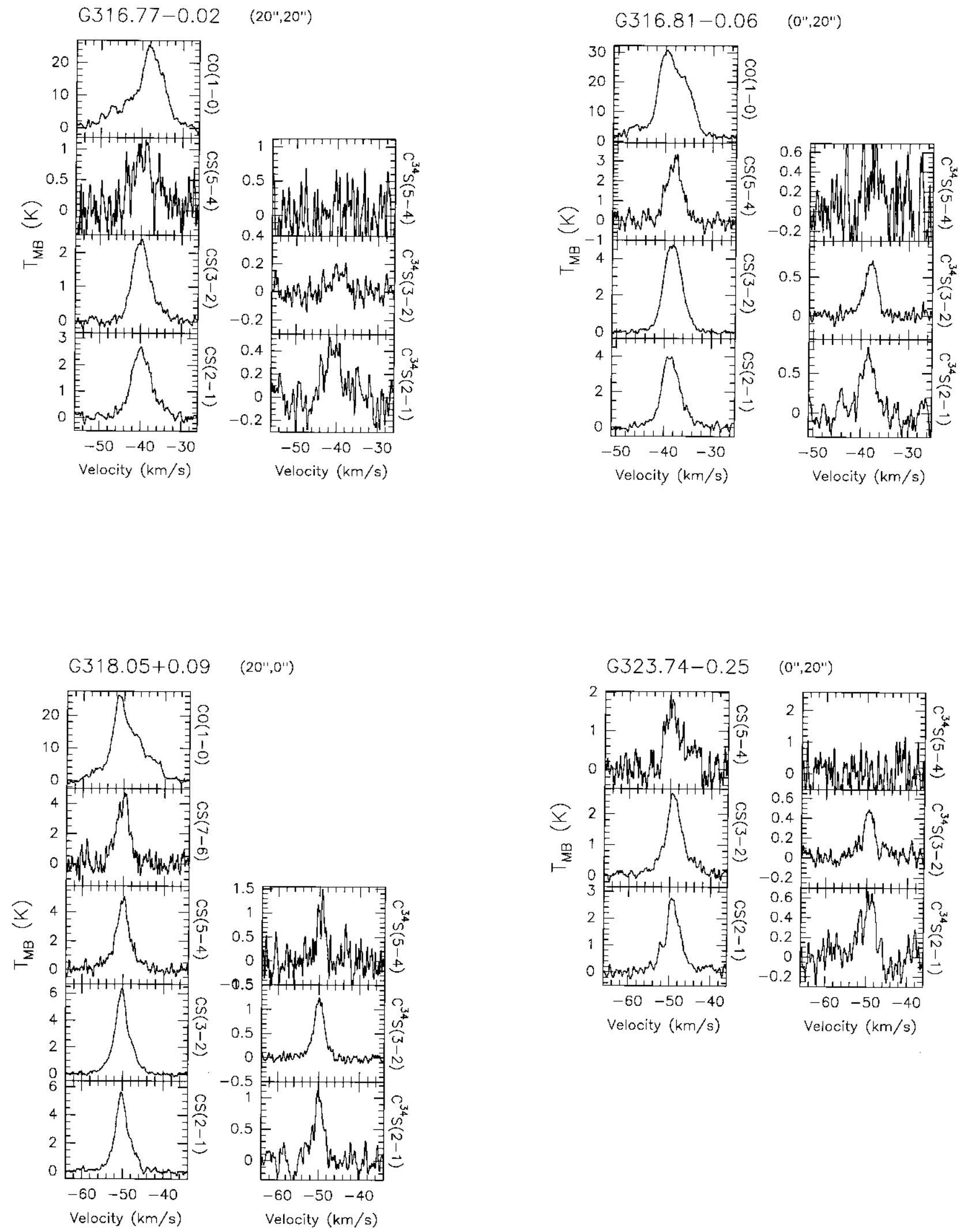

Fig. 3. continued 


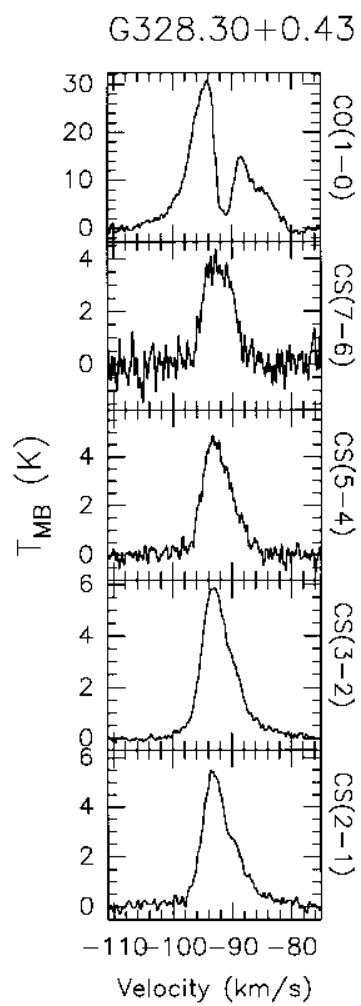

$\left(20^{\prime \prime},-20^{\prime \prime}\right)$
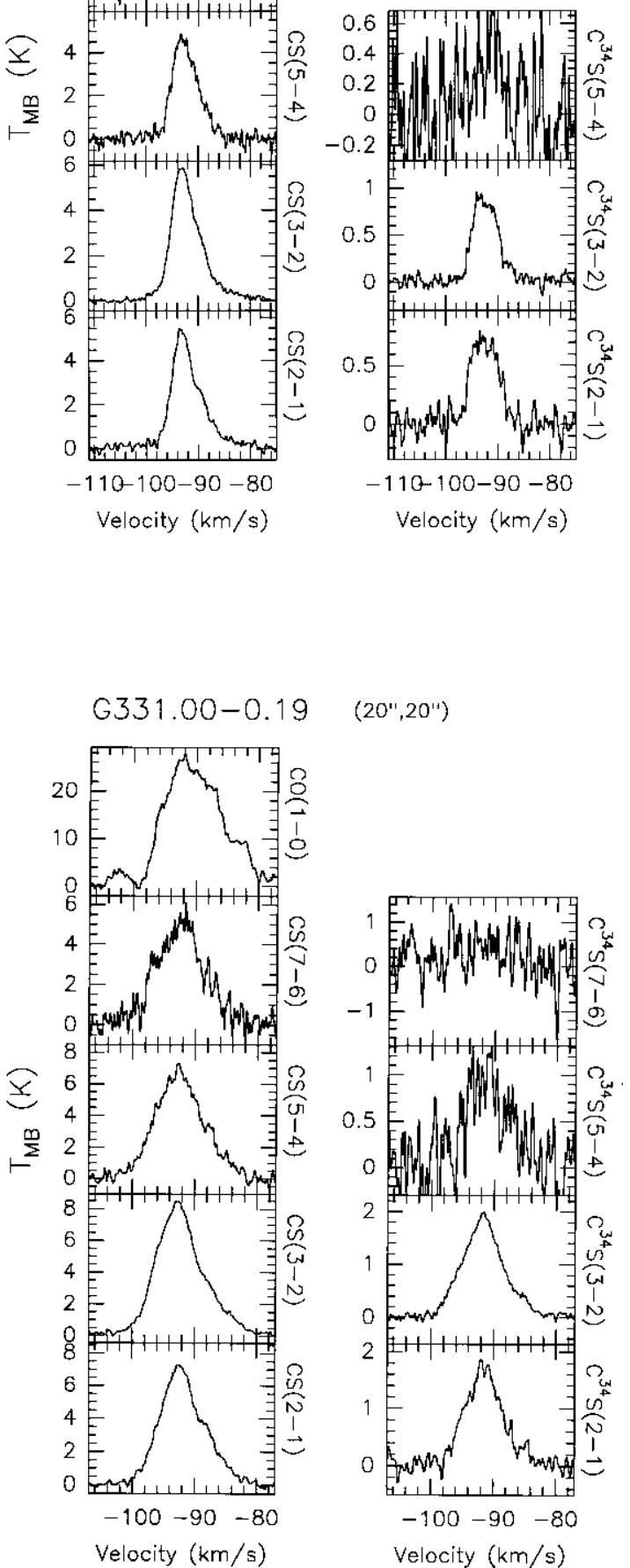

$\left(20^{\prime \prime}, 20^{\prime \prime}\right)$

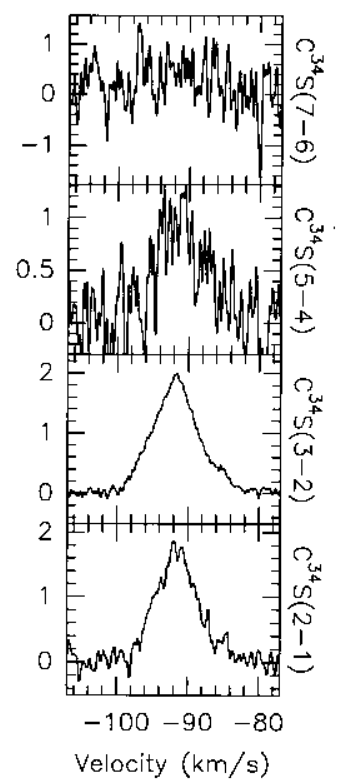

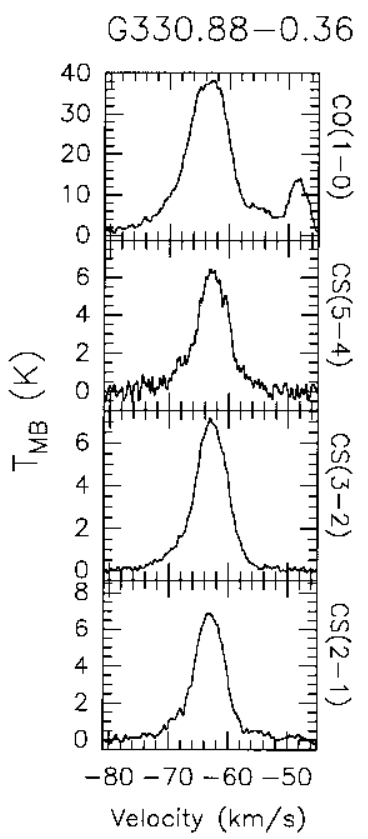

$\left(20^{\prime \prime},-20^{\prime \prime}\right)$

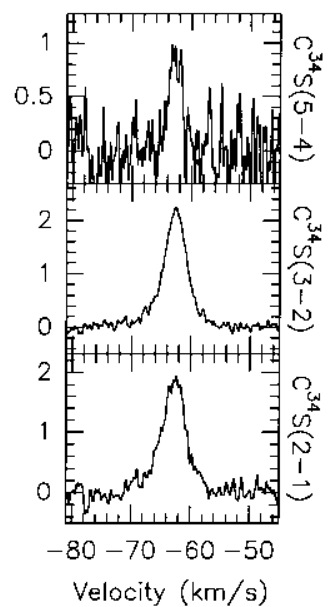

Fig. 3. continued 

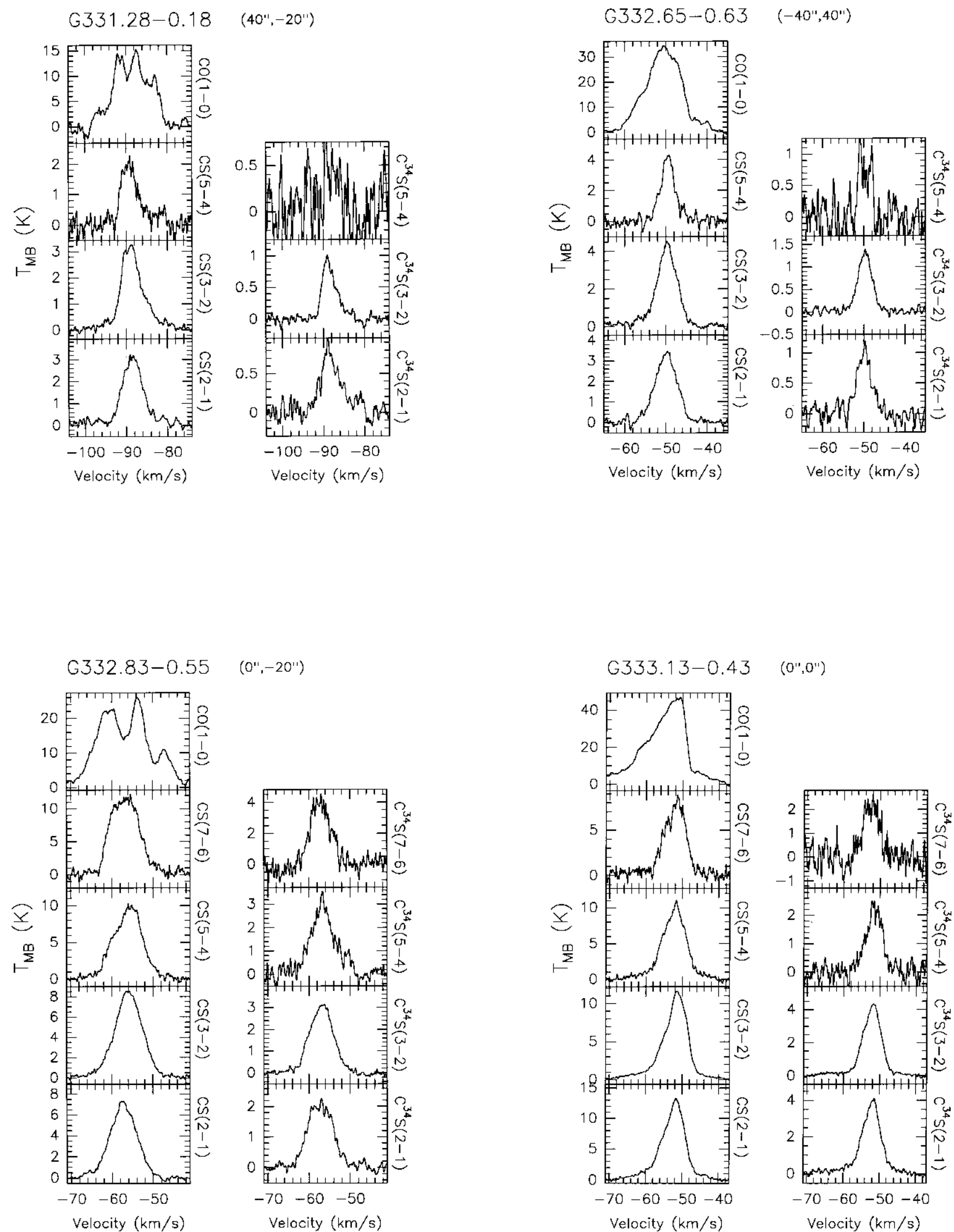

$\left(0^{\prime \prime},-20^{\prime \prime}\right)$

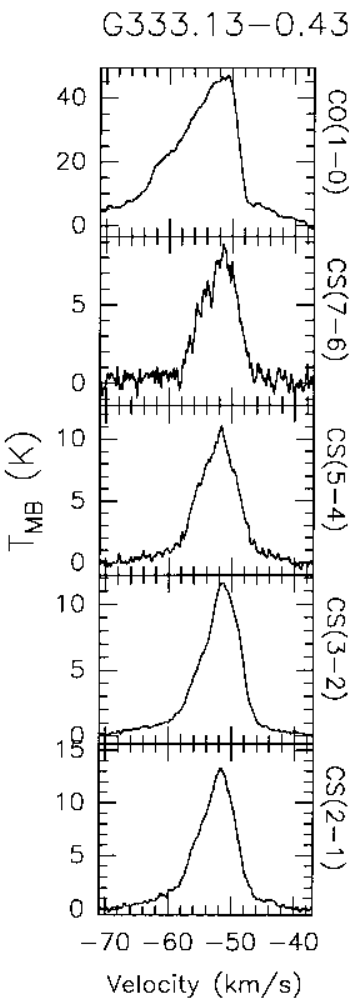

$\left(0^{\prime \prime}, 0^{\prime \prime}\right)$

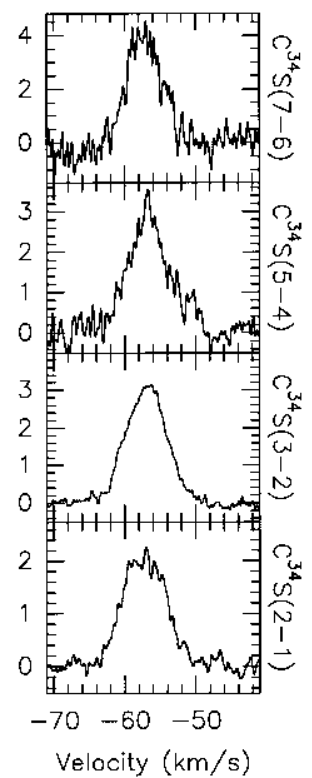

Fig. 3. continued 

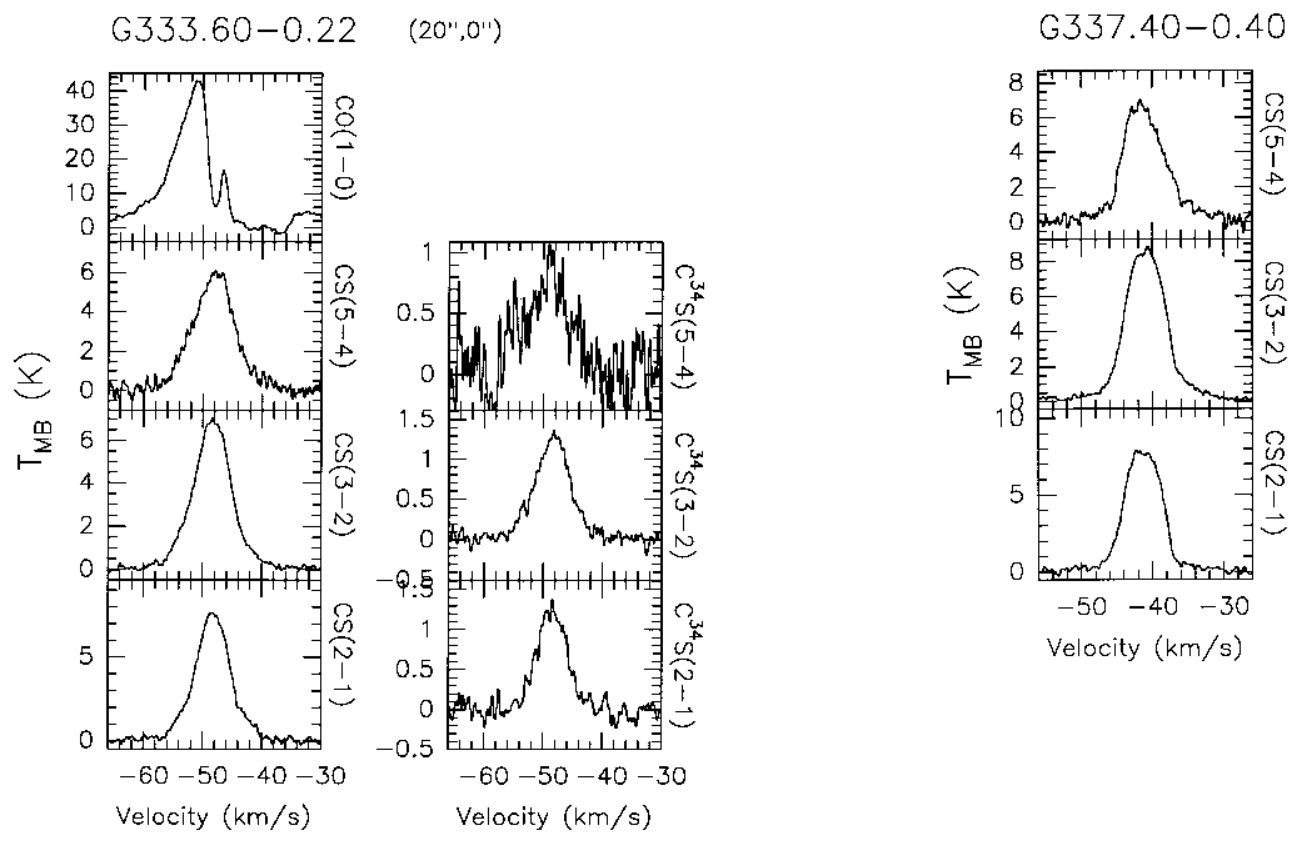

$\left(20^{\prime \prime}, 20^{\prime \prime}\right)$
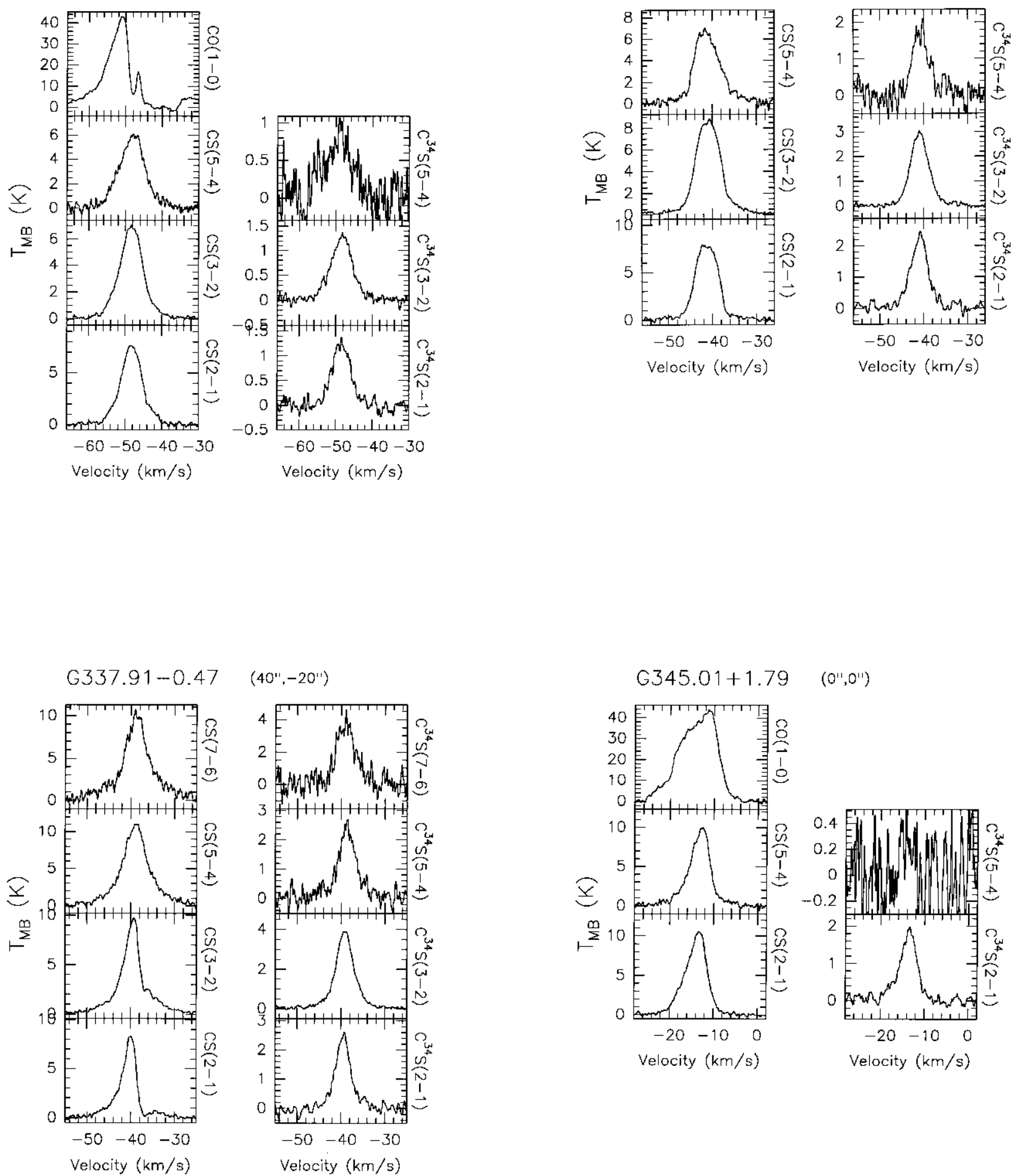

$\left(40^{\prime \prime},-20^{\prime \prime}\right)$

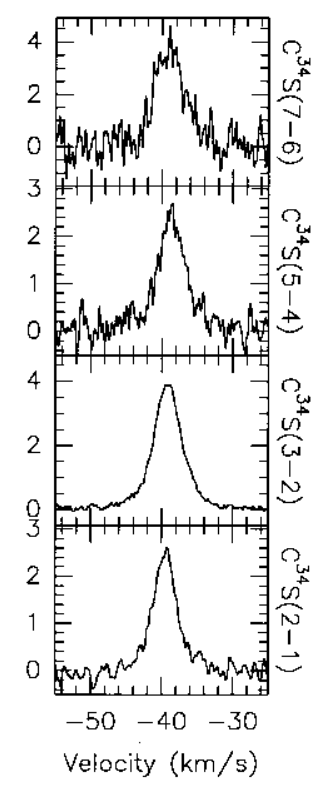

G345.01+1.79 (0", O")
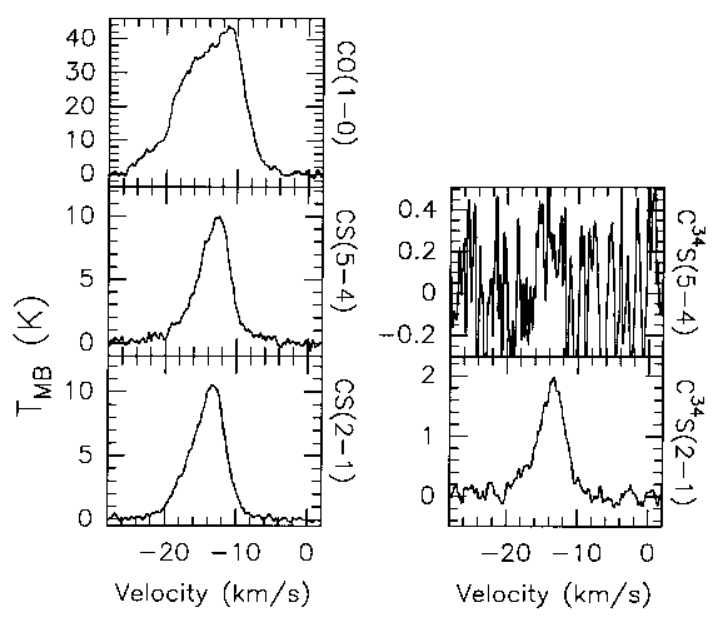

Fig. 3. continued 


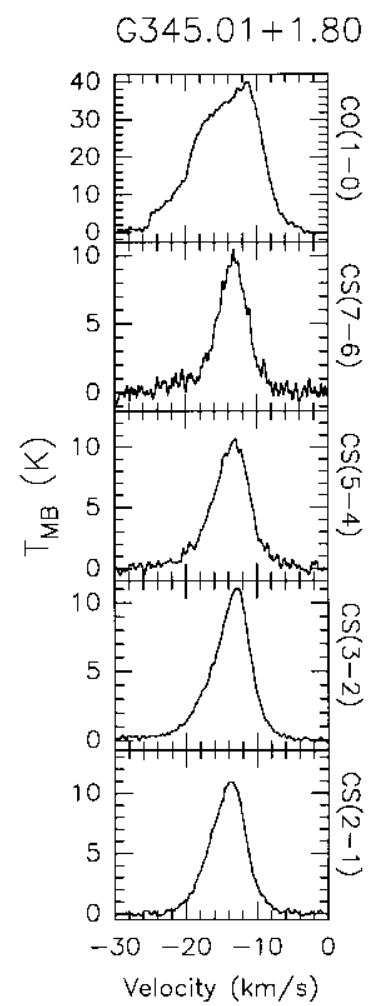

$\left(20^{\prime \prime},-20^{\prime \prime}\right)$
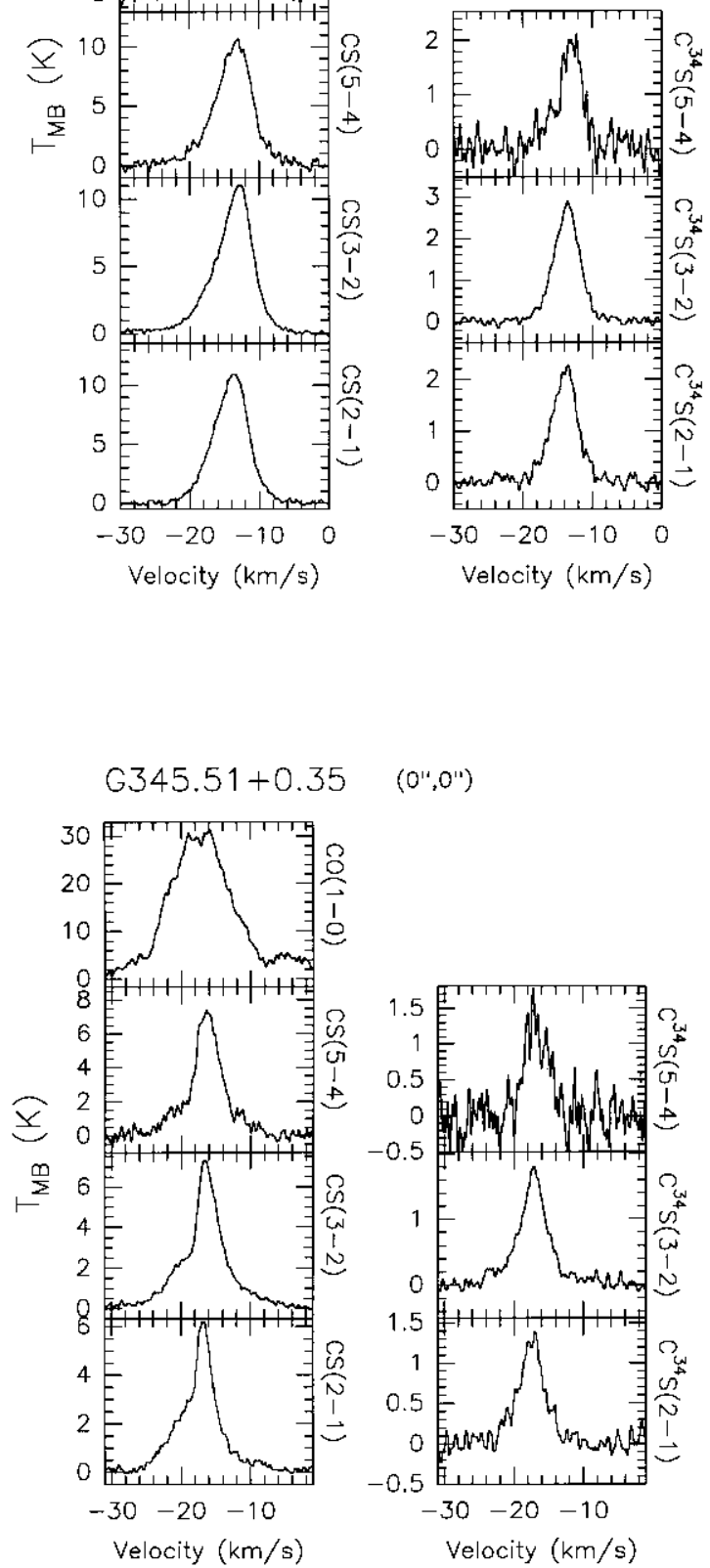

G343.12-0.06

$\left(0^{\prime \prime}, 0^{\prime \prime}\right)$
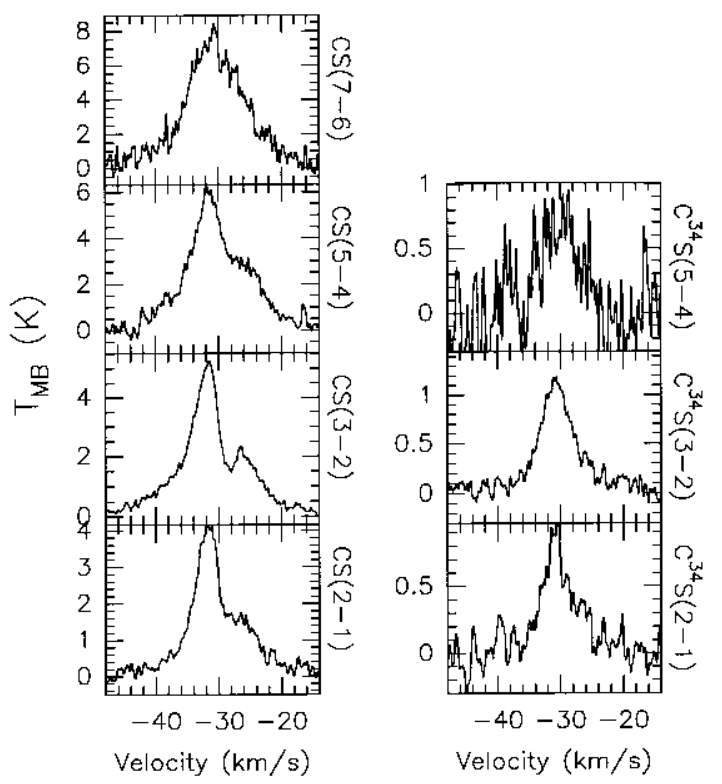

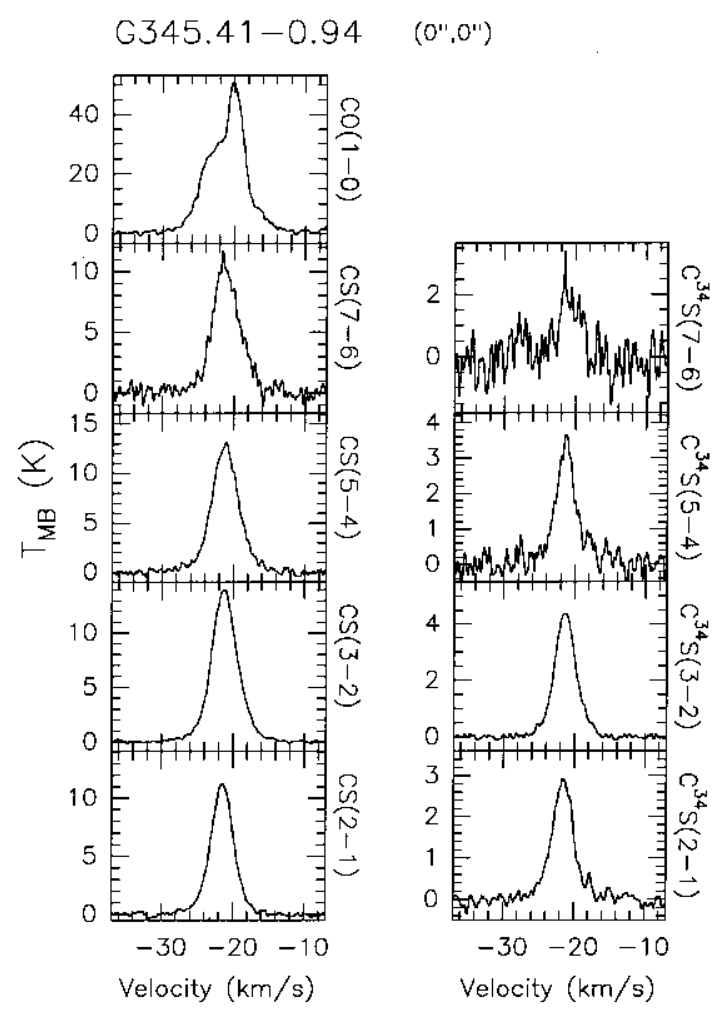

Fig. 3. continued 

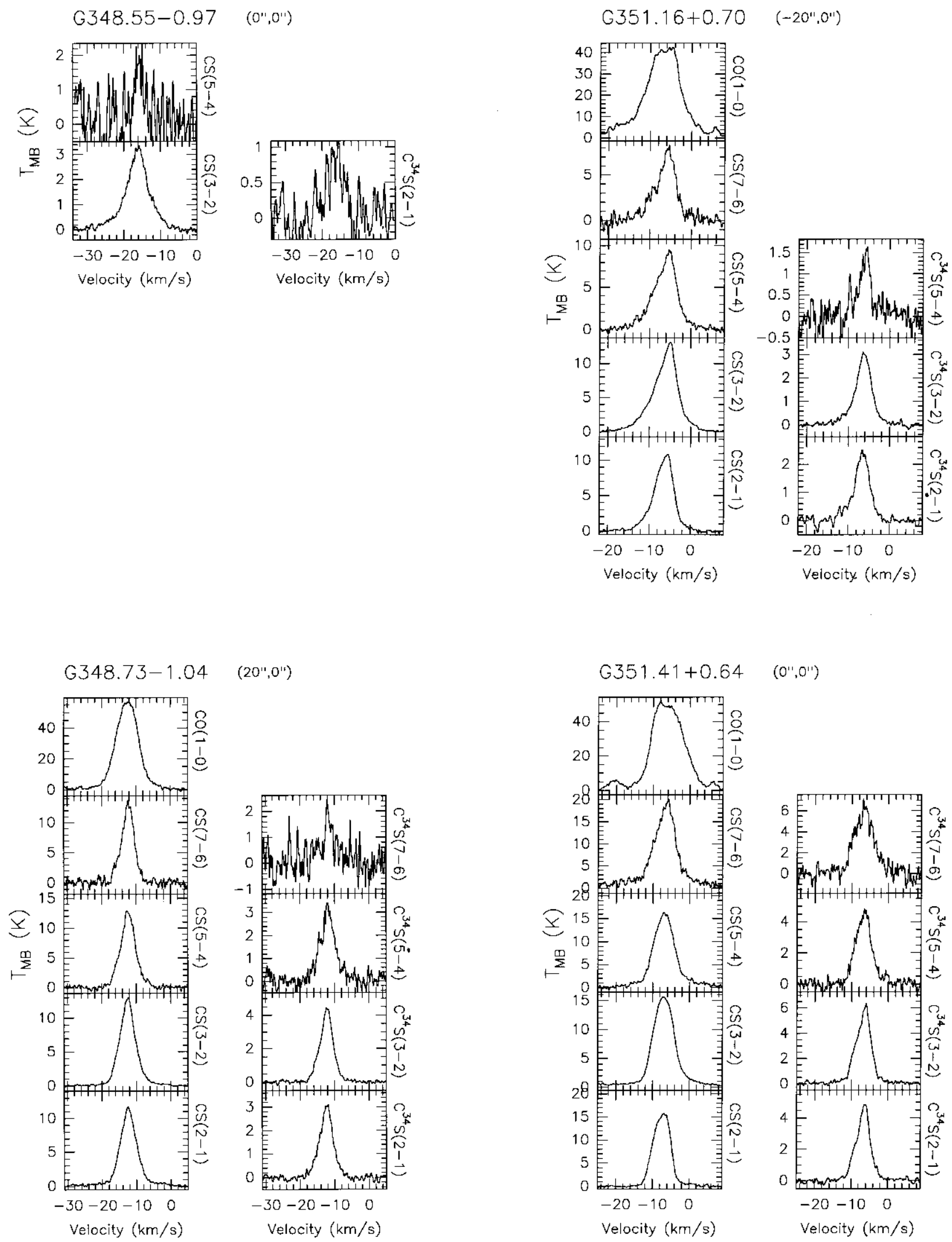

$\left(20^{\prime \prime}, 0^{\prime \prime}\right)$

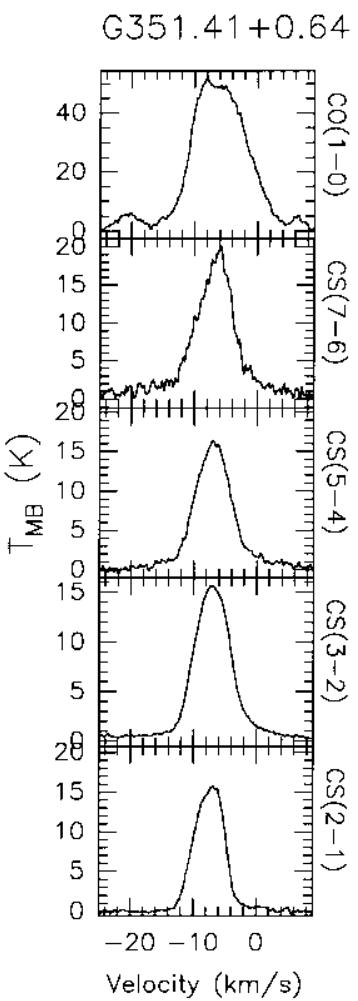

$\left(0^{\prime \prime}, 0^{\prime \prime}\right)$

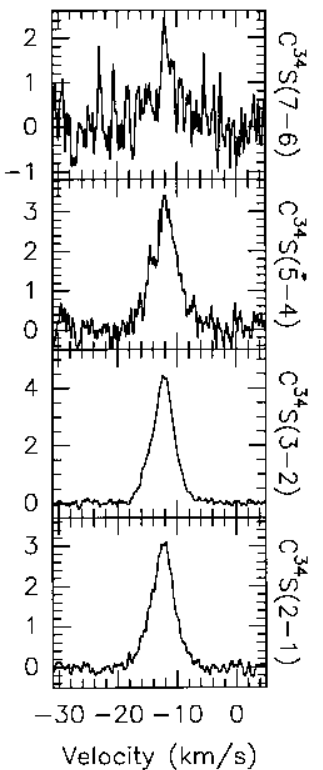

Fig. 3. continued 


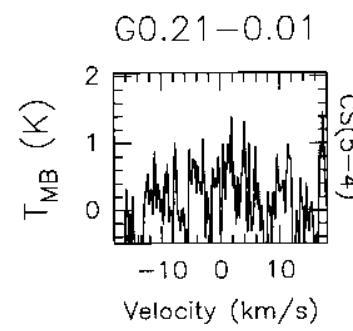

$\left(0^{\prime \prime}, 0^{\prime \prime}\right)$

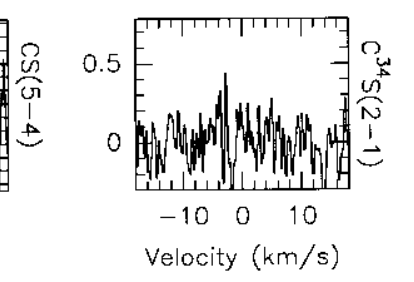

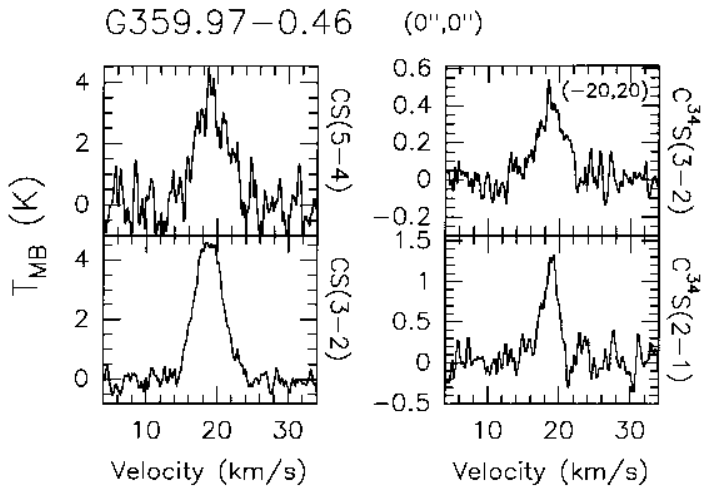

Fig. 3. continued 